\title{
Sustainability of Coalition of Essential School's Professional Development as Perceived by Teachers
}

Kristine E. McGee

West Virginia University

Follow this and additional works at: https://researchrepository.wvu.edu/etd

\section{Recommended Citation}

McGee, Kristine E., "Sustainability of Coalition of Essential School's Professional Development as Perceived by Teachers" (2012). Graduate Theses, Dissertations, and Problem Reports. 451.

https://researchrepository.wvu.edu/etd/451

This Dissertation is protected by copyright and/or related rights. It has been brought to you by the The Research Repository @ WVU with permission from the rights-holder(s). You are free to use this Dissertation in any way that is permitted by the copyright and related rights legislation that applies to your use. For other uses you must obtain permission from the rights-holder(s) directly, unless additional rights are indicated by a Creative Commons license in the record and/ or on the work itself. This Dissertation has been accepted for inclusion in WVU Graduate Theses, Dissertations, and Problem Reports collection by an authorized administrator of The Research Repository @ WVU.

For more information, please contact researchrepository@mail.wvu.edu. 


\title{
Sustainability of Coalition of Essential School's Professional Development
} as Perceived by Teachers

Kristine E. McGee

\author{
Dissertation submitted to the \\ College of Human Resources and Education \\ at West Virginia University \\ in partial fulfillment of the requirements \\ for the degree of
}

Doctor of Education

in

Curriculum and Instruction

\author{
Patricia Obenauf, Ed.D., Chairperson \\ David Callejo, Ed.D. \\ Sarah Selmer, Ed.D. \\ Kim Rotruck, Ed.D. \\ Eva Toth, Ph.D.
}

College of Human Resources and Education

Morgantown, West Virginia

2012

Key Words: Professional Development, Coalition of Essential Schools, School Reorganization, Positive Discourse, Teacher and Student Relationships, Case Study 


\section{Abstract \\ Sustainability of Coalition of Essential School's Professional Development as Perceived by Teachers}

\section{Kristine E. McGee}

Research indicates a strong need to incorporate professional development into a wellorchestrated reform effort. The Coalition of Essential Schools (CES) reform model for this failing school was selected by the county administration and a few select teachers as East Elementary School. The sustainability of the professional development provided by CES is the focus of this study.

This study concluded that East Elementary School was perceived by teachers as having sustainable professional-development components. Major findings included the following: (a) the teachers played a key role in sustaining professional development at this school, (b) professional development changed how teachers communicated with students at this school, (c) professional development changed how teachers established relationships at this school, and (d) the professional-development efforts were sustainable as a result of teacher commitment at this school.

This research adds to the sustainability of professional development as a form of supporting a failing school, by exploring the perceptions of a group of teachers at one Title I school. Implications for practice include allowing teachers to take part in decision making related to professional development activities and developing classrooms that sustain teacher motivation toward reorganization efforts. 


\section{Dedication}

I would like to dedicate this to my very supportive family: Jeff, Zac, Mom, Dad, Leah Jade and Rob who inspire me to be the best person I can and who mean the world to me. Thank you for believing I could accomplish this goal even when I did not.

To my friends; Terri, Stick, Nikki, Diana, Doodle, Sewalt, Dionne, and Lori who were always checking in on me as well as convincing me I really could do this. To everyone who supported me in some way shape or form; Kristi, Courtney, Megan, Heather, Justin and Jamey. And to everyone else who has always believed in me especially those who are no longer here: my Nanny and brother I know they would both be very proud.

To each of my committee members, I thank you for your time and support with this task. Especially to Dr. Kim Rotruck who placed me on the path to higher education many years ago, I aspire to follow in her footsteps. Lastly, I would like to dedicate this to Dr. Pat Obenauf for her patience, guidance and faith in my ability to complete this endeavor. Her kind smile and ever comforting words of wisdom assured me everything would be just fine. She encouraged me to enjoy my journey as well as complete it and I thank her for that advice. 


\section{Table of Contents}

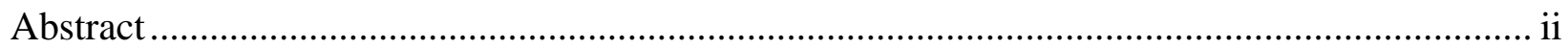

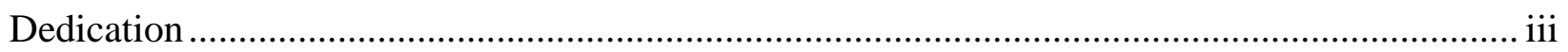

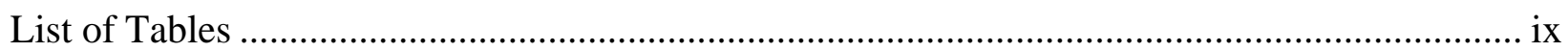

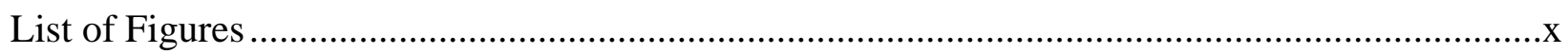

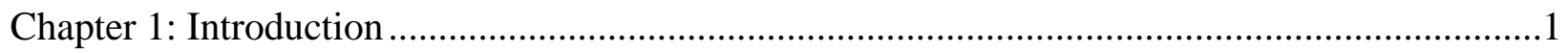

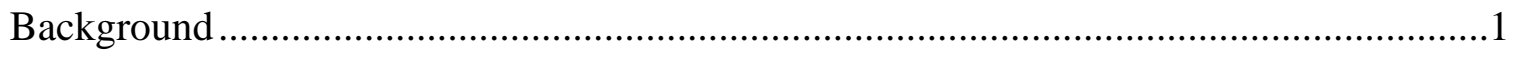

School Reform Model: Coalition of Essential Schools .................................................

Comprehensive school reform: The implementation.........................................4

Reorganization begins spring 2005-fall 2008 ............................................

Sustainable professional development .........................................................12

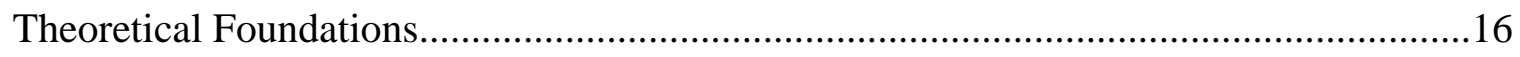

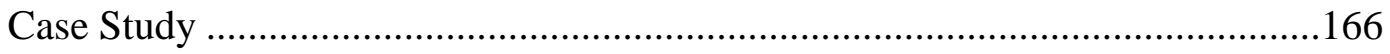

Constructivism .................................................................................... 19

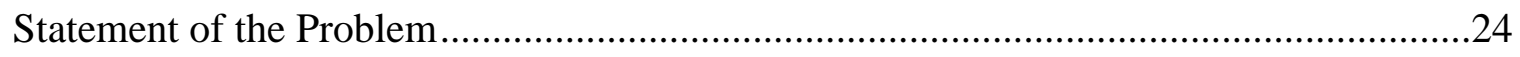

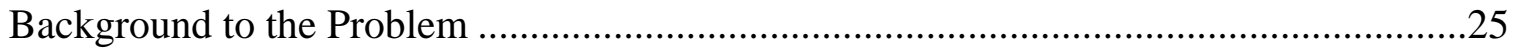

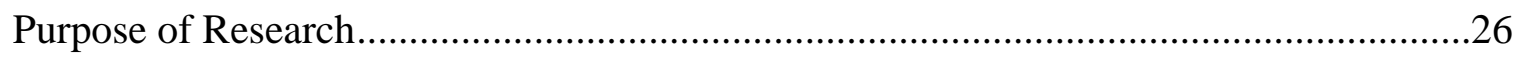

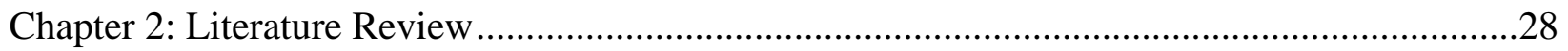

Literature Focused on Professional Development ...................................................28

Professional development as a reform mechanism ......................................28

Philosophical or theoretical premises underlying professional development........31

Professional development: Building teacher commitment ...............................34

Professional development: Ongoing job-embedded opportunities ......................36 
Literature Focused on Relationships and Releasing Responsibility .............................44

Relationships: Positive discourse.................................................................44

Relationships: How students learn...........................................................45

Relationships: Setting goals ..............................................................4

Release of responsibility: Gradual release ................................................47

Release of responsibility: Teacher modeling ..................................................48

Release of responsibility: Collaborative work ..............................................48

Release of responsibility: Guided instruction ...............................................49

Professional Development Evoking Change and Eventually Sustainability ....................50

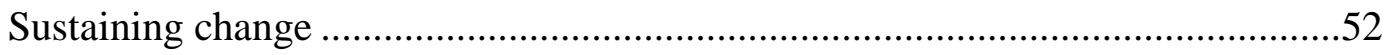

The role of professional development.........................................................54

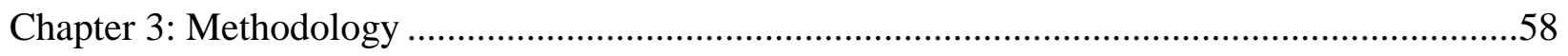

Research Design: Qualitative research—Case Study. ................................................58

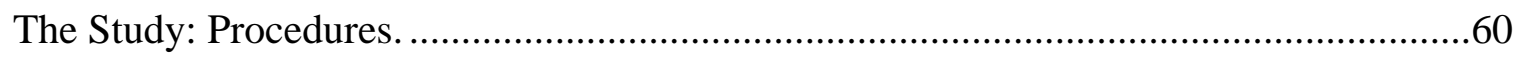

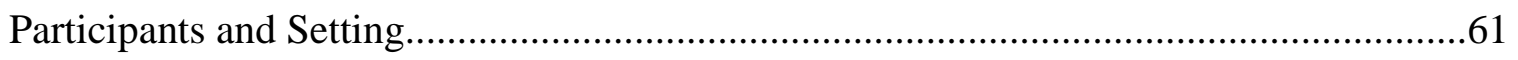

Description of Phase 1 participants.............................................................63

Phase 1 preliminary interview — teachers .................................................63

Description of Phase 2 participants............................................................64

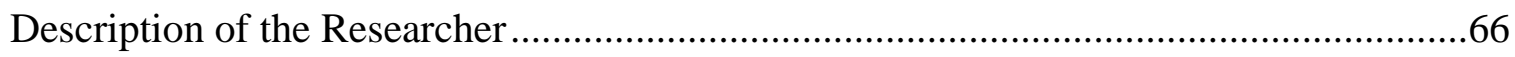

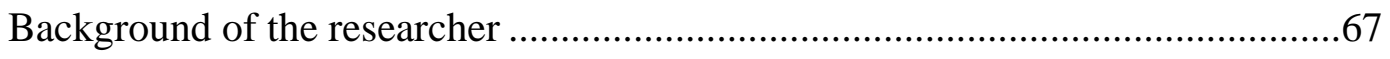

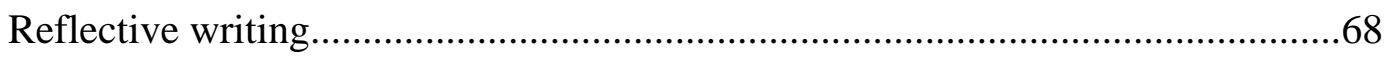

Setting the Context of the Study: Background of CES Professional-Development

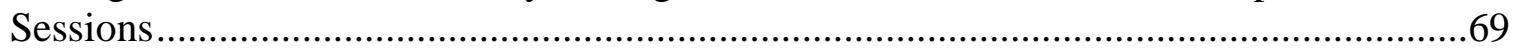

Phase 1: Preliminary Classroom Observation Data: Observing Kara and Katie...............70

Phase 2: All Grade Levels are Observed ................................................................. 71

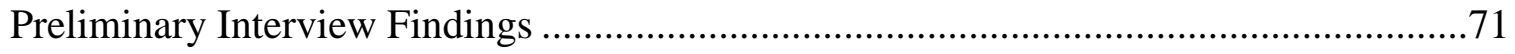




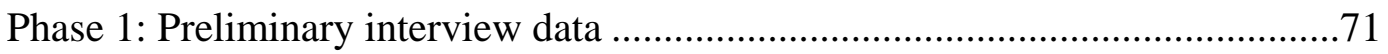

Phase 2: Interview data from participants.....................................................71

Phase 2: The cumulative final survey .............................................................

Trustworthiness, Data Collection, and Analysis.......................................................72

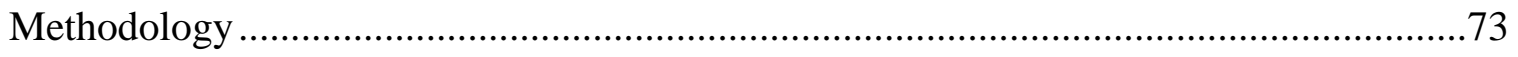

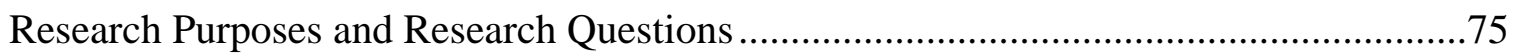

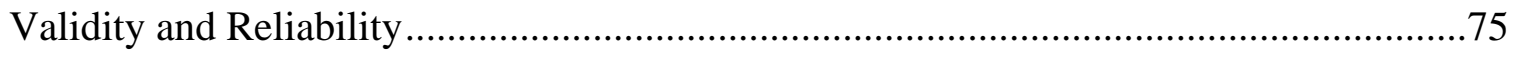

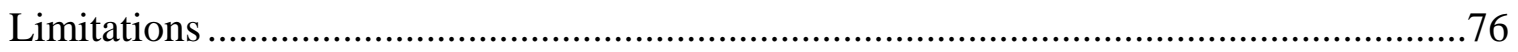

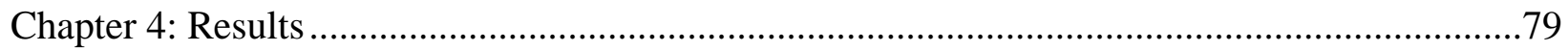

Preliminary Findings: The Observations 2008 and 2009 .........................................79

Research Question 1: Kara and Katie’s observations ...............................................80

Teacher A, Kara’s Cumulative Progress......................................................................83

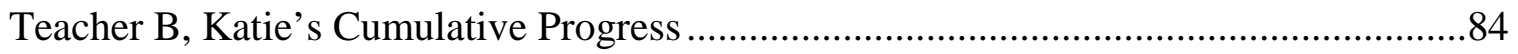

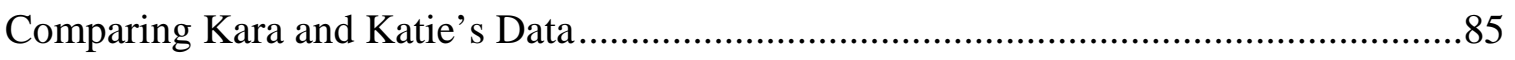

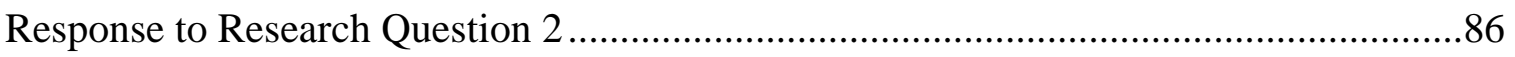

Theme 1: Remain Calm and Listen to Build Relationships.........................................91

Theme 2: Be precise With my Words to Build Relationships .......................................94

Theme 3: Believe in Your Students’ Abilities and Intentions to Build Relationships ......96

Theme 4: Words Into Action to Build Relationships.................................................98

Research Question 3: The Interviews and Final Survey ............................................99

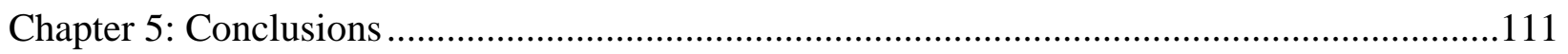

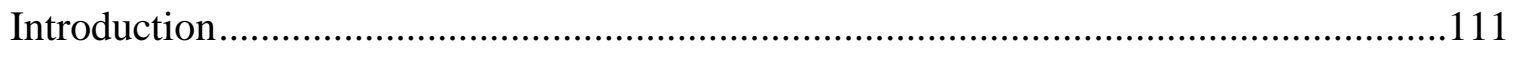

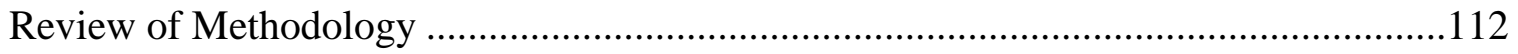

Ongoing phenomenological reflection.....................................................113

Reflective writing as a tool for thinking ....................................................114 
Researcher as an instrument.....................................................................114

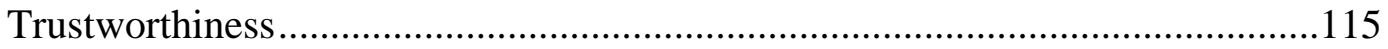

Response to the Research Questions.......................................................................116

Research Question 1 .............................................................................116

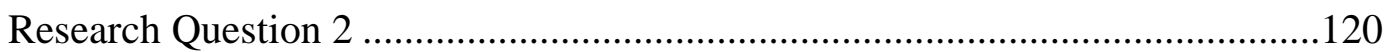

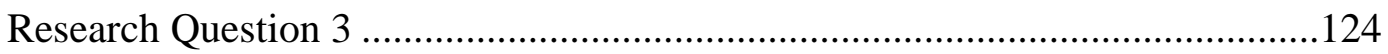

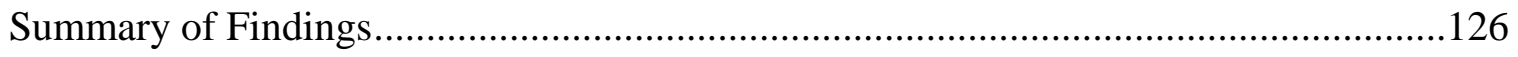

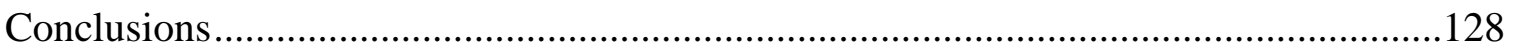

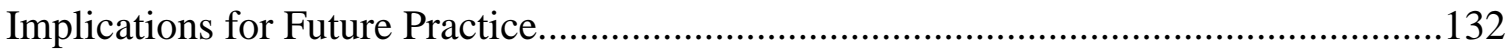

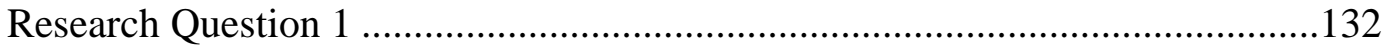

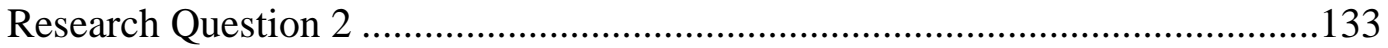

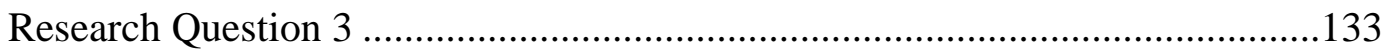

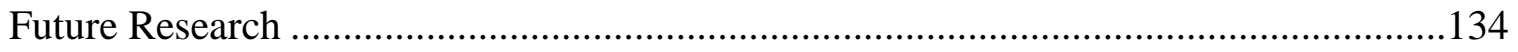

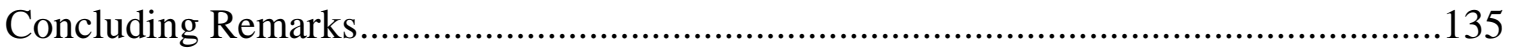

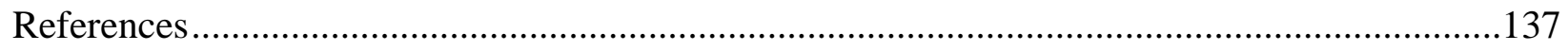

Appendix A: Commonly Used Terms .........................................................................154

Appendix B: The CES Common Principles....................................................................156

Appendix C: Phase 2 Interview Questions 2010-2011 ......................................................159

Appendix D: East Elementary Participant Update...............................................................160

Appendix E: Participant Request Letter .........................................................................164

Appendix F: Observation Tool for Classroom Observations ................................................165

Appendix G: Preliminary Interview Questions: ..............................................................166 


\section{List of Tables}

Table 1 Constructivist Classroom Verses Traditional Classroom .............................................20

Table 2 Demographics of Phase 1 and Phase 2 Teacher Participants.......................................66

Table 3 Formulated Meanings of Teachers’ Perceptions of Professional Development...............91 


\section{List of Figures}

Figure 1. Observations Teacher A, Kara’s room..................................................................844

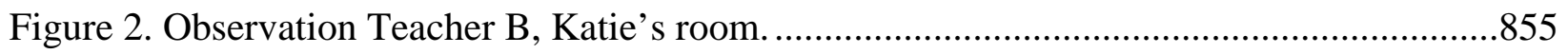




\section{Chapter 1: Introduction}

\section{Background}

“We are not human beings on a spiritual journey. We are spiritual beings on a human journey."

The last 20 years educators have seen an increasingly rapid return to large-scale wholeschool reform efforts heavily embedded in professional development. These efforts include a large investment of time and money for everyone involved. Teachers are the most important component in affecting change (Weissglass, 1994). Consequently, any successful reform effort will use knowledge about the sustainability of the changes in teachers' content knowledge and instructional practices (Borko \& Mayfield, 1995; Borko \& Putman, 1995; Guskey, 1995). For teachers, the conflict between an emphasis on test scores, teaching for understanding, contentknowledge issues, and being asked to use strategies they have never personally experienced as a student must be resolved. Beasley (2000) stressed that cultural change in schools is needed before school reform efforts aimed at professional development can have a serious impact. I argue that professional development is the vehicle by which a change in school culture can be realized, as long as it is sustainable.

Nationally, these school improvement efforts have taken a variety of forms, from a more locally developed Title I schoolwide reorganization project supported by a professionaldevelopment model like the one in this study, to the antithesis, such as efforts to import a business-management team, hire a new staff, and design a new curriculum (Ross, Stringfield, Sanders, \& Wright, 2003). Across the country, underperforming schools have been locally reorganizing their school structures by hiring highly qualified teachers and administrators, with the innate ability to quickly execute fundamental changes to a school's operation and culture, 
aiming to improve academic performance (Vaznis, 2011). Whereas changing the administration, faculty, and staff is an option for a local solution, changing curriculum typically is not an option for most public schools that must teach the state-mandated curriculum. However, in the case of No Child Left Behind (NCLB, 2002), educators did experience the narrowing of the curriculum to prepare for high-stakes tests only in mathematics and reading. Providing professional development for teachers allowed them to strengthen their teaching skill set. Every idea to support an underperforming school and the implementation of its locally designed reorganization plan had to formulated carefully, cautiously, and constructively.

As a reorganization plan comes together, including all voices from administrators to classroom teachers, several challenges arise about the myriad of choices to be made. The reason the school in this study—referred to as the pseudonym East Elementary School—was looking to reorganize itself was because it was laden with the threat and fear of being taken over by the state. The fear of the state taking over was real and stemmed from the school historically failing to make Annual Yearly Progress (AYP; see Appendix A for commonly used terms). NCLB requires all states to measure the achievements of each public schools and districts and establish annual achievement targets for the state. The overarching goal is for all students to meet or exceed standards in reading and mathematics by 2014. Each year, the state calculates a school or district AYP to determine if students are improving their performance based on the established annual targets through standardized-testing measures.

Specifically, East Elementary School had failed to make AYP in the 2004-2005 school year, and in the spring of 2005 the school's data showed it was not going to make AYP for its 2nd consecutive year. Upon 3 consecutive years of failing to make AYP, the state has the power to take over the school, so there was a realistic fear of a potential reform movement. The county 
supervisors and building administrators were interested in reorganizing this underperforming, challenging school by providing a grant-funded reorganization approach, funded under the Comprehensive School Reform (CSR) program (Ed.gov, 2010). The government supported this trend in school reform with money provided by the CSR (Ross 2003, as cited in Ed.gov, 2010) program. The CSR Program is an important component of the NCLB law. Its purpose is to help raise student achievement by assisting public schools across the country implement effective, comprehensive school reforms that are based on scientific research and effective practices (Ed.gov, 2010). This program has provided funding that helps expand the quality and quantity of schoolwide reform efforts that enable all children, particularly low-achieving children, to meet challenging academic standards (Ed.gov, 2010). There are more than 45 reform models funded under the CSR. The Coalition of Essential Schools (CES, Sizer, 1996), the Comer School Development Program (Haynes, 1998), Success for All (Slavin \& Madden, 2001), and Accelerated Schools (Hopfenberg \& Levin, 1993) are just a few organizations in the CSR's family of school reform models. The CES was selected by the administration and a few select teachers as East Elementary School’s reform model.

\section{School Reform Model: Coalition of Essential Schools}

Perhaps one of the best known examples of school reform is the CES, housed at Brown University (Pinar, Reynolds, Slattery, \& Taubman, 2004). Sizer (1984) is the architect of this important national movement. For 25 years, CES has been at the forefront of creating and sustaining personalized, equitable, and intellectually challenging schools. Guided by a set of 10 common principles, CES schools are places of successful student learning, where all students have the chance to reach their full potential (Sizer, 1984). Diverse in size, population, and programmatic emphasis, CES schools serve K-12 students in urban, suburban, and rural 
communities. The CES common principles describe the core beliefs and characteristics of CES (see Appendix B). The CES common principles are as follows:

1. Principle 1: Learning to use one’s mind well

2. Principle 2: Less is more, depth over coverage

3. Principle 3: Goals apply to all students

4. Principle 4: Personalization

5. Principle 5: Student-as-worker, teacher-as-coach

6. Principle 6: Demonstration of mastery

7. Principle 7: A tone of decency and trust

8. Principle 8: Commitment to the entire school

9. Principle 9: Resources dedicated to teaching and learning

10. Principle 10: Democracy and equity

According to Pinar et al. (2004) there are 50 coalition schools that support the values of CES common principles as a framework for their local school redesign. The CES common principles, based on decades of research and practice, are a guiding philosophy rather than a replicable model for schools. As a result of the common principles, CES schools focus on helping all students use their minds well through hands-on, student-centered, real-world learning and performance-based assessments (Sizer, 1984). CES serves as a catalyst to provide specialized professional development for the teachers of East Elementary School.

Comprehensive school reform: The implementation. The teachers of East Elementary School worked with CES from the Fall of 2006 through 2008. The reform model provided specialized professional development based on the CES 10 common principles. Administrators of CES believed it was a match for the needs of the school and was important to its success. 
However, the teachers felt it was best to select three of the 10 common principles of CES to hone and execute well over the 3-year time period working with CES. The following principles were selected:

1. Principle 2: Less is more, depth over coverage

2. Principle 5: Student-as-worker, teacher-as-coach

3. Principle 7: A tone of decency and trust

The selection of Principle 2: Less is more, depth over coverage was based on the idea that it would serve as the overarching goal of the reorganization process. It would be the philosophy and approach taken when dealing with the changes the teachers and administration were going to face during the 3-year reorganization period. As explained by Sizer (1984), the purpose of Principle 2 follows:

The school's goals should be simple: that each student master a limited number of essential skills and areas of knowledge. While these skills and areas will, to varying degrees, reflect the traditional academic disciplines, the program's design should be shaped by the intellectual and imaginative powers and competencies that the students need, rather than by "subjects” as conventionally defined. The aphorism "less is more” should dominate: curricular decisions should be guided by the aim of thorough student mastery and achievement rather than by an effort to merely cover content (p. 2).

Less truly can be more when working through change. It can allow for teachers and students to take small steps in a new direction. Principle 2 described the overarching mindset for teachers and administration during the reorganization process to slow down and aim for mastery and achievement, rather than merely exposure to the curriculum. It allowed teachers time to establish small achievable goals within their classrooms. Principle 2: Less is more, blended well 
with the focus on student-center learning from Principle 5. It provided the much-needed time for reflection for teachers during the 3-year reorganization process.

With the establishment of Principle 2 as the overarching goal and mindset, the following two common principles that focused on these topics most directly were Principle 5: Student-asteacher, teacher-as-coach and Principle 7: A tone of decency and trust. These two principles were the main focus of CES professional-development sessions in the 1st year of the program. Each principle will be addressed in sustainability of professional development in Phase 2 of this study. These two principles were specific to the instructional and emotional needs of students.

Principle 5: Student-as-teacher, teacher-as-coach, was the principle that focused on academics, specifically instructional methods. According to research by Sizer (1984), "the governing practical metaphor of the school should be student-as-worker, rather than the more familiar metaphor of teacher-as-deliverer-of-instructional-services. Accordingly, a prominent pedagogy will be coaching, to provoke students to learn how to learn and thus to teach themselves” (p. 2).

CES Principle 5 does support changing how the teacher delivers instruction. The teacher is encouraged to become the facilitator of the knowledge rather than the imparter of all information, thereby empowering students to take control of their own learning. In the research, Sizer (1984) suggested that best practices for teaching would include being thought of as a coach, an analogy to the work of coaching athletes. Sizer primarily emphasized that education must be characterized by a give-and-take interaction between teacher and student, rather than the traditional approach of teacher lecture.

Principle 7: A tone of decency and trust focused on the relationships between and among the teacher and students. The essence of this principle centered on the tone of the conversations 
between the following: teacher and student, student and teacher, and student to student. This principle expected both the teacher and students to be respectful of one another in the learning environment. According to Sizer (1984) Principle 7 states specifically,

The tone of the school should explicitly and self-consciously stress values of unanxious expectation (“I won’t threaten you but I expect much of you”), of trust (until abused) and of decency (the values of fairness, generosity and tolerance). Incentives appropriate to the school's particular students and teachers should be emphasized. Parents should be key collaborators and vital members of the school community. (p. 3)

Of the three principles selected—Principle 2: Less is more, depth over coverage;

Principle 5: Student-as-worker, teacher-as-coach; and Principle 7: A tone of decency and trusteach works in conjunction with the others to support the development of the learning environment, as well as the student-teacher relationship at East Elementary School. The purpose of this research was to determine the sustainability of the CES's professional development as perceived by the teachers.

According to Noddings (1999), today's school-reorganizing efforts aim almost exclusively at increasing the academic achievement of students. Although this is part of the quest, it was not the only goal in the 3-year reorganization process for the school in this study. East Elementary School did not want to fall short in promoting the discourse that lies at the heart of education. By implementing the three selected CES common principles, the school was able to continue to address which experiences students needed to become engaged participants in life (Noddings, 1999). All three of these principles gave a focus, purpose, and clear direction to East Elementary School teachers so they could begin reorganizing their classrooms with the students at the center. 
Reorganization begins spring 2005-fall 2008. For East Elementary School, the reorganization plan began in February of 2005. Board members selected the new administrative team. The faculty and staff were told they had the opportunity to choose to either reapply to work at East Elementary School, or they could be placed at another elementary school in the county. The principal and two assistant principals, in 2005, along with the former principal from 2004, were the key players in the interview process and selection of the faculty and staff members for the 2005-2006 school year. Teachers who were interviewed and were selected to return to East Elementary School were given a new contract. The contract stated the teachers who accepted the position were making a 3-year minimum commitment from 2006-2008 to remain at East Elementary School. It also stated the work week would be extended by an additional 2.5 hours per week. The teachers were compensated for their additional work time. Their additional time was spent immersed in professional development provided by the members of the CES staff.

The professional-development activities were designed based on the three common principles selected by the teachers. Principle 2: Less is more, was the overarching goal or mindset when the professional-development activities were planned. The topics for the professional-development sessions provided strategies to strengthen classroom instruction as well as to help teachers understand how to develop relationships between and among their students. The activities also had strong "real world" connections. The point was for the students to be able to construct their own meaning and therefore develop their own learning as a result. Professional-development topics stemmed from the following CES principles: Principle 2: Less is more, depth over coverage; Principle 5: Student-as-teacher, teacher-as-coach; and Principle 7: Tone of decency and trust. 
Professional development designed to retrain teachers how to communicate and build relationships with their students was at the core of the reorganization movement. It was important for the teachers to be committed to the professional development for both the academic success and the emotional success of the students of East Elementary School. CES members supported teachers as instrumental in driving the daily topics presented in professional development sessions. In a study conducted by Desimone, Porter, Garet, Yoon, and Birman (2002), the authors stated "professional development is considered an essential mechanism for deepening teachers' content knowledge and developing their teaching practices” (p. 81). Avalos (2010) stated, "Professional development is about teachers learning, learning how to learn, and transforming their knowledge into practice for the benefit of their students' growth” (p. 10). Professional development depends on the objectives and needs of teachers as well as of their students.

According to research by Desimone et al. (2002), professional development could be a cornerstone of systemic reform efforts designed to increase teachers' abilities to teach to higher standards. The staff from CES and the team of teachers at East Elementary School collaborated to learn the specialized CES strategies through professional-development strategies. There was an understanding that not all professional development, even those with the greatest evidence of positive impact, is relevant to all teachers. Just as instruction for students needs to be differentiated, so does professional development opportunities for teachers. It was important to continue to allow teachers to be actively involved in the selection of the professionaldevelopment activities, provide them with time to discuss and reflect on their learning, and ensure teachers' commitment to the plan and to the learning of the students as well as to their own (Avalos, 2010). 
The professional-development sessions with CES staff began in the fall of 2006 and lasted until the fall of 2008. The contract with CES ended in the fall of 2008, however the teachers at East Elementary were still required to complete an additional 2.5 hours of professional development per week based on the 3-year contract each teacher signed in 2005. Additional professional development was provided and will be addressed further in the section titled Sustainable Professional Development.

As CES continued to work on providing professional development for its teachers at East Elementary School, there was a realization for participants that in education, reorganizing a school requires change. The teachers agreed the professional development should focus on how to effectively change how they communicate and build relationships with their students. Additional professional development was designed to develop the teachers' instructional strategies and content knowledge base.

The teachers were provided information from the professional-development sessions and strove to develop students with a greater understanding of material being taught rather than students with limited knowledge of the disciplines that are assessed. This was possible through intense specialized professional development. The process of school reorganization was about a new beginning for everyone involved: the students, the faculty and staff, and all stakeholders (Rose, 2010). The reorganization process included a recommitment to an underperforming, struggling school in order to bring about change (Borman, Hewes, Overman, \& Brown, 2003). The idea of specialized professional development is that it comes with a specific plan and purpose to impact the school in a positive way. For this school, the impact was not only instructional, but emotional, through communication and building relationships with students. 
East Elementary School was changing the way they were supporting their teachers and students. When considering a change such as this, it was important to consider what would change and what would remain constant. The constant variable was the students in the reorganizing process. The students would not be offered the option of attending another school at the county's transportation expense during the study. Therefore, the students who attended East Elementary School prior to the reorganization process would be the students who attended the school during the reorganization process. The second major change was the building administrators would be replaced and the selection would be made by the board members.

Change for the teachers looked different than it did for the administrators at East Elementary School. They would be considered a constant variable if they were rehired, or they could be considered part of the change if they left and new teachers filled their positions during the reorganization process. If they choose to interview for the position again, the teachers may or may not have been rehired to return to the school. Some teachers chose not to interview again, but decided to move to another school. Leaving the school would be their own choice. Several teachers wanted to interview again and stay at East Elementary School to work through the reorganization process. The administrators, the teachers who were hired new to East Elementary School, along with the members of CES were the new people in the school. These people who were newly hired, including the teachers who were retained, were part of the first decision set made during the reorganization process to implement change at East Elementary School.

By locally reorganizing a school with efforts that followed a restructuring format or one that implemented a reform model such as CES, it was hoped the plan would have positive effects on the school and community (Datnow \& Stringfield, 2000). Research by Datnow and Stringfield claimed that by involving the administrators and teachers in the design of a whole- 
school reorganization plan based on the needs of the school, it sets a school on the path to success. Per a decision at the county board level, East Elementary School had involved their administrators and teachers in the plan so far, and had intended to keep them involved during the planning of the professional-development sessions with CES.

Sustainable professional development. In the fall of 2008, there was a transition at East Elementary School. The grant funding ended; therefore the professional development provided by CES since the fall of 2006 ended. It ended 1 year short of its 3-year commitment, due to lack of funding. It would now become the responsibility of the teachers at East Elementary School to continue or sustain the professional development CES had presented to them over the past 2 years. The teachers were expected to continue to implement everything they had been taught in the CES professional-development sessions. There was continued support for the teachers at East Elementary School, however it was not the formal specialized professional development they had grown accustomed to with CES.

In the spring of 2009, professional development in the form of content-specific instructional support was provided by curriculum and instruction (C\&I) specialists. The C\&I specialists were teachers in the county who were specialists in one content area, such as mathematics or reading. They provided support for any school or schools that requested additional instructional support for teachers. The school administration decided to provide the C\&I specialists on the average of once a month for the teachers. Even though the teachers were no longer receiving 2.5 hours of additional specialized professional development by CES, the teachers contractually had to work those extra hours. They worked by tutoring students for 2.5 hours after school. Teachers tutored students twice a week for 45 minutes, either before or after school. This use of the contracted extra hours was determined by the board of education when 
the grant funding ended for CES. The administrators provided content-specific professionaldevelopment sessions monthly for the teachers, however this professional development was provided in their regular work-week hours. The professional development was based on their expertise and the needs of the teachers and students of East Elementary School. C\&I specialists visited the school to provide additional information about best practices.

After the CES program ended, the idea of professional development was designed more using a behaviorist approach to learning, focusing on the transmission of knowledge from an expert to a novice (Spillane, 2002). The C\&I specialists were the experts who would come to East Elementary School to share their expertise about different content knowledge. The teachers were still provided with a voice as to the topics about which they wanted to learn, but it was not the professional development provided by CES that the teachers experienced during the reorganization period. It would be up to the teachers to sustain the information about each of the three CES principles East Elementary School selected as the focus.

With the departure of CES, teachers needed to become self-sufficient. They would have to work independently on stressing less is more, and teach for depth rather than for coverage, as stated in CES Principle 2. They would need to continue to privately work to become the facilitator and empower the students to be in charge of their learning, as emphasized in Principle 5: student-as-worker, teacher-as-coach. For the final principle the teachers had selected Principle 7: a tone of decency and trust. This principle was designed to help teachers and students establish and develop relationships and safe learning environments. All of the information and strategies provided by CES in their previous professional-development sessions were now left to teachers to determine if they would be able to sustain the information gained from the time invested with CES. 
When the school transitioned from the CES professional development to the professional development provided by C\&I specialists, not only did the format of the professional development shift, but so did the motivation for the teachers. This time span was during the reorganizing process. Teachers were internally motivated about professional development between the spring of 2009 and the fall of 2011, after the granted-funded professional development with CES had ended.

When teachers had a voice and opportunity to choose the topics discussed during professional development, it served as a motivator (Darling-Hammond, \& Richardson, 2009). When working with CES, the teachers had a voice. The professional development provided by CES was determined by the teachers. They decided what the focus of the sessions would be based on the needs of their students. The teachers matched the needs of their students to the instructional-strategy ideas and to one of the three CES common principles: Principles 2, 5, or 7. Each CES common principle provided the framework for the professional-development sessions. When the professional development with CES ended, the instructional support for teachers was provided by C\&I specialists. They continued to keep the teachers’ voice at the forefront of the decision making on professional-development sessions; however the sessions were sporadic. Whereas the CES professional development was every week for an extra 2.5 hours, the C\&I specialists’ instructional support sessions occurred on the average, one session per month. There was no additional professional development about the CES common principles or CES instructional strategies. However, the teachers continued to have a voice in which topics were discussed and made sure the topics were based on their students and their needs.

Even with the two variations of professional-development offered to teachers by CES and the C\&I specialists, one constant element was the practice of reflection on student work and 
teachers' lessons. Providing time to reflect began with CES and continued with the C\&I specialists. It was important to provide teachers time to reflect both during and after professional-development sessions (Servage, 2008). Much information was gleaned from teachers' discussions in the sessions, from the facilitator of the session, and also from networking between and among teachers themselves. In the professional development provided by CES during Phase 1 of this study, teachers were provided with specific time to reflect on student artifacts, and on their lessons. In Phase 2 of the study, the C\&I specialists made sure there were also opportunities for teachers to continue to focus on student work, as well as to debrief with one another about their own lesson successes and struggles. Providing time to reflect allowed for a greater chance for teachers to retain the material shared in each professional-development session (Servage, 2008).

All of the data collected in Phase 2-the observations, the interviews (questions located in Appendix C), and the final survey (located in Appendix D) —-were conducted to ascertain the teachers' perceptions of the sustainability of the professional development they had experienced since working at East Elementary School. Phase 2 looked at the sustainability of CES professional-development efforts that used instructional support. Teachers began to network with one another, collaborating in problem solving and the discussion of content. Collaboration along with reflection had the greatest chance of impacting teaching practice over a period of time (Lewis, 2002). To sustain what teachers were taught, teachers needed to be actively engaged in observing each other and reviewing student work.

Also, teachers desired topics that were relevant to other activities directly involved in teaching. This supported the need for continued professional development even after the funding ended in the fall of 2008. The support provided by C\&I specialists worked to help the teachers of 
East Elementary School create flexible networking sessions. The sessions addressed the additional needs of students and teachers, as perceived by teachers. Operating inside a vision of professional development that was aligned with teachers’ foci meant that C\&I specialist must address the fact that developing teachers and their skill sets was a complex task that occurs with teachers expressing varying needs. These varying needs were uniquely different from teacher to teacher in this study. Therefore, continued professional-development opportunities were needed that considered the specific situations in which teachers work (Guskey, 1995).

Helping teachers access the knowledge currently available was one strategy of CES during the reorganization-process, but developing teachers with skill sets to sustain what they have learned, as well as to continually access new knowledge, also became important as a focus throughout the journey. If teachers only learned about current knowledge, teaching would become stagnant as soon as current knowledge was outdated. The professional-development sessions pushed teachers to change and grow. Change was one of the many skills teachers developed through the professional-development experience. Franke, Carpenter, Levi, and Fennema (2001) called this skill “generative change.” Generative change was seen as helping teachers become continuous learners, even when they were not participating in a professionaldevelopment program. Teachers who created generative change were teachers who reflected on their practices, searched for solutions to identified problems, and who used multiple tools to assess the effectiveness of those solutions. Teachers can strive to sustain the knowledge they have learned by embracing change.

\section{Theoretical Foundations}

Case Study. This single case study allowed for qualitative data collection strategies using triangulation. Qualitative data collection procedures using interviews, observations, and a survey 
were an appropriate way to explore teachers’ perceptions of the sustainability of the professional development presented by CES. Qualitative research is an inductive process that emphasizes participant perspectives as a part of the research. Using qualitative data collection, the researcher was able to interpret data and reveal patterns about the participants’ experiences (Creswell, 2005; Merriam, 1998; Yin, 2003).

Educators who are interested in learning more about a particular issue or event in their school commonly use the case study method. "Case studies are the preferred strategy when 'how' or 'why' questions are being posed, when the investigator has little control over events and when the focus is on a contemporary phenomenon within some real-life context” (Yin, 2003, p. 1). The case study focus is on description and explanation. According to Merriam (1998), “Case Study has proven particularly useful for studying educational innovations for evaluating programs and for informing policy” (p.41) Yin (2003) defined a case study as “A phenomenon within its real-life context, especially when the boundaries between phenomenon and context are not clearly evident” (p. 13). This particular case study explored the phenomenon of lived experiences of the participants of this group. It specifically looked at the relationship between teacher and student in the learning process through a reflective lens. The administrations' quest was to reorganize the teaching style through communication and relationship building with the students in the school.

The first step in East Elementary School's reorganization plan was to focus instruction through specialized professional development. The professional development aimed to train teachers how to communicate effectively and build relationships with their students. The specialized professional development was the phenomenon of the lived experiences of the participants of this group. This phenomenon included the researcher. As an observer and 
participant of this experience, I was able to note the changes in communication between students and teachers.

The ideas for the specialized professional development as well as the selection of the three principles 2,5, and 7 were based on the needs of the school before reorganization process began. The teachers assessed their students' needs not only based on data but also based on the students' emotional needs as well. Along with the teachers, CES members also looked at student data. They discussed the teachers' concerns and observed them in their classrooms to agree on the discussion topics for the professional development sessions. CES also used this information to confirm the selection of the three principles 2,5 , and 7 for the focus of the school. The teachers continued to determine the topics they would like to discuss in their professional development sessions still based on student data and the emotional needs of the students.

The specialized professional development provided opportunities for the teachers to network, reflect on their work, as well as be exposed to the CES protocols for student engagement. The specialized professional development sessions were tailored discussions where teachers brought student work to share, discuss and reflect in small groups (Darling-Hammond \& Richardson, 2009). These sessions fostered collaborative reflection within as well as across grade levels. The teachers' and students' needs were the focus for each of the tailored professional development discussions over the two years with CES. Along with the discussions, CES provided a myriad of different protocols for the teachers to engage their students in learning, as well as promote the students to become responsible for their own learning (Elmore \& Burney, 1999).

The strategies learned in professional-development sessions were implemented by teachers in their classrooms. Teachers were striving to help students make real-world 
connections to academic experiences to allow them to personalize their experiences. Van Manen (1997) described a similar experience to this research in a reading scenario; the reader underwent a spiritual transformation as the story acted on the consciousness in unexplainable ways. The mere act of reading itself did not always constitute change unless there was a personal meaning attached to the experience. Personal connections for the students of East Elementary School were now an instructional focus in teachers' classrooms.

Constructivism. Schubert (1995) stated that curriculum was the interpretation of lived experiences. The constructivist approach to learning acknowledged that both teacher and student bring prior knowledge to the learning experience. The theoretical backing of constructivism can be traced to the works of Dewey, Montessori, and Bruner. The concept of the teacher, the student, the method, and the evaluation in a postmodern framework was different from those from a traditional viewpoint.

Traditional education viewed the student as a passive learner, providing the student with a predetermined list of objectives. It used teacher-centered approaches to attain these objectives along with predetermined, teacher-centered evaluations (see Table 1). However in constructivism, student characteristics and choices are important in learning, as well as in the instruction provided. Borman et al. (2003) stated that individuality and subjectivity were the key components of the new paradigm in teaching. 
Table 1

Constructivist Classroom Verses Traditional Classroom

\begin{tabular}{ll}
\hline \multicolumn{1}{c}{ Constructivist classroom } & \multicolumn{1}{c}{ Traditional classroom } \\
\hline $\begin{array}{l}\text { Teaching approach: Inquiry-based learning, } \\
\text { activating prior knowledge, interactive } \\
\text { discussions and labs }\end{array}$ & $\begin{array}{l}\text { Teaching approach: One-sided lectures, traditional "sit and get” } \\
\text { approach, little or no interaction between the teacher and } \\
\text { student }\end{array}$ \\
$\begin{array}{l}\text { Teacher roles: facilitator, coach } \\
\text { Teacher role: primary deliverer of material and information }\end{array}$ \\
$\begin{array}{ll}\text { Student role: reflective, active learning, students } \\
\text { engaged in hands-on experiences }\end{array}$ & $\begin{array}{l}\text { Student role: passive learner, empty vessel to be filled by the } \\
\text { teacher }\end{array}$ \\
\hline $\begin{array}{l}\text { Note. The information in the table is a compilation of ideas and beliefs from Dewey, Freire, and CES. From Toward } \\
\text { lives worth living and sharing: Historical perspective on curriculum coherence, by W. Schubert, 1995, in J. Beane }\end{array}$ \\
$\begin{array}{ll}\text { (Ed.), Toward a coherent curriculum (pp. 146-157). Alexandria, VA: Association for Supervision and Curriculum } \\
\text { Development. }\end{array}$
\end{tabular}

Dewey (1938) challenged and partially rejected traditional teaching practices that viewed the student as a passive learner. Dewey (1938) proposed that over time and through interaction with others in a learning environment, the student constructs new meaning as a knowledgebuilding process. The new knowledge is built onto former knowledge, piece by piece. This concept differs from the modernist view in which children are considered empty vessels waiting to be filled.

The modernist view was described through the works of Freire. Freire coined the phrase banking concept of education in his text, Pedagogy of the Oppressed (1970). The banking concept was a belief that knowledge could simply be deposited into the learner just as easily as money can be deposited into an account. In the framework, the teacher lectured, and the students received, memorized, and repeated that information back to the teacher.

It was a very oppressive way of teaching for the teacher as well as a very oppressive way of learning for a student. It promoted an environment where teachers know everything and students were assumed to know nothing. Teachers were the ones doing most of the thinking 
rather than the students. In this environment prior to the reorganization process, choices were made by teachers, and students were simply expected to comply with those decisions.

In a traditional modern classroom, teachers are the subject of the learning process, whereas students are merely objects. East Elementary School was locked into the traditional, modern banking concept of teaching prior to the reorganization period. The CES professionaldevelopment sessions provided the venue for teachers to learn different approaches to instruction and move towards a more constructivist approach. CES members modeled hands-on strategies and inquiry-based skills to be implemented in the teachers’ classrooms.

A teacher who is a constructivist focused on the idea that students should retain what they have learned by experiencing it. The true learning occurs from the experience itself. Freire’s (1970) banking concept was a concrete example of what Dewey was trying to express about concerns of teachers simply imparting information to their students. Both Dewey (1938) and Freire (1970) were advocates for the CES-advocated pedagogical approach that involves actively engaging students. The CES common principles also melded with this pedagogical approach.

CES members found it necessary to emphasize the importance of active social-learning environments rather than one-sided lectures in their professional=development sessions. They presented learning as the active construction of knowledge through engagement with ideas in meaningful contexts, rather than a passive collection of isolated bits of information, as Dewey advised. Constructivism allows students to move from passive observers to active learners who construct knowledge by integrating new information and experiences into what they previously came to understand. Students revise and reinterpret the old knowledge and it with new information. Then, students determine what they have learned. 
Freire maintained that education must be engaged with the common experiences of students. Dewey (1938) stated learning took place in meaningful contexts that allowed students to build on the knowledge they already had. The approaches of both Freire (1970) and Dewey (1938) asked educators to consider language, experiences, and social constructs of students to build meaningful lessons. Both Freire and Dewey (1938) argued that educators need to understand the experiences and world views of their students to successfully further the learning process.

Understanding the background of students allows for a stronger connection with the activity or lesson so greater learning can occur. This takes time, effort, and a serious commitment by teachers to build a relationship with each student (Irving \& Fraser, 1998). Building relationships was one of the main reasons for the need to reorganize East Elementary School. With an honest and safe relationship with students, clear and positive communication occurred. With a clearer understanding of what the overall learning goals were, perhaps students could be more successful academically. Teachers were provided support by the members of CES to develop skills in communicating and building relationships between and among teachers and students.

In addition to communicating and building relationships, students needed to reflect to achieve greater academic success. By incorporating the reflections of students into daily instruction, teachers measured student growth. Dewey (1938) and Freire (1970) associated learning with a process of actions. These actions included reflection, actively seeking after truth, and being able to apply that learning to future problems.

A constructivist approach also recognizes the importance of providing time for reflection for teachers and students. In constructivism, the focus of teaching is on the empowerment of the 
student. Teachers engage students in the discovery of knowledge and provide them opportunities to reflect on and test theories through real-world applications of knowledge. The constructivist approach to teaching and learning moves students away from the rote memorization of facts to metacognition and self-evaluation. It moves toward and encourages reflection (Hoskins, 1995).

Allowing the teachers to have time to read, discuss, and reflect on student artifacts provided an opportunity for authentic professional growth (Darling-Hammond \& Richardson, 2009), as CES did. Freire (1970) claimed a good lesson can become great if there was an opportunity for some reflection for both students and teachers. Allowing time for students and teachers to reflect on previous activities provided opportunities to determine where to go next in each group. Learning gains its power, strength, impact, and longevity from reflection time. The power of reflection is where true learning happens because it is so personalized (Freire, 1970).

The research of the theorists also drew a connection between reflection and politics, with Freire (1970) linking reflection with the fight against oppressive social conditions and Dewey (1938) linking reflection to responsible and ethical democratic citizenship. Maintaining a classroom where everyone strove to be productive citizens based on the idea that knowledge is power, students knew they had the chance to make a difference. In the school building, anything can be possible and the students were left feeling empowered. The beliefs of CES and the philosophy of constructivism resonated with those ideals of Dewey (1902/1956) and Montessori and George (1912). All believed instruction should be student centered and hands-on with the student learning through experience and exploration.

The idea of what was best practice for students was the driving force behind the decisions made during the reorganization process. By focusing on the students' needs, it was important to consider that students generally spend more time interacting with their teachers than with their 
parents (Borman et al., 2003). What happened inside schools has a deep and lasting effect on the mind sets that children developed toward lifelong learning.

In Experience and Education (1938), Dewey stated, "What avail is it to win prescribed amounts of information about geography and history, to win the ability to read and write, if in the process the individual loses his own soul?” (p. 49). If the school experience itself does not nurture the children's spirit to learn, their sense of wonder, their curiosity about the world, and their willingness to care for others, have educators done their job-no matter how well students may or may not perform on standardized tests? Ross et al. (2003) reported the ongoing process of curricular improvement aimed to change the role of teachers as well as of students. It aimed to change the educational process: its content goals, methods, and approaches to teaching. This was an area of universal concern in underperforming, struggling schools such as East Elementary School. Educators must think about how they use professional development to support teachers’ needs to grow professionally.

\section{Statement of the Problem}

The improvement of education relies on the development of a highly qualified teacher workforce with the knowledge, skills, and disposition to stimulate exceptional student learning in today’s classrooms (Darling-Hammond \& Sykes, 1999). Student learning is dependent on what teachers know, are able to do, and are willing to learn (Killion, 2002). Most agree the objective of professional development is to improve teaching and ultimately enhance student learning. Without professional development, teachers' content knowledge and skills waiver (Shulman, 1987). Teachers who possess and maintain the knowledge skills and dispositions have the greatest impact on strengthening instruction as well as strengthening relationship building in high poverty, high minority school districts. Research indicates a strong need to incorporate 
sustainable professional development into a well-orchestrated reform effort (Craig, 2006;

Elmore, 2002; Fishman \& Marx, 2001). However what remains to be considered is if the information from professional-development sessions is sustained?

\section{Background to the Problem}

Statistically, Title I schools struggle to achieve AYP but specifically at East Elementary School, the subgroups that struggle most include students with disabilities, free and reducedprice meal students, African American students, White students, Hispanic students, and Englishlanguage learners, as measured by high-stakes tests (Maryland Report Card, 2010). If AYP goals are not met for each subgroup, the school is placed on alert status by the state. Alert status, as defined by the State of Maryland, means the school has entered a cycle of progression toward reconstitution, a point at which the state will take over all control of the school. Reconstitution also means that all families with students at the school have the option to choose to attend another school, with the county paying to bus them to the school of their choice. The school has a 3-year window to achieve AYP in all subgroups or the state will reconstitute it. Reconstitute is a term used by the State of Maryland to describe the reform process. Both reconstitution and restructuring policies vary, but at their core, these strategies involve removing a school's incumbent administrators and teachers (or large percentages of them) and replacing them with educators who, presumably, are more capable and committed (Malen, Croninger, Muncey, \& Redmond-Jones, 2002).

The reorganization of East Elementary School was based on the needs of students and also of the faculty and staff. For East Elementary School, the decision to reorganize was an effort made to be proactive in the final year before possible reconstitution by the state. After working with CES for 2 years, in the last year 2008, the grant funding had ended and the faculty and staff 
ended their mentorship with CES. Even though the relationship with CES had ended, the teachers' 3-year contracts for the county had not. The teachers had to honor their last years of their 3-year contracts. To fulfill the additional 2.5 hours required contractually per week, it was decided by the Board of Education the teachers would tutor students. The tutoring would be in a one-on-one situation with a student who was struggling, defined by AYP criteria.

The data collected during Phase 1 focused on how the two teachers I interviewed and observed communicated and built relationships with their students. The connection was to CES Principle 7: A tone of decency and trust. The preliminary data were collected between fall of 2008 and spring of 2010. These data were used to answer Research Questions 1 and 2 in this study. From this data emerged the overarching research question for this study, which was researched in Phase 2.

\section{Purpose of Research}

The study describes the teachers' perceptions of sustainability of the professional development provided by CES. The first two research questions describe the impact of positive discourse and relationship building between and among teachers and students. Preliminary interview-transcript data was categorized, coded, and analyzed to focus on new emerging themes and to develop additional probing questions.

Because this was an inquiry-based reorganization effort for this school, a qualitative research approach was chosen to elicit the depth of the connections resonating from all of participants' voices. This study sought to understand teachers’ perceptions about the professional development provided by CES. Specifically, this study focused on the sustainability of the professional development provided by CES after the reorganization period. This study involved the identification of sustainable strategies implemented during and after the reorganization 
period, as perceived by the teachers. Using observation and interviews with teachers, their attempts at change in instruction and relationship building were examined through the lens of self-generated change in teachers trying to reform their teaching practices. Specifically, this study examined the following:

In Phase 1 of the study, the following questions emerged from the preliminary research:

Research Question 1: How did CES professional development impact the discourse between and among teachers and students?

Research Question 2: How did the development of positive discourse impact the relationships between and among the teachers and students?

Based on the findings in Phase 1 of this study, the following question emerged for further research in Phase 2:

Research Question 3: Was the information provided by CES during professionaldevelopment sessions sustained, as perceived by teachers? 


\section{Chapter 2: Literature Review}

"Education is not preparation for life; education is life itself."

—John Dewey

This chapter primarily discusses the current research in the field as it relates to the professional development implemented at East Elementary School during the reorganization time period. Literature was examined about effective professional development as a reform mechanism. Also I examined literature about professional development in connection to a myriad of topics: teacher commitment to professional development; strengthening instruction through developing teacher learning communities; and change in education, discussing specifically the role of professional development in building teacher capacity in evoking change and eventually sustaining it. All literature was described in the context of an interpretive, descriptive, qualitative study.

\section{Literature Focused on Professional Development}

Professional development as a reform mechanism. This section reviews research on the theoretical and practical aspects of professional development. Professional-development research revealed the importance of supportive, comprehensive, differentiated professional development that was both research based and supported with money, time, curricular resources, and evidence of support from school administration and local school-board members. Contextual factors as well as knowledge and skill level of the teacher were found to be critical to student learning.

The imperative for ongoing professional development was not due to the perception that teachers were doing an inadequate job, but rather that teachers needed to be supported, retrained, and retained if public education was going to meet the demands of an increasingly complex 
society (Governor’s Commission on Quality Education in Maryland, 2005; Guskey, 2003;

Hargreaves, 1995, 2005; Hartoonian \& Laughlin, 1995; Haslam, Afolabi, \& Hewes, 2005;

Huberman, 1999; Ladson-Billings, 2006; Rényi, 1996). NCLB and the demand for improved teacher quality renewed interest in quality, research-based professional development.

Darling-Hammond, a researcher specializing in teacher-education reform initiatives and past president of American Educational Research Association, joined Sykes to edit the quintessential edition Teaching as the Learning Profession: Handbook of Policy and Practice (1999). The premise of the book was that the improvement of education relied on the development of a highly qualified teacher workforce with the knowledge, skills, and disposition to stimulate exceptional student learning in a highly politicized atmosphere. If any of the 20thcentury education-reform proposals took seed, according to Ball and Cohen (1999), significant professional development would be crucial. Some other chapters included the pedagogy of professional education and curriculum from theory and practice, and the mechanics and conceptual tools of technology as they play a significant role in professional learning. The editors suggested reconceptualizing schools as learning organizations for students and teachers.

The current reform initiatives in science provided a guide for some teacher educators to develop models of professional development for science teachers (Cochran, King \& DeRutier, 1994; Magnusson, Krajcik \& Borko, 1999; Marks \& Louis, 1997). Some of these models have been specific to pedagogical content knowledge development of in-service teachers (Cochran, King \& DeRuiter, 1994; Magnusson, Krajcik \& Borko, 1999). The National Science Teachers Association (1999) highlighted the need for teachers to develop pedagogical content knowledge. Currently, there are a few models for secondary-teacher development (Cheung, 1990; Sakofs, 1995; Saunders, 1994). As part of the standards for accreditation, the National Council for the 
Accreditation of Teacher Education (2004) suggested that professional-development programs adopt a model that explicates the purposes, processes, outcomes, and evaluation of the program; this includes collaborating with content-specific professors, infusing hands-on learning experiences, and pairing beginning teachers with mentors. Strong endorsement from National Science Teachers Association (1999) and noteworthy scholars developing research and teaching models moved reform forward. State departments of education integrated curricular standards with the requirement of continuing-education credits and teacher-developed professionaleducation plans into their teacher-accreditation process.

Student learning was dependent on what teachers know and were able to do in the classroom. Killion (2002) of the National Staff Development Council (NSDC) described the importance of professional development as “Deeper content knowledge, more content-specific instructional strategies, and greater understanding about how students learn. This enabled teachers to craft instruction to meet the varying needs of students and helped them to achieve rigorous content standards” (p. 16).

Several researchers (Governor’s Commission on Quality Education in Maryland, 2005; McFarland, 2005; Rényi, 1996; Sparks, 1994, 1998) reported that the single largest factor affecting academic growth of student populations was differences in the effectiveness of individual classroom teachers. Available research on learning and student achievement demonstrated the necessity for educators to keep informed about improved methodologies to meet students’ diverse linguistic, cultural, and academic needs and to connect pedagogy with subject-matter content. Educators needed more opportunities to refine their conceptual knowledge of the content and to maintain their craft knowledge. 
Most would agree that the objective of professional development is to improve teaching and ultimately enhance student learning. Researchers (Fullan, 2004; Lieberman \& Grolnick, 2005; Lieberman \& Wood, 2002; Shulman, 1987; Sparks, 1994) stressed the importance of teacher expertise in improving student learning. Good instruction requires that teachers have a deep knowledge of the subjects they teach, a repertoire of instructional skills to teach the content, knowledge about their students, and attitudes that encourage high levels of learning for their students.

The implications of professional development continued to plague education researchers, administrators, and policymakers. In the last few years, numerous surveys, studies, and reports were conducted and published providing some context to this complicated problem, which seems to have the greatest impact on instruction in high-poverty, high-minority school districts.

Research indicated a strong need for incorporating professional development into a wellorchestrated reform effort (Craig, 2006; Elmore, 2002; Fishman \& Marx, 2001; Fullan, 2001b; Lieberman \& Grolnick, 2005; Senge, Cambron-McCabe, Lucas, Dutton, \& Kleiner, 2000). These efforts should be supported by policymakers, and teaching must be treated as a learning profession requiring renewal of professional-development experiences for accreditation (Ball \& Cohen, 1999; Heller \& Greenleaf, 2007; Maryland State Department of Education, 2004).

\section{Philosophical or theoretical premises underlying professional development. Most}

professional-development researchers and practitioners assert there is no one theory or philosophy underlying professional development (Borko, 2004; Cochran-Smith, 2003; Fullan, 2001a; Hawley \& Valli, 1999; Warren Little \& McLaughlin, 1993). In addition, no one theory or set of ideas are sufficient to build a successful professional-development model, because there are so many perspectives to consider. Adult-learning theory should be examined in relation to the 
teachers’ ability to internalize and implement a professional-development plan (DarlingHammond \& McLaughlin, 1995; Saphier \& Gower, 1997). Some suggest studying the significance of the contextual conditions such as nurturing structures, collegiality, and feedback (Darling-Hammond \& Bransford, 2005; Elmore, 2000; Elmore \& Burney, 1999). The research on social realities of teaching and the practice of professional development were other aspects of professional development that could be investigated (Darling-Hammond \& Bransford, 2005; Rényi, 1996). Another consideration should be the systematic reform process. Senge et al. (2000) believed unless a system changes, it would continue to create the same results with different individuals. Accordingly, new structures and systems needed to be in place for change to occur, along with policy needed to support the structure (Corcoran, 1995; Elmore \& Fuhrman, 1993; Fullan, 2001a). In public policy debates about teacher quality, such as the mandates (highly qualified teachers) in NCLB, goals and outcomes needed to be defined much more narrowly. Schools and teachers do not exist in vacuums; therefore, external forces need to be considered when designing a professional-development plan. Critical education theorist LadsonBillings (2006) was concerned about forces that affect society and how these forces were putting pressure on existing institutions such as public schools. The complex relationships in society must be examined to understand the implications for schools and educators. The growing achievement gap among the more diverse populations of students in this era of teacher and school accountability is a reality (Arce, Luna, Borjian, \& Conrad, 2005; Center on Education Policy, 2005; Elmore, 2002; Hargreaves, 1995, 2005). Professional-development coordinators were pressured to meet the mandated teacher-quality needs and address the achievement gap of urban poor people (Elmore, 2000; Guskey, 1998; Meier \& Wood, 2004). 
To prepare teachers for a changing world, teacher educators need to organize discussions around a conceptual framework relevant to effective teaching and learning. Darling-Hammond and Bransford (2005, p. 10) recommended teachers acquire three general skills: (a) knowledge of learners, (b) concepts of curriculum content and goals, and (c) an understanding of teaching in light of the content and learners. These connections among the teacher, learner, and content are encompassed by two conditions: teaching is a profession with moral obligations, and education must serve the purposes of democracy.

This framework is also reminiscent of Dewey's (1902) observations in The Child and the Curriculum: the needs of the child and the demands of the curriculum were reconciled by teachers. Later, Ball and Cohen (1999) incorporated Dewey’s ideas into a framework that included teachers, students, and content in different environments that influenced practice.

Teachers' knowledge is directly related to and influenced by what they already know. Professional development that focuses on expanding and elaborating on teachers' knowledge is particularly essential in education reform (Darling-Hammond \& Bransford, 2005); Reformers were asking teachers to teach in ways different from those they knew or by which they had been taught themselves. Brophy (1991) suggested the expression "teaching for meaningful understanding and self-regulated learning” (p. 346) captured several of the important common elements in these new conceptions of teaching. To understand these reform approaches and use them in instruction, teachers need to consider the changing demographics of the schools, the students, the subject matter, and the whole teaching-learning process (Darling-Hammond \& Bransford, 2005; Elmore, 2000; Elmore \& Burney, 1999). Instructional leaders needed to provide the time and opportunity for teachers to meet, discuss, and learn from one another as a professional community. 
Borko and Putnam (1995) considered three successful professional-development programs (p. 58). All assumed that fundamental change in teaching requires growth in teachers' concepts of subject matter, pedagogy, and subject-specific pedagogy. Specifically, professional development should encourage and support teachers to adopt a more constructivist, studentcentered view of the learning process. The message to planners was that the process of professional development for teachers should reflect the approaches to teaching and learning that teachers could then adapt to their own classrooms.

Professional development: Building teacher commitment. Reorganizing a school was intended to "raise the bar and get everyone over it" (Little, 2001, p. 24). In the reorganizing process, schools were granted supplemental resources as well as additional grant monies, and urged to reinvent themselves to bring about change for their students, families, and entire school communities (Louis \& Kruse, 1995; Muncey \& McQuillan, 1996). A universal concern in all schools was ensuring students were being taught by the most qualified teachers possible and learning in the most positive environment possible. All efforts to reorganize and improve schools were to be done with the teachers at the center so they could lead their classrooms and schools toward authentic standards of excellence (Lieberman \& Miller, 2001).

The process of reorganizing a school can be quite a challenging journey, and one embedded with professional development can be even more challenging if teachers are not committed to the process. Building teacher commitment was a crucial piece of the reorganization plan and process at East Elementary School. Agreeing there was a need for change was the first step in building teacher commitment to the process. Next determining specifically what needed to be changed and how to approach making that change needed to be defined. There were differences in the definition of best practices instructionally in a classroom as well as the 
definition of a productive relationship between teachers and students. To convey the intensity and turbulence teachers experienced during the reorganization process, this study captured the voices of the preliminary participants. Through observations and interviews, the essence of this process was preserved. Hong (1996) titled a first-hand account, Surviving School Reform, whereas Muncey and McQuillan (1996) spoke to the "resistance to reform" that intertwined in sites affiliated with CES. The common threads between these works in connection to school reorganization and professional development efforts are listed as follows:

1. First, school-reform models such as CES had the potential to enhance or threaten the intellectual, moral, and emotional satisfaction experienced in classroom teaching.

2. New responsibilities outside the classroom also stand to affect the rewards of teaching. While such added responsibilities sometimes enabled teachers to pursue personal interests such as technology, they also diminished the time and attention available for classroom teaching.

3. Models, such as CES, in the reorganization process had potential to unite or divide colleagues in the professional community. This was a result of the increased level of teacher interaction and collaboration, especially in newly designed teaching teams and programs.

4. Lastly, the reorganization process had potential to consume teachers' private lives and strain family relationships. The commitment itself entailed an increase in personal commitments of time, emotional and intellectual energy, and curricular work.

The reorganization process and reform model selected by the school are represented by their advocates inside — teachers and administrators—and outside the school by board members. It was noted that the process and model remains subject to individual, collective, and schoolwide 
interpretations (Little, 2001). A model such as CES had its advocates, but it remained to be seen through this research how to interpret its results for East Elementary School. Responses to any level of reorganization constitute an ongoing interpretive act for the administration, the teacher, and the student. Each act was personal, interactive, and continuous during the reorganization process. Little (2001) stated that all of this interpretive work in some way directly addressed teachers' concerns about what this meant for them. Teachers adopted a stance toward reorganization, drawing not only on others' claims but also on what they knew about their expertise and experience, the principles and values that govern their teaching, and the judgments of colleagues they trust and admire. Teachers could not have been expected autonomously to accept and apply these profound changes by themselves. The reorganization process and professional-development decisions included the entire learning community: building administrators, teachers, and students as interactive key decision makers in the plan. Therefore, a reorganizational plan embedded with professional development in which building administrators, teachers, or students merely carry out the changes as simple directives, rather than living the experience themselves, may yield undesired results (Kalin \& Zuljan, 2007).

Professional development: Ongoing job-embedded opportunities. Most goals set in a reorganization plan call for reflective changes in the established methods and approaches to work. The underlying process of this was a transition from the prevailing conception of instruction as transmission of knowledge, to interactive, student-oriented instruction aimed at quality learning (Dewey, 1938). This demanded a change in the focus of the teacher's role-a transition from the teacher who transfers content to a teacher who encourages quality learning and plans an engaging learning environment. It represented a need for higher-quality professional development that included academic goals as well as meta-cognitive goals. It 
required professional development which expands strategies of thinking, most of all critical and reflective thinking, along with problem-solving to impact teacher learning, student learning and the learning environment in general (Kalin \& Zuljan, 2007).

Stein, Smith, and Silver (1999) defined a new paradigm for professional development as one that discards the unproductive professional development drive-by workshop model of the past few decades. It changed professional development in favor of a model that provided empowering opportunities for teachers. Professional development was more effective, according to research conducted by Darling-Hammond and Richardson (2009), when schools approached it not in isolation, or in the traditional one-shot workshop, but rather as a coherent part of a school plan. This plan helped avoid disparities between what teachers learn in professional-development settings and what they actually implemented in their classrooms. A professional-learning opportunity seamlessly links curriculum, assessment, and standards together (Darling-Hammond \& Richardson, 2009). In addition, effective professional development involves teachers both as learners and as teachers, and allows them to struggle with the uncertainties that accompany each of these roles. Professional development today also means providing occasions for teachers to reflect critically on their own practice and to fashion new knowledge and beliefs about content, pedagogy and learners (Darling-Hammond \& McLaughlin, 1995).

Saxe, Gearhart, and Nasir (2001) compared three types of support for professionaldevelopment sessions for teacher learning. In their study the focus was specifically on mathematics:

1. a traditional professional workshop,

2. a professional community-based activity that offered support to teachers using new mathematics curriculum units only, and 
3. the Integrated Mathematics Assessment (IMA) approach, which directly engaged teachers in learning mathematics in the new curriculum as well as developing instructive content knowledge necessary to teach the curriculum.

Students whose teachers participated in the IMA program showed the greatest gains in conceptual understanding (Darling-Hammond \& Richardson, 2009). The key component of the IMA approach as professional development was the sense of empowerment felt by teachers along with the interactive role they played in their learning. All teachers attended a 5-day summer institute and continued to meet once every 2 weeks throughout the year to dialogue about their progress and to solve problematic situations. The teachers were also provided with a large amount of time to review and discuss student work and artifacts. The artifacts were in the form of videotapes so the teachers truly assessed the learning environment by watching the student and the teacher interact. Teachers used the artifacts to develop their own rubrics and assessment tools that they in turn shared with each other. This particular study capitalized on student-based learning and resulted in successes (Saxe, Gearhart, \& Nasir, 2001). The CES reform model encapsulated the concept of the IMA approach, not only with its 10 principles, but also with the emphasis placed on the importance of teacher reflection on student artifacts to guide instruction.

Professional development: Teacher learning communities. Additional research by Kennedy (2010) and Darling-Hammond and McLaughlin (1995) agreed effective professional development focused on deepening teachers' understanding of the processes of teaching and learning and of the students they teach. Their research defined the common characteristics of effective professional development as follows: 
1. It engaged teachers in concrete tasks of teaching, assessing, observing, and reflecting that clarify the processes of learning and development.

2. It was grounded in inquiry, reflection, and experimentation that were student centered.

3. It was collaborative, involving networking of knowledge among educators and focusing on professional-learning communities of practice rather than on individual teachers.

4. It was connected to and resulting from teachers' work with their students.

5. It involved choice for the teachers, and then resulted in choice for the students.

6. It was differentiated to meet the needs of all levels of teacher learners in order to extend their current knowledge base.

7. It was sustained, ongoing, intensive, and supported by modeling, coaching, and the collective solving of specific problems of practice.

8. It was connected to other aspects of school change.

The research described here points to the effectiveness of sustained, job-embedded, collaborative teacher-learning strategies through professional development. A professionaldevelopment approach that met these criteria, and has been increasingly featured in literature, was the model of a successful professional-learning community (Darling-Hammond \& Richardson, 2009).

In a successful professional-learning community, teachers worked together and engaged in continual dialogue to examine their practice and student performance and to develop and implement more effective instructional practices. In ongoing opportunities for collegial work, teachers learned about, tried out, and reflected on new practices in their specific context, sharing 
their individual knowledge and expertise. In a successful professional-learning community, teachers worked together to engage in continual dialogue to examine their practice and student performance and to develop and implement more effective instructional practices. When professional-development opportunities were ongoing and offered opportunities for collaborative work, teachers learned about, experienced, and reflected on new practices in their specific context. Teachers were sharing their individual knowledge and expertise in the safety of a professional-learning community (Darling-Hammond \& Richardson, 2009). Professionallearning communities changed practice and transformed student learning when they had in place the processes and structures that make true joint work possible and desirable by the vested parties. According to Darling-Hammond and Richardson (2009), providing intensive, contentrich, and collaborative learning opportunities for teachers improved both teaching and student learning.

Building teacher commitment to professional development began at East Elementary School when the teachers recognized the importance of being lifelong learners, just as the students did. East Elementary school leaders helped teachers understand that improving practice by acquiring new knowledge and skills was a professional obligation and that the work of becoming a great teacher was a career-long endeavor and one not accomplished alone (DarlingHammond \& Richardson, 2009). Professional-learning communities provided the support East Elementary School teachers needed to grow professionally, and provided more than one-time exposure to new ideas. Over time, the professional-learning communities changed their day-today teaching by learning together, applying their learning to the classroom, and reflecting on what worked and why. Just as learning improved for students when they had the structured opportunity to reflect on what they knew and did not know in relation to the goals of instruction, 
adult learning also benefited from intentional reflection on classroom practice. A professionallearning community transformed the nature of adult interaction and learning in East Elementary school by engaging teachers in the same process of continual learning and improvement asked of students in their work (Chappuis, Chappuis, \& Stiggins, 2009).

Research on effective professional development highlighted the importance of professional-learning communities. These networks helped develop communities of practice to promote school change beyond individual classrooms (Darling-Hammond \& McLaughlin, 1995; Hord, 1997; Knapp, 2003; Louis, Marks, \& Kruse, 1996; Perez et al., 2007). Collective work in trusting environments provided a basis for inquiry and reflection, allowing teachers to raise issues, take risks, and address dilemmas in their own practice. Teachers were able to grow as a learner themselves.

Understanding professional-development sessions needed to be an opportunity for establishing professional-learning communities; it was important that the design of the professional-development experiences also addressed how teachers learned. In particular, active learning opportunities allowed teachers to transform their teaching and not simply layer new strategies on top of the old (Borko \& Putnam, 1995). These opportunities often involved modeling the new strategies and constructing opportunities for teachers to practice and reflect on them (Garet, Porter, Desimone, Birman, \& Yoon, 2001; Saxe et al., 2001; Supovitz, Mayer, \& Kahle, 2000). When teachers were engaged in their learning and then provided opportunities to share their experiences with other teachers, teaching practices and student learning were transformed. The traditional sporadic, fragmented approach did not allow for rigorous, cumulative learning (Knapp, 2003). Professional development has been proven to have a greater 
impact when schools approached it as a more lucid part of a school's transformation (DarlingHammond \& Richardson, 2009).

Advocates of comprehensive school reform models; such as CES, anticipated reorganization initiatives, motivated instructional improvement, stimulated the formation of a teachers’ professional-learning community, and enabled a better fit between organizational makeup and effective teaching practices (Little, 2001). Allowing teachers to communicate their needs and network with each other strengthened the instruction as well as the instructional support in the school. It is an effort to create that “community in the making” that Dewey (1927) said characterized democracy. We know now it must become a community in which educators’ voices are heard, in which a myriad of voices, the different stakeholders, were given opportunities to speak. According to Greene (2001), this was a constant struggle and it may be our efforts in the design of professional development that educators ignited new ideas for democracy and for imagination and thought. What matters most was what teachers learn. Professional development improved teachers' knowledge of the subject matter they were teaching, and enhanced their understanding of student thinking on specific subject matter. Aligning substantive training with the curriculum and teachers' actual work experience also was vital. Current research suggested engaging professional development linked with teacherlearning communities could change practice and transform student learning, when they have in place processes and structures that made true joint work possible and desirable (DarlingHammond \& Richardson, 2009).

Research supported the result that strong positive effects on practice emerged from professional development that was student centered and designed to help teachers develop the academic expertise to teach content-specific skills (Blank, de las Alas, \& Smith, 2007; 
Wenglinksky, 2000). Student-centered professional development signaled a need to depart from old norms and models of teacher training. It created a new idea or focus for teacher learning in connection to student-centered instruction. It made the difference between enhancing teachers' proficiency levels and focal points as well as simply providing a forum for teachers to talk in professional-development sessions (Darling-Hammond \& Richardson, 2009). Research supported useful professional development that emphasized active teaching, assessment, observation, and reflection rather than abstract discussion (Darling-Hammond \& McLaughlin, 1995).

Professional development: Student achievement. In a recent national survey (Garet et al., 2001), teachers reported that their knowledge and skills grew and their practice changed when they participated in professional development that was logical, focused on content knowledge, and involved active learning. The survey continued to explain that by providing professional development focused on how students learned and how to gauge that learning effectively, research confirmed student achievement was consistently higher, as was growth in students’ basic and advanced reasoning skills. This research suggested professional development that was rooted in subject matter and focused on student learning had a significant impact on student achievement.

The goal of effective professional development was to directly impact student achievement. Darling-Hammond and Richardson (2009) reported that when the professional development was content specific, sustained over the course of time, and engaging, as reported in this literature, it directly impacted student achievement. Darling-Hammond and Richardson also reported that when the professional development was spread out over 6 to 12 months and included teacher-networking opportunities along with continuous follow-up sessions, it showed a 
significantly positive effect on student learning. The professional development had to be valued and supported by the faculty as well as the administration. With these supports in place at East Elementary School, professional development was anchored in the idea of creating a professional-learning community at this school. Professional development has been proven to provide the most supportive learning environment for students (Little, 2001). East Elementary School was willing to commit to this idea.

\section{Literature Focused on Relationships and Releasing Responsibility}

The key to achievement for students from poverty areas was in creating relationships with them (Payne, 1996). According to research conducted by Payne (1996), when students who have lived in poverty successfully moved into the middle class, when they are asked how they made the journey, the answer nine times out of 10 has to do with a relationship-a teacher, counselor, or coach who made a suggestion or took an interest in them as individuals. A successful relationship occurs when students are treated with respect (Covey, 1989). There were boundaries to establishing a successful relationship with a student, but honoring students as human beings worthy of respect and care established a relationship that provided for greater learning.

Relationships: Positive discourse. Teacher relationships were the foundation of student success. Children spend approximately 5 to 7 hours a day with a teacher for almost 10 months out of a year. What happens inside the school has a deep and lasting effect on the mind-sets children develop toward lifelong learning (Wolk, 2008). Relationships were developed through words; teachers cannot begin the school day by greeting students, teaching a lesson, or handling a classroom conflict without using words. Educators' words build students to reach their highest potential, or break them down to a point of perpetual ignorance (Denton, 2008). By building a 
positive relationship, encouraging solving conflicted situations, and creating trust shapes how students think and act, and ultimately, how they learn (Schwab \& Harper, 1969). Learning to use positive discourse to its full potential means becoming conscious of habitual ways of speaking and the messages, positive or negative, educators send to students. It also means listening and then reflecting on not only what educators were saying but the tone in which they were saying it. The process of reframing teachers' comments felt different to different people. However, if intentions behind teachers' words were positive and they genuinely believed in their students in their quest and ability to learn and behave in helpful ways, then communication comes across as sincere to them, even if it seems a little contrived at first (Denton, 2007).

Classrooms are places where students learned to be respectful, responsible, and to take care of themselves as well as others. They also learn to become accountable for their own learning and their own places in the world (Dewey, 1902/1956; Freire, 1970; Montessori \& George, 1912) with the support of a positive teacher behind them. Research by Denton (2007) about the impact of positive-discourse research concluded, "In short, better language makes us better teachers and our students better learners” (p. 10). Words, big or small, are powerful and make a lasting impact. The impact made should be positive. This was what the East Elementary School community wanted for the students. When students interact with teachers, the words should be uplifting not defeating: learning to use uplifting words is an effective investment for students' educational futures.

Relationships: How students learn. Palmer (1998) explained that classrooms must be both welcoming and exciting for students to feel free to speak their minds. At the same time they needed to feel uninhibited, they also need to learn respect and tolerance for the opinions of others. 
The relationship between teachers and students today was far more personal than in the past. Attempting to limit the confines of that relationship to be basic, simplistic, and constrictive was likely to stagnate the creative potential of students who were able to think beyond the basics. Those students who are able to grasp concepts quickly often find the repetitiveness of standard, emotionally disconnected instruction uninspiring.

Palmer (1998) wrote that individuals learned complex concepts and processes most successfully when they were actively and wholeheartedly engaged in the learning process. A natural, innate tendency toward gleaning excitement and motivation from learning is an important quality of a successful student. Yet just as not all students learn the same way, or at the same speed, not all students have the same inner motivation to learn.

Furthermore, teachers are responsible for regularly assessing the progress their students are making; finding out what works and what did not through trial and error. Palmer (1998) asked students questions about their preferences, and observed the progress made in each individual student under both similar and diverse conditions. Teachers promoted students’ development as learners, focusing on the processes that were the most effective in improving the performance of all students, academically and socially. This analysis is an imperative piece in the teacher-student relationship.

According to Palmer (1998), every educator strove to help all students achieve their personal best. Under the umbrella of Palmer's theories (1998), it was suggested teachers devised a myriad of activities to spark a student's interest in learning. At the same time, Palmer (1998) suggested introducing students to various skills and knowledge they must have to succeed. The skills acquired through these entertaining activities were vital to, and directly applied to student levels of proficiency. 
Relationships: Setting goals. Although some use of traditional teaching strategies were still necessary in certain forms at East Elementary School, a teacher's true goal was to invoke students’ responses based on their own thoughts and opinions about the learning process (Palmer, 1998). In other words, teachers focused on helping students become engrossed in meaningful materials and getting them excited about learning. Passive learners did not extract the full advantage of a teacher's instructional methods as much as they did from being an active participant in the learning process (Fisher \& Frey, 2008). Over time, students who were exposed to a more inspirational approach to teaching were expected to develop the ability to ask themselves the important questions independently, and eventually internalize learning strategies; making self-monitoring automatic. By following Palmer's suggestions, students can not only become successful in their education, they can learn to enjoy the process. Noddings (1984) asked that educators remember that the student was infinitely more important than the subject matter.

Release of responsibility: Gradual release. With the amount of time and effort being carefully invested in professional development, the next natural step was the implementation of the skills gained and the knowledge learned. The overarching goal of professional development was striving to achieve student-centered instruction, begun with a gradual release of responsibility from the teacher to the student. If a strong student-teacher relationship was developed, then educators could begin transferring the responsibility for learning directly to the students. This transfer should be done gradually and offered with support along the way for the student (Fisher \& Frey, 2008). To begin the process, the teacher established learning goals and explained the purpose for each activity throughout the day. In the explanation was a description of how this learning connects with and can be applied to real-world situations. Research by Fisher and Frey (2008) supported that a coherent objective or purpose made it easier for learners 
to gain access to background knowledge that could use to build schema for new learning. When the objective was clear and instructional tasks aligned with it, students shared responsibility for learning and were motivated to do so. When the purpose for learning was muddy or students did not commit to it or perceive its relevance, they completed many tasks but had little motivation and assumed no responsibility for their learning (Fisher \& Frey, 2008).

Release of responsibility: Teacher modeling. Teacher modeling was another crucial component of releasing responsibility. Research determined that people were hardwired to imitate other humans (Winerman, 2005). Students deserved to see an example of the kind of thinking and language a new task required before they engaged in that task independently. This was the main purpose of the CES principle; student as teacher, teacher as coach, where the teacher guided or coached students to learn and ultimately began thinking for themselves rather than emulating the teacher. Teachers can provide a model by either thinking aloud or by showing students their written notes. Teachers then have revealed their thinking process as they solved problems, read, wrote, or generated ideas. Modeling did not mean providing explanations or questioning students; it meant demonstrating the way experts thought as they approached problems (Fisher \& Frey., 2008).

Release of responsibility: Collaborative work. When students were prepared with a clear learning objective and examples of the kind of thinking and actions they should have employed, then they were ready to work-but not to work independently yet. First, they needed time to test their basic understandings in collaborative work with their classmates. Collaborative work with peers that emulated the collaborative-learning communities teachers were building, transferred even more responsibility to the students while providing them with peer support. It was a safe transition of responsibility. 
In any content area, students learned more and retained information longer when they work in productive groups (Totten, Stills, Digby \& Russ, 1991). Students who worked in collaborative groups tended to be more satisfied with their classes, completed more assignments, and generally liked school better (Summers, 2006). To be productive, groups needed sufficient time to interact, just as teachers did. They needed time lines, clear roles for everyone in the group, and tasks that called for interdependence. Ideal collaborative learning tasks were those that could not be accomplished just as well by one individual, but required interaction and the natural give and take of learning (Fisher \& Frey, 2008).

The key to collaborative groups lay in accountability. Each student was held accountable, just as each teacher was expected to be held accountable, for some aspect of the work produced. According to research by Fisher and Frey (2008) it was important the group ensured that each of its members explained the proof of the task at hand independently of one another. This required a significant amount of reteaching, negotiation, support, and trust. Students assumed responsibility for their learning and the learning of peers. In a classroom where relationships between and among the teacher and the students were built on respect, students felt safe and willing to take those risks as did the teachers in the exchange of responsibility.

Release of responsibility: Guided instruction. Teachers needed to be cognizant that although modeling and collaborative work provided a strong start, some students required guided instruction or further scaffolding to become successful in assuming responsibility for their own learning. Teachers based guided instruction on what formative assessments revealed students' needed (Fisher \& Frey, 2008). This instruction was most successful when delivered in a smallgroup situation. In a small- or guided-group orientation, the teacher had the opportunity to engage students in thinking without telling them what to think. This orientation also provided a 
venue for additional scaffolding of students understanding before they completed tasks independently.

With these purposeful strategies intact, teachers set students on a path to independent learning through a gradual release of responsibility. To make this transfer of responsibility for learning from teacher to student, Fisher and Frey (2008) gave students supports as they took the lead. These supports included stating clear goals, modeling, and scaffolding, to promote lasting ownership of their learning (Fisher \& Frey, 2008).

\section{Professional Development Evoking Change and Eventually Sustainability}

According to research by Fullan (2001b), educators have become accustomed to the presence of change, rarely stopping to think what change implies on the personal level. More important, educators rarely think what it means for others who might be in change situations. The root of change is how individuals embrace reality. Fullan (2001b) stated, "educators greatly underestimate both what change is and the factors and processes that account for it” (p. 39).

Change occurs with assistance from those desiring change and without assistance as well. Change occurs in many areas of our personal and professional lives, usually simultaneously occurring across various levels (Moffet, 2000). Webster lists 31 definitions of change. The definition that holds the significance for a discussion about current educational reform is Number 2: "to transform (usually followed by into): The witch changed the prince into a toad" (To Transform, 2004). This example exemplifies a common misconception about change; that it is quick, always noticeable, and usually unpleasant.

Understanding that change is a process and not a product is crucial to the success of the implementation of a new program such as the CES in this study. Change is innovation that is multidimensional (Hargreaves \& Fink, 2003). The difficulty arising when we explore which 
aspects of a given change were to be implemented, is that educational change is not a single entity. Fullan (2001b) identified that there are at least three components or dimensions at stake in implementing any new program or policy: (a) the possible use of new or revised materials referring to instructional resources such as curriculum materials or technologies, (b) the possible use of new teaching approaches, and (c) the possible shift of beliefs, such as pedagogical assumptions and theories underlying particular new policies or programs. Therefore it is logical to conclude that change must occur in practice along the three dimensions to affect the outcome. Along this line of reasoning it would follow that a teacher could use new curriculum materials or technologies without altering the teaching approach. Or a teacher could use the materials and alter some teaching behaviors without coming to grips with the conceptions or beliefs underlying the change. (Fullan, 2001b, p. 39)

Teachers are at different levels of understanding and/or implementation of a desired innovation. Researchers found that teachers ranged in understanding of the implementation process and the underlying principles and rationale for the changes they sought to make. In fact, some teachers' implementation of the new program caused their instructional practices to be less valuable for students than their previous classroom teachings (Ball \& Cohen, 1999; Bussis, Chittenden \& Amarel, 1976; Stigler \& Hiebert, 1999).

According to researchers McLaughlin and Mitra (2001), change does not begin until teachers and the educators leading the reform develop an understanding and common language through which to discuss and implement change programs based on the theoretical project. McLaughlin and Mitra (2001) explained the theoretical project as the perfect world example of a given situation. Understanding the theoretical project and how practice reflects theory is critical to teachers developing insightful decision-making practices that make sustaining change more 
likely. Therefore those implementing change act in an informed manner to use new materials and approaches as they create change. The change created looks and sounds different from what teachers did before. The difference is defined by the new innovation being implemented and the level of understanding and commitment of the teacher. The problem then is not only teachers learning how to teach the material, but how to deepen their practice to sustain new practices in the face of changing context (McLaughlin \& Mitra, 2001, p. 10).

It is possible to form a definition of educational change from the works cited here. Educational change is multidimensional and involves the possible use of new or revised materials, new teaching approaches, and the alteration of beliefs (Fullan, 2001b). In addition educational changes develop at the most profound level of change when teachers learn the theoretical underpinnings of the project in order to build understandings to develop and deepen new practices (McLaughlin \& Mitra, 2001). In fact, McLaughlin and Mitra (2001) emphasized that sustained change cannot occur unless those implementing the desired change have an understanding of the theoretical project.

Sustaining change. Sustainable improvement is enduring, not momentary. "Sustainability does not simply mean whether something can last. It addresses how particular initiatives can be developed without compromising the development of others in the surrounding environment, now and in the future” (Hargreaves \& Fink, 2000, p. 32). Sustainability, develops and draws on resources and supports at a rate that can match the pace of change, and that promoters of sustainability cultivate and recreate in an educational environment that possesses the capacity to stimulate ongoing improvement on a broad front (Hargreaves, 2002, p. 192).

Critical to sustaining educational change is a discussion of what is to be sustained and how teachers know when they have attained change that warrants sustaining. "In education, it 
matters that what is sustained is what, in terms of teaching and learning is itself sustaining. To sustain is to keep alive in every sense of the word" (Hargreaves, 2002, p. 192). The Organization for Economic Cooperation and Development proffered the following:

Sound education, good teaching, and learning are inherently sustaining processes. Supporting and maintaining those aspects of teaching and learning that are deep and that endure, that foster sophisticated understanding and lifelong learning for all defines the core of sustainable education. This includes not just knowing what, but knowing why (deep understanding), knowing how (application) and knowing who (building social networks and social capital). (2001, p. 11.).

Sustainable education is that which is driven by student need and teacher practice. It is not the design of a prepackaged, research-based, and externally developed educational program. However, programs can be a vehicle for change if those implementing them have the deep understanding, resources, and knowledge to implement the program in a way that fosters student, teacher, and systemic sophisticated understandings and lifelong learning.

Datnow's (2005) sustainability study provided an example of how comprehensive schoolreform models can foster distinct approaches that interface with CSR models and the demands brought on by turbulent district and state contexts: (a) approaching new demands with an effective attitude and continuing with reforms, (b) postponing reform activities while incorporating new district and state policies, (c) dropping the reform completely as a result of new contextual constraints, and (d) using turbulent district and state contexts as opportunities to discontinue reforms for which there was waning support or that were not working well (p. 136). Three of thirteen schools adopted efficacious attitudes in response to changing district and state demands. In doing so, they were able to meet new mandates head-on with either 
symbolic or practical responses and, at the same time, sustain their reforms. (Datnow, 2005, p. 136)

The teachers and the leadership of the three schools researched by Datnow (2005) met district urges to adopt programs with a sense of efficacy and self-assurance that guided them to make decisions protecting their successful change implementation from intrusion.

Simultaneously, it allowed the adoption of district initiatives that supported and integrated their core programs (p. 137). Intertwined in the telling of effective attitude is the description of teachers and school leadership deeply committed to the implemented change structures to meet the needs of their students. Educators used this knowledge of their school needs and a commitment to develop the model in place to meet those needs, creating a stage of continuity for sustaining change when new initiatives were presented.

Datnow’s (2005) work concurs with the work conducted by McLaughlin and Mitra (2001) in which they presented the need to understand the theoretical reform project in order to create change. When teachers in Datnow's study moved their beliefs into actions, it was based in their understanding of the work they were engaged in and the success of it. The teachers in this school stated that their work encompassed Fullan's dimension of change in the classroom. In Fullan's research (2001b), what is sustainable is that for which educators become a constituency of believers.

The role of professional development. One of the NSDC (2008) learning standards discussed the importance that staff development assist educators in moving beyond comprehension of the basic features of a new idea or innovation. The NSDC learning standard suggested that in order to improve student achievement, adult learning, largely professional development, must promote a deeper understanding of a topic and provide many opportunities 
for teachers to practice new skills. Along with practice, teachers need to be provided with feedback on their performance until those skills become automatic and habitual. According to the NSDC, typically, deeper understanding requires a number of opportunities to interact with the idea or procedure through active-learning processes that promote reflection, such as discussion and dialogue, writing, demonstrations, practice with feedback, and group problem solving.

This standard emphasizes the consideration of other important aspects of teacher engagement in change processes. The three aspects considered are the feelings that change often evokes in individuals: anxiety, fear, and anger. Different learning styles and strengths make it important for educators to have opportunities to learn alone and with others and, whenever possible, to have choices among learning activities (Darling-Hammond \& Richardson, 2009). The life stage of individuals may affect individuals' availability and interest in additional work responsibilities of their life. Knowledge of the three aspects helps educational leaders know that professional development will help educators align their vision of teaching (Hammerness, 2001) with leadership’s vision of change, and create a more likely arena for success.

Improving the Quality of Education For All Project in England, The Manitoba School Improvement Project in Canada, and Success for All in the United States highlight the classroom as the "locus of change.” These programs also recognize that structural changes are required to facilitate pedagogical change, creating a need for teacher development and training to become an integral part of the program. They each identify the importance of building self-sustaining communities of practice. These professional-learning communities are places where teachers share and learn from each other to reach their shared goal. Their shared goal in this study is to build capacity and the capability for positive change at the school and classroom level (Harris, 2003, p. 372). 
There is evidence from all three projects that providing teachers with the opportunity to work together and inquire into their pedagogical practice fosters positive relationships. Shared norms, shared values, agreed goals, and common aspirations stem from teachers' involvement in exploring pedagogy. In addition, trust and respect among teachers are at the core of all developmental work. This is created through the deliberate effort of staff and students to communicate and collaborate with each other. A common denominator of all three projects is the way in which teachers are encouraged to learn together (Harris, 2003, p. 378).

The three initiatives (Improving the Quality of Education For All Project in England, The Manitoba School Improvement Project in Canada, and Success for All in the United States) bring into fruition the development of professional-learning communities "where teachers participate in decision making, have a shared sense of purpose, engage in collaborative work and accept joint responsibility for their work” (Harris, 2003, p. 380). Learning communities instinctively operate under the intent of the NSDC's learning standard to build teacher and school capacity. Building teacher capacity is a cornerstone of learning communities.

Teacher capacity building is the most productive investment for schools and far exceeds the effects of teacher experience or class size (Greenwald, Hedges, \& Laine, 1996, p. 414). Darling-Hammond and Ball (1999) credited huge gains in reading and mathematics on the U.S. National Assessment of Education Progress in 1992 and 1996 to the development of 4-week institutes with follow-up coaching for teachers at all grade levels. Researchers working with the Chicago City schools (Newmann, Smith, Allensworth, \& Bryk, 2001) found that teachers who were offered high-quality professional development followed through in using teaching methods they were taught, leading to higher achievement gains on the Iowa Test of Basic Skills in selected schools. In a similar study, a comparative analysis of more highly successful schools 
with less highly successful schools, lower achieving schools had limited professional development and teacher collaboration (Riley, Smith, Ginsburg, \& Plisko, 1999). Mosenthal, Lipson, Mekkelson, Russ, \& Sortino (2001) supported Riley and colleagues’ findings in their comparative analysis of highly successful schools and lower achieving schools in that lower achieving schools had limited professional development and lacked common vision.

To implement effective change, it is important to construct appropriate change structures (Fullan, 2006). One increasingly important change structure reviewed here is professional development. Professional development that is designed to establish a deeper knowledge base for teachers requires engaging a number of opportunities to interact with the idea or ideas being presented. It also requires opportunities for active-learning processes that promote reflection such as dialogue, discussion, writing, demonstrations, practice with feedback, and professionallearning-community support time. The professional development should use all aspects to inform, educate, and nurture teachers to a deep pedagogical shift, to then bring about positive change. 


\section{Chapter 3: Methodology}

"The way we see the problem is the problem."

—Steven R. Covey

"A journey of a thousand miles must begin with a single step."

\section{Research Design: Qualitative research—Case Study.}

The purpose of this study was to identify and describe the teachers' perceptions of the sustainability of the professional development provided by CES. A case study approach was selected because an "investigation must cover both a particular phenomenon and the context within which the phenomenon is occurring” (Yin, 1993, p. 31). This particular case was chosen to explore how sustainable the professional development may be as perceived by the teachers who taught at the school in the study. Case study research was a conscious choice to study a specific case in order to further understand a particular interest (Stake, 1994).

In order to ensure that accurate conclusions were drawn, multiple sources of data were collected and analyzed. These sources included multiple teacher interviews, field notes taken during classroom observations, and survey conducted at the culmination of the study. The focus of this qualitative research was to describe the teachers' perceptions of the sustainability of the professional development that occurred during the 2006-2008 school years. This intensive research described the setting of the environment and the professional development activities that occurred over a period of time, and evaluated the meanings of the actions and settings of the participants (Miles \& Huberman, 1994) by observing the teachers in their classrooms and interviewing them about their perceptions of the professional development 
that occurred during those two school years. A case study approach was used to describe the context of the setting (Yin, 2003).

This particular case was chosen in order to describe the teachers' perceptions of the sustainability of the professional development provided by CES. Specifically, what were the school-wide perceptions of these opportunities, and what impact did professional development have on individual teacher practices, and on the school as a whole?

The case study design was appropriate for collecting multiple sources of data to understand and convey a clear interpretation of the phenomena of the lived experiences of the participants in this study. Using this design provided opportunities for the researcher to convey the results of the study in common language, rather than using scientific jargon (Yin, 2003). This case study design focused on describing the teachers' perceptions about the sustainability of the professional development provided by CES with the express intent of describing the lived experiences of the participants. Qualitative research relies on bringing together multiple sources of data using triangulation as evidence to support the research questions. The research design in this case study “is the logical sequence that connects the empirical data to a study's initial research questions and, ultimately, to its conclusions” (Yin, 2003, p. 20). Multiple sources of data were collected, analyzed, and triangulated to draw conclusions. By collecting various qualitative data this allowed for multiple interpretations of perceptions and descriptions that add to the validity and reliability of the study (Merriam, 1998).

The participants in this study shared their experiences based on their own backgrounds and prior knowledge. These two factors determined their own realities as they experienced the CES’s professional-development activities. Patton (2002) stated, there was no separate or objective reality for people. There was only what the people know their experience is and means. 
The subjective experience of the participants incorporated the objective item in the study: CES's professional-development activities in which the teachers were involved. The melding of the subjective experience with the objective item became the reality of the participants. The participants focused on constructing meaning as the essence of the lived experience. The researcher has not asked questions about how the participants in this study learned the information being taught during the professional-development sessions. This research asked about the perceptions of participants’ experiences during and after CES professionaldevelopment sessions.

\section{The Study: Procedures.}

As the qualitative researcher of this case study, I have gained the understanding of the essences of the lived experiences of the participants in this study. By understanding these lived experiences as explained by Patton (2002), the research became focused on exploring how people make sense of experiences and how they transformed their experiences into consciousness. It required the ability to methodologically, carefully, and thoroughly capture and describe how participants described their experiences during and after professional-development opportunities. The research also explained how participants felt about the overall experience, remembered it, made sense of it, and finally discussed the sustainability of the professionaldevelopment sessions offered to them during their time at East Elementary School (Patton, 2002).

Qualitative methods were used in this case study. The research involved devising a sampling plan to ensure the appropriate participants were available and willing to answer questions. Information or data were obtained by interviews and classroom observations, with a final cumulative survey given in the fall of 2011 at the close of the research. The interview data 
were transcribed and prepared for analyses along with the classroom observation data. The Phase 1 preliminary observation and interview data and Phase 2: observation and interview data, were analyzed using a process of coding and categorizing the information into themes. The coded data provided the themes and therefore were the foundation for the questions on the final cumulative survey (see Appendix D). Conclusions were drawn regarding the phenomena based on these themes (Patton, 2002), as well as the results of the final cumulative survey. Finally, through triangulation, the findings were confirmed by the researcher to ensure the credibility of the conclusions.

Due to the fact the research for this study focused on both Phase 1 - preliminary data— and Phase 2, observation and interview data, the experiences of the participants in this research have been described from both aspects. I have chosen to coordinate the analysis of the Phase $1-$ preliminary classroom observations and interviews data-with the Phase 2 classroom

observations and interviews. The preliminary themes from Phase 1 were considered but I was not limited from developing new themes. All data, Phase 1 and Phase 2, were used to determine the important information or themes of participants’ perceptions in conjunction with the sustainability of the CES’s professional-development opportunities.

\section{Participants and Setting}

For this study, I used purposeful sampling (Patton, 2002). In purposeful sampling, selection of participants was based on desired attributes. According to Creswell (2005), “in purposeful sampling, researchers intentionally select individuals and sites to learn or understand the central phenomenon” (p. 204). In this study, the desired attributes were teachers who understood CES and had participated in at least 1 year of professional development provided by 
CES at East Elementary School. This was the criteria to specifically define my participant pool for this study.

The participants for Phase 1, the preliminary observation and interview data, were two fourth-grade teachers who were rehired to work at East Elementary School during the 3-year contractual reorganization period between the fall of 2006 and spring of 2009. The main difference between these two teachers was their years of experience in the classroom. One teacher was entering the second year of teaching when rehired for the 2006-2007 school year. The other teacher was a brand new hire entering the first year of teaching for the 2006-2007 school year. These teachers were also selected to be observed because they had positive attitudes toward the reorganization efforts and neither teacher had any experience with reform-based professional-development sessions. Both of these teachers were under the age of 30. Commonalities among these teachers' efforts during this reorganization process may be partially explained by the environment in the school, or by the synergy developed by being able to collaborate and reflect on their efforts on a daily basis. The commonality of these two teachers made them of great interest to me.

For Phase 2 of the study, I needed additional participants. I wanted to have a teacher from every grade level represented. There were a minimum of four teachers in each grade level at East Elementary School, so I selected the remaining five teachers at random. I selected them based on their varying numbers of years of experience teaching and with CES professional-development sessions. The participants had to have at least 1 year experience working with CES.

If a person did not want to participate in the study, it was not a problem. I was interested in teachers who were positive about their careers and truly concerned about their students. Participants who had vested interests in growing professionally were approached to participate. 
Those who expressed having an open mind and genuine interest in the school and moving it forward were welcomed during Phase 2, the observations and interview data collection.

Description of Phase 1 participants. In the fall of 2008, Teacher A: Kara (pseudonym), was in her fifth year of teaching. She was a teacher who would move up with her students to fifth grade to continue being their teacher. At the end of the fifth-grade school year, Kara would return the following year to begin the same cycle by teaching fourth grade. Kara had already completed two cycles by the spring of 2008. She had looped twice from fourth to fifth grade. In the fall of 2008, she returned to teach fourth grade and begin the cycle again with another group of students. Kara is Caucasian and under the age of 30. She received her undergraduate degree in elementary education from Shippensburg University.

Teacher B: Katie (pseudonym), was in her third year of teaching fourth grade in the fall of 2008. She had just received tenure in the fall of 2008. She earned her undergraduate degree in education from the University of South Carolina at Penbroke. Katie is Caucasian and under the age of 30. She also earned her master's degree from Frostburg State University prior to her first year of teaching at East Elementary School in the fall of 2005.

Both Kara and Katie attended the CES training sessions from 2006 through 2008.

Phase 1 preliminary interview_teachers. The participants for the preliminary interviews were Kara and Katie. The preliminary interview data collection occurred between the fall of 2008 and the spring of 2010. The preliminary data helped provide the context for the beginnings of this study. The two participants were formally interviewed once and informally interviewed once between the fall of 2008 and the spring of 2010. The purpose of formal and informal interviews was to glean their perceptions of the impact of the professional development provided by CES. The teachers' interviews were conducted at different random times over the 
course of the 2.5 years during Phase 1 of this study. As required by the Institutional Review Board (IRB), names were changed to provide anonymity to the participants. The same interview questions were used each time a participant was interviewed to establish the themes that emerged in Phase 1 preliminary data and provided the questions for Phase 2 of the research.

Description of Phase 2 participants. Teacher A, Kara and Teacher B, Katie were observed again in Phase 2. These two teachers were both teaching fourth grade in the fall of 2010. In addition to the two original observations of Kara and Katie, one teacher per grade level was selected from the participant pool to be observed. The observations were in kindergarten, third-grade, and fifth-grade classrooms, with Grade 4 represented twice by the two original participants. A total of seven teachers were observed in the second phase of this study. The following teachers were observed from the following grade levels:

Teacher C, Terri (pseudonym), was a kindergarten teacher in her 22nd year in 2010. She is Caucasian and between the ages of 41 and 50. She received her undergraduate degree in early childhood education from Frostburg State University. Her master’s degree in early childhood education is from Hood College. Terri has taught kindergarten her entire career. This is only her second school, she taught at her first school for 16 years before coming to East Elementary in 2005. She participated in all of the CES professional-development sessions.

Teacher D, Valerie (pseudonym), was a 7th-year teacher. Teacher D is Caucasian and between the ages of 21 and 30. She received her undergraduate degree in early childhood education from Hood College. Valerie has taught kindergarten and first grade at East Elementary School. This is the only school she has worked at in her career. During the Phase 2 observations, she was teaching first grade. Valerie participated in one year of the CES professionaldevelopment sessions. 
Teacher E: Leah (pseudonym) was a 20-year teacher with teaching experience in fifth, fourth, and third grades. She has also been a reading and mathematics intervention teacher. Leah is Caucasian and between the ages of 41 and 50. Her undergraduate degree in elementary education is from Towson University. She has a master's degree in curriculum and instruction from Frostburg State University. Leah has taught in five different schools in the county. During the Phase 2 observations she was an intervention teacher who worked predominately with second-grade students. She participated in all of the CES professional-development sessions.

Teacher F, Sabrina (pseudonym), was an 8-year teacher in her 6th year at East Elementary School. She is Caucasian and between the ages of 31 and 40. Her undergraduate degree is in education from the University of South Carolina at Penbroke. Her master's degree in education is from Frostburg State University. She had teaching experience in third grade as well as in the field of reading and mathematics intervention. Sabrina was currently an intervention teacher serving as an additional Grade 3 teacher. She attended 1 year of the CES training.

Teacher G, Shari (pseudonym) was a 6th-year teacher. Shari is Caucasian and between the ages of 31 and 40. She received her undergraduate degree in elementary education from Frostburg State University. Her master’s degree in curriculum and instruction is also from Frostburg State University. Teacher G has taught fifth grade for the past 6 years. Shari had 1 year of CES training.

Table 2 provides demographic data about all teacher participants from Phase 1 and Phase 2 of the study. 
Table 2

Demographics of Phase 1 and Phase 2 Teacher Participants

\begin{tabular}{|c|c|c|c|c|c|c|}
\hline Pseudonym & Gender & Race & Age & $\begin{array}{l}\text { Years as an } \\
\text { employee of } \\
\text { the school } \\
\text { system }\end{array}$ & Grade level & $\begin{array}{c}\text { Participant } \\
\text { letter }\end{array}$ \\
\hline Terri & $F$ & $\mathrm{C}$ & $41-50$ & 22 & Kindergarten & $\mathrm{C}$ \\
\hline Valerie & $\mathrm{F}$ & $\mathrm{C}$ & $21-30$ & 7 & 1 & $\mathrm{D}$ \\
\hline Leah & $\mathrm{F}$ & $\mathrm{C}$ & $41-50$ & 21 & 2 & $\mathrm{E}$ \\
\hline Sabrina & $\mathrm{F}$ & C & $31-40$ & 8 & 3 & $\mathrm{~F}$ \\
\hline Kara & F & $\mathrm{C}$ & $21-30$ & 7 & 4 & A \\
\hline Katie & $\mathrm{F}$ & C & $21-30$ & 5 & 4 & B \\
\hline Shari & $\mathrm{F}$ & C & $31-40$ & 6 & 5 & G \\
\hline
\end{tabular}

Note. Teacher Participants Kara and Katie were the original participants from Phase 1.

Participants who were selected for the Phase 2 interviews were sent a letter explaining the study and asking if they would like to participate or continue to participate (see Appendix E). Commensurate with IRB requirements, names were changed to provide anonymity to the participants. Each participant was interviewed twice. The first interview was formal and the second interview was informal.

I observed and interviewed the Phase 2 participants who have the shared the phenomenon of the lived experiences of specialized professional development. The findings reported results and reflections of the experiences of the participants during classroom observations and interviews. All participants in this study were involved with CES professional development at one time at East Elementary School during the reorganization years between fall of 2006 and spring of 2009.

\section{Description of the Researcher}

The specific goal of this study was to minimize the influence of my point of view on the participants, so their opinions and points of view were clearly documented. However, any 
interaction between researcher and study participant would introduce bias, so the researcher was considered a participant in this study.

Background of the researcher. Having described the participants, I will try to help the reader understand the lens through which I operated. My experiences have influenced who I am and necessarily influence how I interpret the events around me. Therefore, knowing something about my past experiences will help the reader better understand how I have interacted with the data in this study.

My experience as a public school teacher began 21 years ago. I have worked in affluent schools as well as Title I schools where professional-development opportunities were offered as a staff-development activity. Some forms of professional development have helped me keep my teaching certificate current, whereas other professional-development opportunities were simply for my personal growth as a teacher. Each opportunity was different, with the common thread always focusing on how this information would impact my students. This continues to be at the heart of why professional development is offered to teachers today.

In my 15th year of teaching, I decided to transfer to East Elementary school. I arrived in 2004 to teach fourth grade at this school. In the Spring of 2005, the reorganization process began for East Elementary School. When we, the teachers, were told our school was going to be reorganized due to its failing record according to AYP, we were all taken aback. We did not understand what was happening. The reorganization process was explained to us. We were told we would need to reapply for our jobs, but many teachers decided not to return to East Elementary School. Instead, they accepted teaching positions elsewhere in the county. I decided I did want to reapply and was happy to be rehired for the 2006-2007 school year. I agreed to work at East Elementary School for the 3-year contractual reorganizational time period between fall of 
2006 and spring of 2009. I was placed in fourth grade at the time and participated in the CES professional development provided between the fall of 2006 and the fall 2008. The funding for CES ended in the fall of 2008, and the professional development provided by CES was phased out in our building.

That fall semester, I moved into an intervention position at East Elementary School. An intervention position is a teaching position designed for the teacher to work with small groups of two to three students from kindergarten through second grade (Allington, 2008). The students who receive services are at least two grade levels behind in either mathematics or reading or both. I was in the intervention position until the fall of 2011.

In 2011, I returned to the classroom to teach third grade. Over the past 8 years, I have worked as a teacher in some capacity at East Elementary School. I was involved with the professional development provided by CES from the fall of 2006 to the fall of 2008. I was also involved with the professional development provided by the C\&I specialists form the spring of 2009 through the fall of 2011.

Reflective writing. In this case study, writing is the method not for just reporting my findings, but for describing the significance of the participants involved in the experience. Writing according to Forget (2004) helps one generate ideas, become engaged through concrete commitment, clarify one’s thinking, and organize one’s ideas in useful and meaningful ways. By writing I am able to see themes that are otherwise undistinguishable. I agree with the assertion by van Manen (1990) that reflective writing is a means of seeing consistent with my own experience of reflective writing. Reflective writing was the tool that enabled me to see recurring themes and be able to describe them to the reader in this study. 


\section{Setting the Context of the Study: Background of CES Professional-Development Sessions}

In 2006, the first year of professional development with CES, the sessions addressed the core of establishing a tone of decency and trust in the classroom. The teachers met three times a week for professional development. Twice a week the sessions were an hour in length, and once a week the session lasted a half an hour. The sessions were held prior to the beginning of the school day.

In the sessions, it was explained to the teachers how important it was to build a relationship with their students. The relationship began with trust, and trust was built on positive words and communication. Teachers were trained in different ways to communicate positively and frame their comments in a positive way to students. Teachers were taught how to use and model positive discourse in classrooms. By teachers carefully selecting their words each day, they were working toward establishing an environment where students felt safe and where they felt like they were risk takers.

The professional development also addressed the importance of introducing contentspecific vocabulary words in the classroom. The professional-development sessions also addressed the fact many students lack the background knowledge needed to comprehend contentspecific words. CES stressed to the teachers, that as important as the content-specific vocabulary is to instruction, the positive words said to children were what made a lasting impression on them. According to research conducted by Denton (2007), the exchange of positive discourse was what made students feel safe or not. The teachers of East Elementary School first needed to focus on the positive comments made in their classrooms to build relationships. Other forms of discourse were to be addressed after the relationship piece was in place. 


\section{Phase 1: Preliminary Classroom Observation Data: Observing Kara and Katie.}

In the preliminary observational research, two teachers, Kara and Katie, were observed for an average of 30 minutes. The length of the observation was determined based on the average length of the teachers' lessons. My observation tool was designed to focus on two aspects of CES principles. The first aspect was the tone in the classroom, exhibited by the exchange of positive discourse. The second aspect was the structure of the lesson, whether it was teacher led or student centered.

During each observation, I recorded the structure of each lesson and proceeded to record how many positive comments were exchanged between the teachers and the students during the 30-minute observation. I recorded the comments made by the teachers and students in the context of the structure of the lesson. Next I interpreted the data.

The data were coded at three levels. At the first level, the data were examined line by line, and at the second level, the data were compared and contrasted to create categories or clusters. At the third or final level, themes emerged and data reduction or filtering of the data began. The process of selective sampling was used to prioritize the data collected. Information relevant to the topic was compiled for further research, whereas extraneous information was discarded. In the first study, saturation was achieved because data had been collected until no further new information was found.

In Phase 1, Kara and Katie were each observed once in the fall and once in the spring for 2 years. These observations took place after the professional-development sessions had concluded with CES. The first year after CES had concluded, it was expected the teachers would implement any strategies or skills they had acquired from the professional-development sessions provided by CES. By the second year after CES had been gone, according to Kara and Katie, 
there was little mention of the expectation to use the information gained from CES. It had become a teacher choice at that point.

\section{Phase 2: All Grade Levels are Observed}

Beginning in the fall of 2010, I conducted seven classroom observations, one per grade level from kindergarten through third grade, fifth grade, plus the two observations in Grade 4. Each observation lasted for approximately 30 minutes. The observation time was based on the average length of the teachers' lessons. The observation tool is located in Appendix F. The observational time frame remained consistent. The observational start times varied from room to room due to the different schedules in the building. However, the observations were always scheduled to start at the beginning of the teachers' lessons to maintain consistency in each observation. No two rooms were observed at exactly the same start and finish time mainly due to scheduling in the school day.

\section{Preliminary Interview Findings}

Phase 1: Preliminary interview data. The preliminary data stemmed from interviews with Kara and Katie. To build context for this research, I referenced the original data from these two teachers. Comments from these interviews were used to develop the questions used in Phase 2 of the study. The preliminary formal interview questions are in Appendix G. This information helps define the starting point for East Elementary School, according to these two teachers' perspectives.

Phase 2: Interview data from participants. New one-on-one interviews were conducted with a total of five new interviewees. I used qualitative research methods throughout this process. I conducted one formal interview and one informal interview with each classroom teacher from kindergarten through third grade, fifth grade, and my two original fourth-grade 
teachers. As the researcher, I provided anonymity and confidentiality assurances to all individuals who were willing to be interviewed. Interviews were carried out with individuals; the small-group option was not requested by any of the interviewees. Interviews were taped. In all cases, I took detailed notes as well. Formal interview questions are listed in Appendix C. To encapsulate constructivism in the study, quotations from the Phase 1 preliminary participants’ interviews and observations are used, as well as comments from the Phase 2 interviews and observations. All quotations give voice to the participants, both past and present.

Phase 2: The cumulative final survey. A final culminating survey was given to the current teaching staff at East Elementary School in the fall of 2011. The survey addressed the themes that emerged from the Phase 1 preliminary data and continued to be present in the Phase 2 data. The survey was a final attempt to capture the teachers' perceptions about the sustainability of CES’s professional development at East Elementary School. It was distributed to the 25 classroom teachers on staff at East Elementary School in the fall of 2011. Among the 25 surveys distributed, 24 were returned. See Appendix D for the survey.

\section{Trustworthiness, Data Collection, and Analysis}

Trustworthiness is established in when the researcher is (a) systematic, (b) explicit, and (c) rational in the collection, analysis, and interpretation of data (van Manen, 1990). The trustworthiness of this research study was derived from reflecting on the cohesion between data collection and analysis and researched sources, according to both van Manen (1990) and Fetterman (2010). The steps consisted of the following:

1. Systematically conducting observations. Each observation lasted for 30 minutes and always began at the beginning of the teachers' lesson or activity. The observation sheet was standard for each classroom. Every interview was conducted in a private 
setting with a given set of IRB-approved questions. The final survey was distributed at a school faculty meeting, so all teacher participants received the document at the same time. They were provided time to complete the survey at the end of the meeting.

2. Following an explicit pattern for identifying the themes. The "chains of evidence" were laid out that supported, contradicted, or qualified emergent themes and interpretations, as well as extended prominent patterns.

3. Developing rational descriptions of narrative accounts of participants' perceptions and experiences of the sustainability of the professional development provided by CES.

Throughout the data collection and analysis process, I worked to corroborate the accuracy and consistency of information I received from new interview data. I compared the themes that were evident in, absent from, or challenged by the information provided by multiple participants. I cross checked the information secured through the new and archived interviews with data from new and archived classroom observations, as well as the final survey information. As a further check for bias and error, key informants who have expertise in education policy but are not involved in this study reviewed the research reports.

\section{Methodology}

Methodology links a particular philosophy to the appropriate research methods, and bridges philosophical notions to practical and applicable research strategies. This case study was to describe the teachers' perceptions of the sustainability of the professional development provided by CES. To examine this phenomenon, the case study method was the preferred approach, using interviews, observations, and surveys to support the triangulation process. According to Merriam (1998), “case studies involve description, explanation, and judgment” (p. 
39). Qualitative methods such as the case study are used to explore a phenomenon from the participant perspectives since many of the variables are expected to emerge as the data is collected and analyzed (Creswell, 2005). “In general, qualitative research is an inductive process by which the researcher allows data interpretations to evolve and reveal patterns before, during, and after the data collection process” (Hanley-Maxwell, Hano, \& Skivington, 2007, p. 100). Denzin and Ladin (2005) specifically explained qualitative research design as the problem and experiences under investigation. This case study focused on the how questions to make new discoveries and generate specific themes on impact and sustainability of professional development as perceived by the teachers. The case study method has specific advantages when the "how question is being asked about a contemporary set of events, over which the investigator has little or no control” (Yin, 2003, p. 9).

In this research, classroom observations became focus groups where lived experiences were expressed through language and the interviews became narratives. I created the context of this research based on the interpretations of Phase 1 preliminary data and Phase 2 new data, with the help of the participants who provided the data in the study.

The value of using a qualitative research methodology such as case study was embedded in the subjective and often emotional nature of the issue under study. The qualitative paradigm, with its emphasis on description, understanding, and interpretation was appropriate for my study, which aimed to determine the impact of the participants' perceptions about the sustainability of CES’s professional development after the fall of 2008.

The research captured the essence of this school, once the CES professional-development activities ended in fall of 2008. I observed and interviewed teachers during the spring of 2009 through the fall of 2011 when professional development was still provided for the teachers, but 
through another venue, the C\&I specialists. By immersing myself in the research, I hold a more candid perspective of exactly how the teachers believed they were moving forward in their own professional growth, based on their perceptions of the sustainability of the information presented by CES between fall 2006 and fall 2008.

\section{Research Purposes and Research Questions}

There were two phases of research in the study. Phase 1 of the research was intended to revisit the preliminary data and present the results of implementing the two CES common principles between fall of 2006 and fall of 2008. In Phase 1 of the study, the following questions emerged from the preliminary research:

Research Question 1: How did CES professional development impact the discourse between and among teachers and students?

Research Question 2: How did the development of positive discourse impact the relationships between and among the teachers and students?

Based on the findings in Phase 1 of this study the following question emerged for further research in Phase 2:

Research Question 3: Was the information provided by CES during the professionaldevelopment sessions sustained, as perceived by the teachers?

\section{Validity and Reliability}

Validity and reliability were met through triangulation by using multiple sources of data, and multiple data-collection methods such as interviews and observations, as well as a culminating survey to confirm results. Additional conversations with peers and other interested parties about the development, theory, and exploratory explanations of the findings were integrated with other strategies promoting validity and reliability. The following strategies were 
used: critical self-reflection; sufficient immersion with the data to the point of saturation; deliberate, focused search for differences or variety in the data to make the study more relevant to a greater audience; and vivid, substantial depictions that follow the consumer of the research to identify with the content and perspective to establish that the results can be transferred (Merriam, 2002).

Phase 2 data were collected from fall 2010 through fall 2011. The analysis of the data in this study connected to the aim of this research: To describe the sustainability of the professional development provided by CES, as perceived by the teachers.

\section{Limitations}

One major limit of this case study is the naïve position researchers can take when using observations (Harper, 1998). The observations in this study are only brief glimpses into the teachers’ practices and are replete with researcher bias. While the notes provided valuable information, that information must be confirmed using other sources. As Harper (1998) said, “it is easy to see that empirical evidence is both constructed and real” (p. 31). The observations provided a picture that has been drawn with many different hands and is a limited view of the classroom. The observations can also been seen as constructed by what the observer chooses to see or ignore.

Limitations may also arise from the fact the researcher was a participant in the reorganization process and professional-development sessions at East Elementary School and was also the interpreter of the data. I am a researcher with over 20 years of teaching experience. I have a very different view of the classroom than a researcher with no teaching experience, which is even different from a researcher with 5 years of teaching experience. The data I collected was translated and analyzed through one particular lens, mine. 
Research by Darling-Hammond and McLaughlin (1995) addressed the teacher perspective and reported the importance of involving the teacher(s) "both as learners and as teachers [thereby allowing] them to struggle with the uncertainties that accompany each role” (p. 206). My role was unique in the respect, I was not only a teacher and learner in this process but as the researcher I was also another form of a learner. These multiple perspectives allowed me to have a myriad of lenses from which to grow from this experience and research. As stated earlier in this study, people can only interpret the past from their position in the present. Because all interpretations are related to the present and are based on each interpreter's traditions, there is no one right interpretation but rather multiple perspectives (Gadamer, 1975).

Eichelberger (1989) described the work of constructivist researchers and stated, “They do a great deal of observation, read documents produced by members of the groups being studied, do extensive formal and informal interviewing, and develop classifications and descriptions that represent the beliefs of the various groups” (p. 9). Eichelberger also concluded that hermeneutists “are much clearer about the fact that they are constructing 'reality' on the basis of their interpretations of data with the help of the participants who provided the data in the study" (p. 9). Lastly, Eichelberger argued that depending on the background of the individual researcher, the methods used by the researcher, and the purpose of the study, various interpretations can be expected of the same data set.

Limitations may also arise from the inherent biases of the researcher whose personal middle-class background may affect the interpretation of the data. Denzin (1989) explained value-free interpretive research is impossible ... because every researcher brings preconceptions and interpretations to the problem being studied. The term hermeneutical circle or situation refers to this basic fact of research. All scholars are caught in the circle of interpretation. (p. 23) 
Limitations may include that I observed only two teachers in Phase 1 preliminary data, and they both taught the same grade. In Phase 2 data collection, seven teachers were observed, one from each grade level of kindergarten through Grade 3, Grade 5, and two in Grade 4.

Limitations may exist as a result of the difference in the number of interviews conducted between Phase 1 and Phase 2. There were only two participants during Phase 1, and each participant was interviewed twice over 2 years, totaling eight interviews for Phase 1 . In Phase 2 there were seven interviews, but only one interview was conducted with each participant, unlike the interviews in Phase 1. 


\section{Chapter 4: Results}

“Things do not change; we change."

- Thoreau

The purpose of this study was to determine the sustainability of the professional development provided by CES, as perceived by the teachers of East Elementary School. This chapter presents the results from the two phases of this study. In Phase 1, the preliminary observations and interview data were collected from the fall of 2008 through the spring of 2010. In Phase 2, the observations and interview data were collected from the fall of 2010 through the fall of 2011, along with a cumulative final survey conducted in fall of 2011. The findings from this study are grouped in a two-fold fashion. The findings are grouped according to the relationship to the three research questions that have framed this study. In addition, the findings are grouped in response to each question chronologically, with the observations presented first and interviews presented second.

Sample comments made during the observations are given in figures to more clearly define the findings. The interview findings from each phase of the research are presented in a narrative format. Specific quotations from the participants are included from several different sources. The direct quotations are used frequently to diminish the likelihood of relying on my interpretation of the teachers' perceptions, rather than their own thinking. The final results from the cumulative survey taken in the fall of 2011 are presented in figures and by brief narratives.

\section{Preliminary Findings: The Observations 2008 and 2009}

In 2008, the period in which the preliminary research commenced, the CES professionaldevelopment sessions had just ended in the fall. I began my classroom observations in two different fourth-grade classrooms. I returned to the same two teachers' classrooms in 2009 to 
conduct follow-up observations. It was the expectation of the administration of East Elementary School for teachers to implement strategies and skills they had been taught in the CES professional-development sessions since 2006. The first set of observational findings addressed the first research question, how CES professional development impacted the discourse between and among teachers and students.

In what follows, I will describe my observations addressing the first question: How did CES professional development impact the discourse between and among teachers and students? I observed two teachers I labeled Teacher A, Kara, and Teacher B, Katie in Chapter 3. In the fall of 2008, Kara was in her fifth year as a teacher and was returning to fourth grade after moving from fourth to fifth grade with her previous students. Katie was in her third year of teaching fourth grade. Both teachers are Caucasian and between 21 and 30 years of age. Also, both teachers had attended all the CES professional-development trainings between 2006 and 2008.

\section{Research Question 1: Kara and Katie’s observations}

In response to the first research question, how did CES professional development impact discourse between and among teachers and students, I conducted preliminary observations of Kara and Katie’s classrooms during the following months: October 2008, April 2009, October 2009, and April 2010. The CES professional-development sessions had just ended in the fall of 2008. There was an expectation by the administration that teachers would implement what they had been taught by CES members about how to communicate by positively framing comments and questions to students during a lesson. The findings reflect the impact of this training on the amount of positive discourse exchanged between teachers and students, and among students over the course of 2 school years. 
Katie premised the first observation with comments from her first interview to provide background about her feelings on tone of East Elementary School prior to the beginning of the professional-development sessions with CES. Katie described East Elementary School in the following way:

The tone within the school [before the CES reform model was in place] was very negative. Teachers ignored rude behaviors and comments made by the students instead of addressing the action(s) with different choices. The behaviors were masked as something other than the rude behavior they truly were. Teachers provided excuses for the ways in which students were acting and responding in the classrooms.

As an observer of the phenomenon, I was able to note the same characteristics in the students in my own class. When I observed the students in Kara and Katie’s classrooms, my reflection allowed me to agree that the tone of the school was very negative in the beginning. I had experienced first-hand teachers overlooking inappropriate comments made by students, dismissing the rude comment and then trying to justify it by stating the students did not know any better. If that was the case, then as the teacher I believed it was my job to learn how to model the appropriate behavior from the specialized professional-development sessions provided by CES.

In both classrooms, I listened and recorded the dialogue exchanged between the teacher and her students. I recorded the number of positive comments exchanged while the teacher was instructing the students on a specific strategy or skill. I maintained a consistent observation time frame in each classroom and during each observation. I observed for a 30-minute block of time. The lesson may have been longer or shorter, but my observation time was consistently 30 minutes. I scheduled my observations to begin at the beginning of the teacher's lesson each time 
for consistency as well. I recorded the positive discourse exchanged between the student and teachers during the 30-minute observations. The positive discourse included encouraging remarks and supportive comments between teacher and student as well as among students.

I recorded when positive discourse was used by the teacher to a student or group of students during a 30-minute time period. Initially the teacher was the facilitator for these activities and therefore did most of the talking. In the October 2008, I observed in Kara’s classroom. I recorded only seven positive comments made by Kara during a 30-minute lesson. The students spoke very little during the lesson because it was facilitated by Kara. When the students did speak, I only recorded three positive exchanges between them. The numbers were just as low in Katie’s room during the October 2008 observation. I only recorded six positive comments from Katie and two positive exchanges between students. Accordingly, the October 2008 observations identified little positive discourse recorded in both teachers' classrooms.

It was now the second semester after Kara and Katie had completed the CES program; I returned to their classrooms to complete the second set of observations. The expectation by the administration was the teachers would implement the concepts and ideas taught to them during the CES specialized professional-development program. I continued to record the positive comments made by the teachers and students during a 30-minute observation. In this second round of observations, the lessons in Kara and Katie’s classrooms were still facilitated predominately by them.

The second set of observations continued to address Research Question 1: how CES professional development impacted discourse between and among teachers and students. The findings showed an increase in positive discourse exchanged between teachers and students since I recorded comments during the fall of 2008. Kara used eight more positive comments in her 30- 
minute lesson during the April 2009 observation. These finding more than doubled the amount of positive discourse recorded in her 2008 observation. Katie increased her positive discourse with her students by using six additional comments in her lesson, almost twice as many positive comments than in her October 2008 observation.

Even though the positive comments exchanged between teachers and students increased from the fall of October 2008 to the spring of 2009, the positive comments exchanged by the students were still very low in both classrooms. In both Kara and Katie’s classrooms the students’ positive comments had doubled since the October 2008 observations. However, there were only a total of six positive student comments recorded in Kara's room during the 30-minute lesson, and only a total of four positive student comments in Katie’s classroom. The findings show when the students were provided the opportunity to talk they framed their words in positive ways in their classrooms. The students understood how to frame their comments positively; they needed the opportunities to practice positive discourse in their classrooms. In what follows, I will discuss these findings in greater detail, using the example of Kara and Katie. The findings are in relationship to Research Question 1, how CES professional development impacted the discourse between and among teachers and students.

\section{Teacher A, Kara's Cumulative Progress}

The increase in the number of positive comments that occurred between teachers and students as well as among students from all the observations is shown in Figure 1. The amount of positive comments recorded in Kara’s classroom increased from seven positive comments in October of 2008 to 28 positive comments by April 2010. The observations were still conducted within a 30-minute window of time. The findings show Kara used 21 more positive comments 
during her lesson by April of 2010. That was an increase of four times as many positive comments in a 30-minute lesson observed over a year earlier.

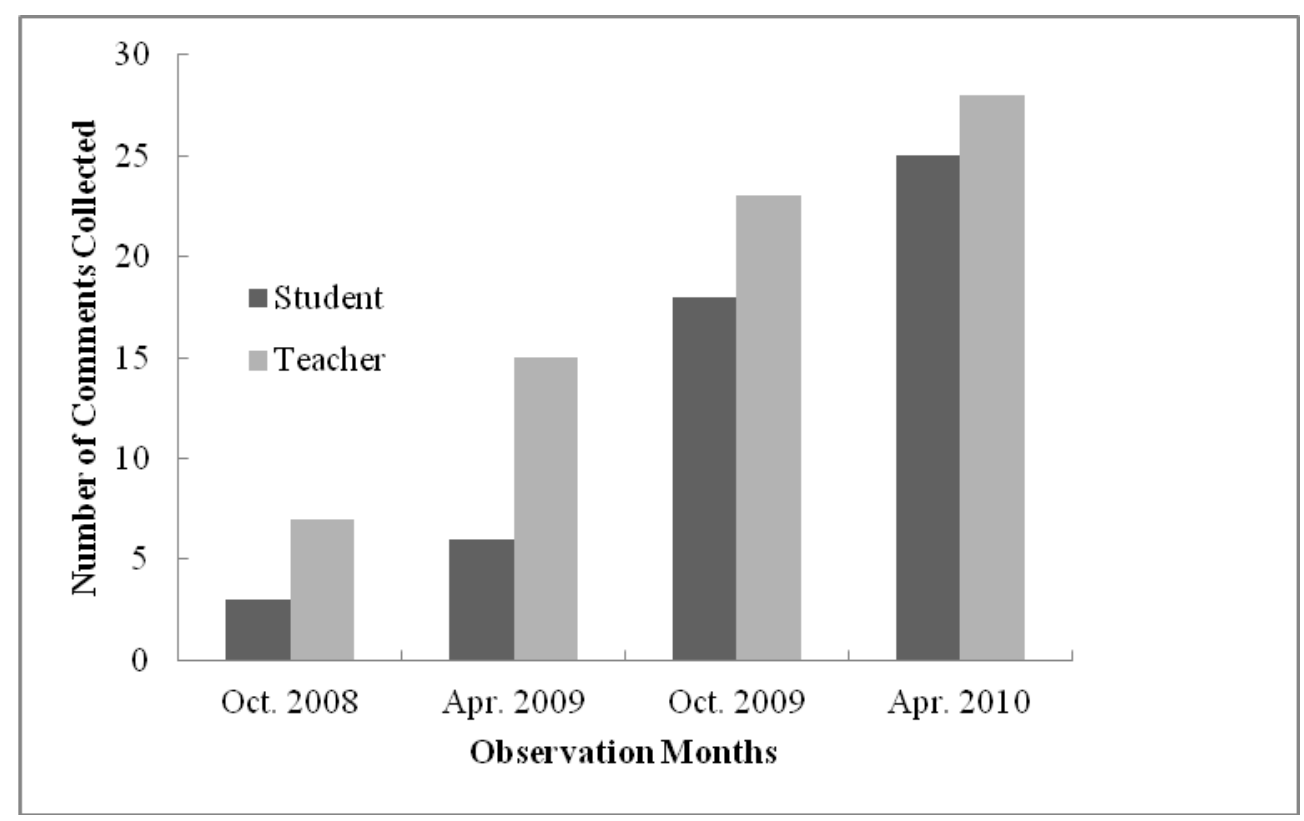

Figure 1. Observations Teacher A, Kara’s room.

In the student findings from Kara’s classroom, the students were talking more in the second two observations than in the first two observations. I noted in the observations that the lessons were student-led activities rather than teacher-directed lecture-style lessons. The students were provided opportunities to communicate with Kara and other students more during the student-led activity. The findings reflected an increase of almost eight times as many positive comments from the students during the student-led activities than in the initial observations.

\section{Teacher B, Katie’s Cumulative Progress}

Katie's class experienced the same increases in the amount of positive comments exchanged during a 30-minute observation as did Kara’s class. Her results are compiled in Figure 2. Her exchange of positive discourse increased from seven positive comments in her 30minute lesson during the October 2008 observation to 27 positive comments during her 30- 
minute lesson observed in April 2010. By the last observation, Katie increased the number of positive comments exchanged in one 30-minute lesson by 20 comments. I recorded almost four times as many positive comments in the final observation than I recorded in the original observation in October 2008.

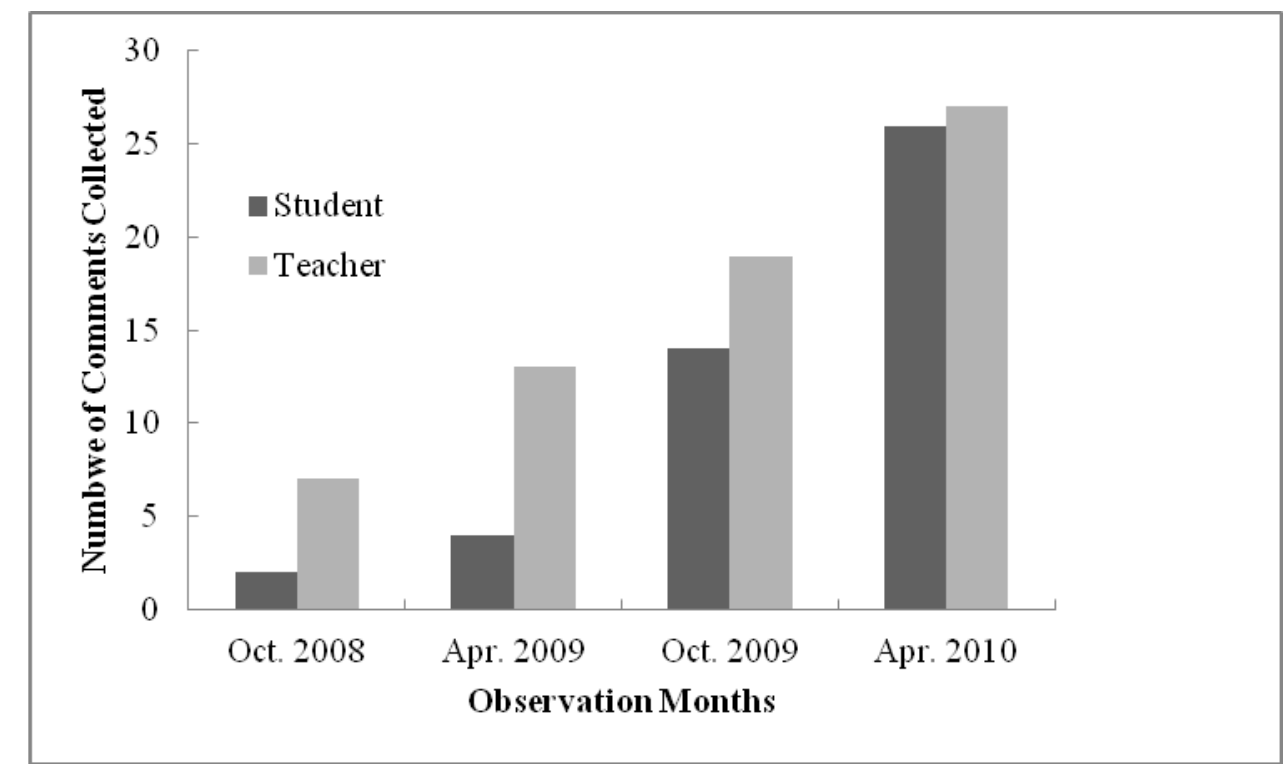

Figure 2. Observation Teacher B, Katie’s room.

As also shown in Figure 2, the student's exchange of positive discourse had also increased in Katie’s classroom from October 2008 to April 2010. I had observed the same transference from teacher lecture to student-led activities in Katie’s classroom as in Kara’s classroom. I recorded 13 more positive comments made by students in Katie's room during her April 2010 observation than I recorded in her original observation over a year ago.

\section{Comparing Kara and Katie’s Data}

I compared the findings of the amount of positive teacher comments in a 30-minute lesson to the amount of positive student comments in a 30-minute lesson. In Kara’s classroom, I recorded three more positive comments from the teacher than from the students. In Katie's classroom, I only recorded one additional positive teacher comment than I recorded positive 
student comments. The findings show that the teachers and the students in both classrooms increased positive communication with one another in their classrooms.

\section{Response to Research Question 2}

The first research question was about implementing positive discourse in the classroom. The natural theme that flowed from the findings about implementing positive discourse was to study the impact of the positive discourse and thus the second research question emerged. The following findings were in response to the second research question: How did the development of positive discourse impact the relationships between and among the teachers and students? The findings were from the observations conducted in Phase 1 and Phase 2. The findings were grouped based on themes that emerged during the observations of the seven teacher participants. Samples of teacher comments and nonverbal cues exchanged that demonstrated positively established relationships were recorded in this section. To be recorded in the sample, the comment or nonverbal cues needed to be observed at least three times by the teacher or student in the classroom. Samples of the common positive comments and nonverbal cues exchanged between the teachers and the students were as follows:

1. Teachers greeted students with a positive comment as they entered the room. "Hi and welcome," and "Glad you are here today," as stated by Terri. These positive comments were recorded as they were heard in the other six classrooms.

2. During the lessons observed, teachers often thanked the students for working hard and being committed to the task. In Katie’s room a few of her comments were: "You did a nice job sticking with that problem until you mastered it," and "You were a problem solver today, well done!” The other teachers made similar positive comments during their lessons. 
3. Teachers framed their concerns in a positive manner. Shari said, "I’ll wait until you're finished talking to give my directions. I wouldn’t want to talk over you, it would be rude. Is everyone finished now? Thank you, now I can go on with my directions.” Each of the teacher participants observed framed comments in a related way.

4. Teachers expected students to be responsible for their own learning and were consciously pausing during the lesson to check for understanding. Leah said, "Are you each doing what you're supposed to be doing? Stop and think what the directions were. If you need to ask a friend or the teacher, please do so if you are not sure if what you are doing is on task.” All seven teacher participants were mindful of asking the students to be responsible for their own learning.

5. Teachers provided nonverbal visual cues to encourage their students, as well as verbal cues. Smiles and nods of reassurance were exchanged also as a means of positive discourse during the teachers’ lessons.

6. During the lessons I observed, the teachers promoted the concept of students being a “bucket filler” as opposed to being a "bucket dipper.” A “bucket filler” is a person who lifts another person up with positive, kind words and positive nonverbal cues. A bucket-dipper is a person who dips into someone’s bucket by saying something negative, mean, or unkind to them to make them feel sad. In Sabrina’s classroom, there was a moment when she actually stopped the lesson and asked the class if what a student was doing would be considered being a bucket dipper or a bucket filler. The students replied the classmate was being a bucket-dipper. They continued a brief discussion about the situation. 
The positive comments exchanged between students sounded very similar to those positive comments exchanged between teacher and student. Samples of the positive discourse exchanged between the students were as follows:

1. Students asked politely if they could use the pattern blocks if they needed them during the activity. Students in Valerie’s first grade classroom commented, “May I please have those when you are finished," and "Who is going to go first?” Similar comments were recorded in the other classrooms between students.

2. In all seven classrooms, the students waited their turn when participating in a group activity without complaining.

3. While students moved around the classroom in Kara's room, they used manners as they interacted with each other. Simple comments such as; "Excuse me,” "Thank you,” “Will you sharpen my pencil please,” “I need some help please,” were just a few examples of the positive discourse exchanged during the activity. Similar comments were made in the other six classrooms as well.

4. If there were not enough materials in Leah's room, students shared them without making negative comments. Each teacher had a system the students were familiar with for sharing in their rooms. The students executed the system in their rooms without any discrepancies or disagreements when it came to sharing materials.

5. In all seven classrooms, the findings showed the students smiled, laughed, and seemed genuinely happy while engaged in their activities. Several students in Terri's class even commented the activities they were doing were fun. Many of the students in Sabrina's classroom asked if they could do the activity again or continue playing it 
during inside recess? The students were observably engaged and excited about the lessons they were involved in while I was observing them.

6. When the students were working on a challenging activity in Shari's room, they encouraged each other not to give up or not to quit. They would encourage each other by saying, "You can do it,” or "Do you want me to give you a little clue?” Students in other classrooms were encouraging to one another during the activities as well.

7. The students in each of the classrooms were interested in being "bucket fillers." They were able to explain what it meant to fill someone's bucket. If they were filling someone's bucket, they made sure they were acknowledged for their efforts by their classmates. At the same time, the students also held each other accountable for when someone was dipping into someone else's bucket. In each of the classrooms, there was evidence of this schoolwide program and commitment from the students.

In 2010, 2 years since the CES program had ended, there was no longer an expectation by the administrators at East Elementary School that the teachers had to use the strategies and skills taught to them during the CES professional-development sessions.

In the fall of 2010, I returned to conduct my Phase 2 observations. I was continuing to collect data on the positive comments exchanged in the classroom between teachers and students. I used the same observation tool as I used for the previous observations. I began by returning to Kara's and Katie’s fourth-grade classrooms first. Then I conducted observations in five other teachers’ classrooms. I observed in every grade level from kindergarten through fifth grade. Fourth grade was represented twice due to the fact the two preliminary observation teachers in this study were the fourth-grade teachers. 
As an observer of the lived experiences of the teacher participants, based on the specialized professional development provided by CES, I was able to describe the impact of the positive discourse exchanged at East Elementary School. Based on the strong impact of positive discourse, the next research question emerged. Question 2 delved more deeply into positive discourse by asking, how did the development of positive discourse impact the relationships between and among the teachers and students?

During all the observations conducted, I recorded the positive comments stated in the various classrooms. These findings included comments from teachers and students in kindergarten through third grade, fifth grade, and the two fourth-grade classrooms. I also recorded descriptions of the relationships between and among the teacher and students, as well as among students in each classroom observed.

In my initial reflection on the teachers' interviews, I read and reread the teacher participants' responses and identified four themes. The findings for Research Question 2 were grouped based on the four themes that evolved from the interviews. The positive comments were present in each room and were common in the classroom environment. The findings reflected the impact of positive discourse on the relationships of the seven teachers interviewed with the students in each of their classrooms.

What follows is the selective or highlighting approach (van Manen, 1990) to teachers' interview comments. I indicated those statements that appeared essential to what the teachers were expressing in bolded type and numbered them for reference and further interpretation, as seen in Table 3. The samples were collected from all seven of the classrooms I observed during Phase 2 of the study. The comments, statements, and phrases addressed the second research 
question: How did the development of positive discourse impact the relationships between and among the teachers and students?

Table 3

Formulated Meanings of Teachers' Perceptions of Professional Development

Research Question 3: Was the information provided by CES during the professional-development sessions sustained as perceived by the teachers?

Formulated meanings of the final five research themes

References

\begin{tabular}{ll}
\hline $\begin{array}{l}\text { Maintained or increased content knowledge; content vocabulary } \\
\text { Maintained or increased skills in pedagogy }\end{array}$ & $\begin{array}{l}23,24 \\
\text { Broken down, the data are as follows: }\end{array}$ \\
$\quad 13,18,19,20,22,23,25,26,28,29$ \\
$\quad$ essential questions & 20 \\
$\quad$ higher order questions & $18,19,25,26$ \\
$\quad$ inquiry-based lessons & 13 \\
$\quad$ CES principles & 28,29 \\
$\quad$ Protocol: Speed circle & 22 \\
$\quad$ Protocol: Four corners & 23 \\
$\quad$ Protocol: Chart chat & $14,21,27,33,34,35,36$ \\
Increased involvement in professional-learning community & $1,2,6,7,10,11,15,16,30,31,37$ \\
Increased ability to communicate positively & $3,4,5,8,9,12,17,32$ \\
Increased ability to establish relationships &
\end{tabular}

Note. Numbers reference bolded phrases in teacher participants' interview comments provided previously.

To determine which comments, statements or phrases seemed essential to teachers, I focused on the recurring phrases of related statements in the interviews and the observations. As I studied the lived-experience descriptions and discerned the themes that emerged, I was able to effectively describe the commonalities in the research for the reader (van Manen, 1990).

\section{Theme 1: Remain Calm and Listen to Build Relationships}

The seven teacher participants talked about how important it was to take time to build a relationship with each student in the classroom. The teacher participants stated that the relationship is not something that is simply given to you, it is built on trust and respect. The 
teachers agreed that by speaking to their students in a positive tone, they were able to reach the students and gain their trust more quickly.

One phrase each teacher participant stated in her interview and also practiced in her classroom was to remain calm and listen. Each agreed there were times throughout the day or week when they needed to pause during their teaching. They took a minute to breathe, think, and then respond to the students and the situation that just occurred. Each teacher agreed if they had a quick reaction to something, sometimes the situation escalated. Leah commented,

[1] I try really hard to think before I speak. If I am really upset, I tell the student that. I will say to him or her, [2] “I am so upset with you right now that I can't even talk to you at this moment. I need a little time to calm down and then we'll chat. I will call you back up in a little bit to discuss this with me.” Then I call the student up to meet with me a little later on that same day, but I do make sure it is that same day. [3] We are then able to discuss it more calmly. By doing this, not only am I being careful with my words, but I am modeling what to do when I don’t have the words I need to discuss what I want to discuss in an appropriate manner. It serves as a win-win situation ... a double modeling example.

As I observed this happening in Leah’s classroom, the student responded in a very positive way. He shook his head and replied, "I get it"; then he returned quietly to his seat. He then proceeded to pull out his class cash. Leah and many of the teachers at East Elementary School work on a cash system in their classrooms. Students are paid for the positive things they do and in return pay a fine when there is a consequence for their actions. This child seemed to know he was going to need to pay money for his actions that day. 
After about 10 minutes, Leah called the young man over to her table. They discussed the situation calmly. She expressed her side, and the child did the same. As the observer of the situation, I was able to discern a mutual respect being exchanged between the teacher and the student. The student determined an amount of money to pay. Leah said it was too much. They discussed it some more and then agreed on an amount that was fair and suitable for the offense. The student returned to his seat and the class resumed as though nothing ever happened. Terri, who is a kindergarten teacher, expressed a few different views about this theme:

I always remind myself that I am the adult in the situation and it is important that I conduct myself in that manner. This is why it is so important to just take a minute before I speak ... because it is not only [4] what I am going to say to my students which will impact them, but it is how I say it that could possibly scar them and damage my relationship.

Reminding herself that her students are only 5 years old is important to Terri. Observing Terri with her kindergarten children and watching how they are very in-tune with everything she says, made me reflect on how my students listen to me the same way. As the teacher, we are the adults and the students are looking to us to model the behaviors we expect from them. Terri continuously modeled those positive relationship examples in her room.

Another participant, Valerie agreed with Terri and her comments about the teacher being the adult. Valerie continued to comment on the topic and added the importance of listening to her first-grade students:

When I wait for my students to speak, I am also continuing to develop our relationship by showing them the respect they deserve. I am telling them that [5] I believe that what they have to say is important, by not saying anything at all. So as powerful as words 
can be, silence can be just as powerful ... [6] which is why it is important to think before I speak.

While I was in Valerie’s room, this was one practice I noted under building relationships. When a student had something to share, as first-grade students seemed to do often, Valerie never brushed the student off and asked them to wait until later. She always took time to listen to her students. I noticed the students were very mindful of when they asked to share a comment. It seemed as though Valerie had taken time to establish some sharing-time rules with her students. Valerie’s students were very respectful of their time together. Based on my findings, the relationships between Valerie and her students were ones build from respect and trust.

\section{Theme 2: Be precise With my Words to Build Relationships}

The second commonality to emerge from the interviews and observations was that teachers and students need to be precise with their words. As I reflected on the findings, I observed teachers saying what they mean, and using a kind, straightforward tone, and as a result their students trusted them.

In the rooms I observed, I probed the students and asked if they felt safe and/or respected by their teachers. In each of the seven classrooms, students commented they felt very safe, as well as respected. In the primary classrooms, my probing questions sounded slightly different than in the intermediate classrooms. I asked the students if they trusted their teachers and if they thought their teachers trusted them. All the students knew what was expected of them because their teachers were precise with their words.

The common thread through the interviews was that teachers agreed it is important to be clear and straightforward with students. Sabrina explained it as follows: 
When I was a student teacher, I watched my teacher compliment the students who were conducting themselves the way she wanted the other students to conduct themselves. This was confusing to me as a student teacher, so I thought it might be confusing to my students as well. It was at that point that I decided that [7] I would simply state exactly what I wanted my students to do as opposed to making them guess or try to figure it out based on what another student was or wasn't doing right at that moment in my room. Sabrina was addressing a form of indirect communication where the teacher was trying to win compliance for the other students in the class at the expense of another student.

In my observations I recorded examples of several teachers using the indirect form of communication. For example, the teacher would comment, "I like the way Mary is sitting. She is ready to begin.” All of the students had to look at Mary, discern what she was doing and then adjust themselves according to do the same thing. The teacher made this comment hoping other students would realize they were not ready.

I have additional findings from Leah and Katie’s classrooms, where I did not observe indirect communication. I observed direct communication, where the teachers asked the students precisely what they wanted them to complete. For example, if Leah or Katie wanted a student to put a book away and get ready for lunch, that is precisely what they asked the student to do. The amount of time it took the student to complete the task was much less time in Leah and Katie's room than in the other rooms. In my observations from the other classrooms, students had to figure out what they needed to do to in order to win the teacher's approval. My findings show this approach took much more time to accomplish.

Another form of indirect communication I observed being used in the classrooms was sarcasm. During an interview session, Shari explained a time when she was a student herself, and 
was a victim of a teacher's sarcasm. She remembered how her teacher embarrassed her and how it felt. She could remember it as though it had just happened, and it occurred over 35 years ago. She now takes great care to make sure her students never feel that way in her room. She continued to explain how she handles challenging situations in her room:

I handle sensitive situations and issues one on one, instead of in front of the entire class. I make sure [8] I pull the student aside away from the others, however I can still see the rest of my class, but they can't hear what words I am exchanging with this student. I think it makes a difference if you have experienced something like that for yourself as to how you handle it with your own class, but we really should think twice before we use sarcasm to make our point.

In my observations, I did notice time and time again teachers pulling students aside to have different discussions, one on one. The idea of public humiliation was not present in these classrooms. The teachers treated their students with respect in discipline situations. My findings show the students were receptive to these one-on-one discussions and typically the end results were positive. The teaching would resume and the student remained in the classroom for the instruction.

My observation notes describe the teachers' voices as firm from time to time, but never loud. My findings show no teacher yelled at a student in a loud voice. The exchange of words were typically calm and framed positively in both instruction and disciplinary situations.

\section{Theme 3: Believe in Your Students' Abilities and Intentions to Build Relationships}

This theme emerged because the teachers interviewed each commented about how important it was to communicate high expectations to the students while supporting them in achieving teachers' goals. All the teacher participants agreed it was imperative to be clear and 
consistent when communicating expectations to students. However each of the teachers also commented about how extremely important it was that their students knew their teachers believed in them. Kara explained it as follows:

Students are very perceptive. It would be better to say nothing at all than to say something disingenuous. Students want to be respected and they feel strongly about developing a strong sense of trust. When they know [9] you believe in them, they will interpret even sharp, harsh-sounding comments as statements of care when it is coming from someone [who] cares.

In my findings, the teachers communicated their belief in their students in a myriad of ways. Each of the teachers encouraged their students with positive feedback while they were working on a task in the classroom. The teachers also supported their students with nonverbal positive support such as a comforting smile, a wink, a nod or a gentle pat on the back as encouragement or comfort. Many of the students hugged their teachers and the teachers hugged them back-yet another form of nonverbal communication. My findings also show the students had smiles on their faces while engaging in challenging tasks. The students were all engaged in the activities designed for them during my observations in each classroom.

Being genuine and supportive of students was important to Katie and she added the following comments to this theme:

The fact students are more likely to live up to our expectations of them which is why we must set our [10] expectations high and support the students to aspire to reach those goals. We can do this by using positive language. 
My findings support the concept that the words from the seven teachers were communicated in a calm voice, buoying the belief that students wanted to, and knew how to, listen, cooperate, and perform quality work.

\section{Theme 4: Words Into Action to Build Relationships}

This theme emerged out of the analysis of the each of the seven observations. During the observations, I collected positive comments exchanged between teacher and student and among students. I reflected on the interview comments shared by each of the seven teacher participants as well.

I determined the average number of positive comments recorded during a 30-minute observations in all seven classrooms. The mean number of positive comments exchanged between and among students and teachers was 27 positive comments. Samples of the comments from the classroom ranged from positive greetings to and from the students as they entered the classroom for the day, to students saying excuse me as they passed in front of others. Other comments included the teacher inviting the students to the guided reading table with a simple positive invitation such as "Please join me at the guided reading table for group," to students leaving for the day, happily blurting out, "Have a great night!” as they exited the classroom. My findings in this section addressed Research Question 2, how the development of positive discourse impacted the relationships between and among the teachers and students. The comments, statements, and phrases from the interviews and observations of the seven teacher participants were essential to the phenomenon of this study. The findings of the seven teachers supported their practice of positive discourse in their classrooms, and that they truly believed in building relationships with their students. 


\section{Research Question 3: The Interviews and Final Survey}

The school year 2011 marked 3 years since East Elementary School had worked with the members of CES. According to the teachers interviewed, the administration did not expect the teachers to at East Elementary School to use or even be familiar with the strategies and skills CES had presented over 3 years earlier in their professional-development sessions. There had been several teacher transfers and retirements since CES was involved with the teachers at East Elementary school. Noting all of the changes at this school, the findings in this section will address Research Question 3: Was the information provided by CES during the professionaldevelopment sessions sustained, as perceived by the teachers?

The professional-development sessions presented by CES provided more than communicating and building relationships with the students, the two topics addressed in this study thus far. The findings addressed additional strategies and skills the teachers learned from the specialized professional development, as they described it.

The findings from the teachers' interviews expressed the teachers' perceptions of the changes that occurred, beginning with students' attitudes. The teachers perceived the change in students' attitudes as positive changes. Kara's comment explained how the students were before the teachers focused on positive discourse and a sense of respect:

Students believed if they sat quietly, then they would not have to do any work. Teachers in the past were happy to have students sitting quietly. They did not demand the students to participate or expect them to attempt to complete any of their classwork, only to sit quietly. The teacher was satisfied the student was not bullying another student. It was then okay if he or she did not engage in the lesson. In return, the student did not want to participate. Therefore he or she would sit in the room quietly and not bother anyone. This 
behavior was acceptable. At one point in time, this was even considered being respectful in East Elementary School.

Kara's comments seemed particularly revealing about the phenomenon being described by the perceptions of the teachers I was interviewing. When the CES provided specific professional development on Principle 7, a tone of decency and trust, teachers were exposed to the meaning behind communicating positively and establishing a relationship with their students. Teachers were immersed in promoting positive discourse in their classrooms. According to the interviews, the positive shift began to occur with the school, beginning with simple attempts in each classroom. Katie shared,

I began by [11] greeting my students each day with a smile and simple good morning. For the first several months, many of my students just looked at me with no reply. As the months continued, a few began to smile back at me. I never wavered and each morning [12] greeted each student. Eventually, a few students began to smile and even say good morning back to me, and maybe say a simple hi. I thought it was a start. To enter the building in the fall of 2011, my findings show happy, bubbly, excited students hurrying to get to class. I found students who were greeting adults and students alike in the hallway with smiles and waves and happy "hello"s. The findings show a continuation of positive examples all around the school. Terri commented on her perception of East Elementary School today,

The program CES began [in 2006], we wanted to continue and to be successful. We wanted a place where everyone practiced a [13] tone of decency [CES Principle 7]. We began a [14] collaborative effort as a school in 2006 to [15] speak kindly to one another, to mean what we say, and to listen when someone was speaking. By 2009 
the climate of this school had truly changed, not only in my kindergarten room, but throughout the entire school. Students were smiling when they entered the building in the morning. They initiated the greetings with others in the morning, and at other times throughout the day. Both students and teachers genuinely seemed happy to be here and happy to be working with each other. The [16] communication was positive and there was [17] evidence of relationships between teachers and students. There were even some relationships that were beginning to carry over to the families at home.

Each of the seven teachers interviewed commented how each of them was committed to the success of East Elementary School. They all commented on the success of a school beginning with its teachers. They believed they had been given the tools by CES to begin establishing a classroom where students would want to come and learn. All seven teachers expressed their concern about how they [and the other teachers] would continue to make that goal happen. They were not sure they had spent enough time with CES to maintain their principles without the daily support provided by CES. My findings show originally they believed their schools successful turnaround was a result of the efforts of CES. The teachers commented on how the CES professional-development sessions trained teachers about how to establish positive discourse and build teacher-student relationships, and this resulted in the change at East Elementary School. Their perceptions changed later in my findings.

The following samplings of interviews, along with the results of the survey addressed Research Question 3: Was the information provided during the CES professional development sessions sustained, as perceived by the teachers? The most common thread from the interview findings was the following. Of the seven teacher participants, five participants agreed their 
instruction was more student centered as a direct reflection of the training provided by CES.

Valerie stated,

I use more [18] inquiry-based lessons now. Allowing my students to take control of their learning has been very empowering for both them and for me. With me as the [19] facilitator, the students conduct the math activity or the science lab within their small groups. I present a focus question. CES calls them [20] “essential questions” and they direct the students toward the goal of the lesson. At the close of the lesson we revisit the focus question to determine if we achieved our goal or not and discuss, and problems or successes as well. The discussions have been far deeper than with explicit teaching alone.

The teachers who were not trained by the CES staff on using essential questions to focus instruction were usually trained by their team leaders or sometimes by the C\&I specialists. Leah provided additional insight on how teachers helped those who were not trained by CES: “The CES training was extended by those who were the in-house experts. Teachers were coaches for each other. They established their own [21] professional-learning communities to ensure that no teacher was unfamiliar with the CES common principles.” Additional interviews clarified exactly what information was provided by CES and if the teachers were still using it. All seven teacher participants commented positively about CES protocols. The teachers all agreed they were highly engaging for the students and encouraged students to think more critically to complete the protocol. Katie explained that she still uses the protocols, especially in mathematics lessons. She explained,

I am a huge fan of the CES protocols, especially [22] “Four Corners.” I use Four Corners as a math warm up at least once a week. You can use it for anything at all, but 
for us right now, we are working on addition and subtraction with regrouping. So each student has his or her own card [differentiated based on the student's needs] and they solve the problem and then look for one of the Four Corners with his or her matching answer. The descriptions for the corners this week are: Your sum is greater than 35, Your sum is equal to or less than 35 , your difference is greater than 120 , or your difference is equal to or less than 120 . The students really love the layers of challenges within this warm-up activity. This was one of the first activities I learned from CES and it is still my all time favorite!

I probed a little deeper during our interview sessions and asked Katie if she had shared this protocol with anyone else? She was very excited to explain to me that she had shared this protocol with her team as well as with the staff. She has offered an after-school protocol training for anyone who wants to attend. She has had a high number of teachers in attendance. She said she finds it interesting that the teachers who participate are not always teachers who were not trained by CES. Sometimes a teacher will come to my session because they need a "refresher on a particular protocol,” according to Katie. So my findings show evidence of teachers helping teachers to sustain the specific protocol training provided by CES.

Protocols seemed to be a commonality in the interviews. Sabrina described a different protocol she used in her reading block:

The CES protocols are probably the one thing I liked most about the professionaldevelopment sessions. I really enjoyed when the CES staff members actually used the protocols with the teachers so we could really understand how to use them with our students. I still use the [23] Chart Chat or Chalk Talk protocol with my students in reading. Sometimes I record vocabulary words on the chart and the students record their 
thoughts about their meanings. They really enjoy coding the chart with smiley faces or check marks if they agree with a classmate. I like how this protocol [24] engages them in reading other students' ideas and thinking about whether or not they agree with them. It really does promote [25] critical thinking, plus it's [26] interactive and fun for the students.

Valerie shared how she used protocols in her classroom, as well as how she was taught about the protocols.

I was not here [at East Elementary School] for the first year with CES, and that was when all of the protocol information was taught. However, my team leader made me a packet of the CES protocols and [27] sat me down one day after school and modeled each one for me. We talked about how they would look in the classroom. She spends time with me each week creating a different use for a [28] protocol either in math, reading or science. I am starting to get the hang of it and have written a few activities using protocols myself. I like using [29] speed circle for review in any subject. Sometimes we use it as a warm up in science to name the properties of rocks, and then in math we will use it to close our lesson and name the multiples of six. In Social Studies I will have them speed circle the Maryland symbols. It’s fast, fun, and engaging. Ever since my team leader introduced me to them, I have used them ever since.

Another predominant finding in the teacher participant interviews was every teacher participant spoke about the importance of developing relationships with their students. They all agreed that without the teacher-student relationship, it was difficult to accomplish anything in the classroom. According to the teachers, establishing the relationship began on the first day of school, with the first greeting made to the first student who entered the room. All seven teachers 
stated that one must greet each student every morning with a smile and a happy "hello.” They also agreed all children needs to know the teacher thinks it is important they are in school. These statements or phrases were a common theme among the interview comments.

Another commonality shared by teacher participants was that teachers worked hard to speak kindly, say what they meant, and listen when someone was speaking. My findings support teachers’ perceptions about sustaining positive communication with their students to build a relationship with each one of them. The teachers all addressed the concept of "bucket fillers verses bucket dippers.” Terri teaches kindergarten and explained her perception of speaking kindly,

The concept of [30] speaking kindly, and using positive words has been a push [at] East Elementary School for the past five years. The Coalition begin the push with [31] training on the importance of teachers and their words. We didn't realize how are [32] words impacted our students. The power they carry is tremendous and we need to be mindful of their power. We discussed sarcasm and indirect comments, and what they do to students. The training we received on the power of our words still resonates with me today. Every [33] team leader makes sure their team, old and new teachers, revisit the power of their words at the beginning of each school year. We never forget because our principal leads the way.

Shari taught fifth grade and also discussed the importance of speaking kindly. She also addressed the bucket dipper, bucket filler, and how it ended up at East Elementary School. She explained,

Our guidance councilor found the book, Are You a Bucket-Filler, or Dipper? [author unknown]. Our [34] entire school rallied around the book. The art teacher had the 


\section{students design posters asking Are You a Bucket-Filler or Dipper? for our}

antibullying campaign. This was a wonderful project for my fifth graders. The [35]

Family School Liaison had an evening event where we invited our families to dinner. The [36] teachers were the waiters and all night long we passed out tickets when we heard people being bucket fillers. After dinner, our principal read the book, the staff shared positive stories, and we wrote commitments to [37] speak kindly to each other, say what we mean, and to listen to each other. At the end of the night we revealed why we were passing tickets [ for positive discourse]. Our principal drew the winners and we gave out prizes. It was a powerful evening that our students still talk about today. I was there the evening and it was a powerful night for students and their families. The biggest impression left on me from that night was that each family member wrote on a piece of paper his their commitment to speak kindly, to say what they mean, or to listen was very moving for me as an educator and as a parent. I have always been proud to be part of the East Elementary School community, but I was especially proud that night. The level of commitment to encourage positive discourse and build relationships exceeded our classroom walls and had filtered out into our community. As I reflect on this experience, I ask myself, was this a result of sustainable professional development or commitment by teachers, families and community members?

The definition of sustainability perceived by the teacher participants of this study is explained as follows: narrative or observational evidence of a teachers’ ability to maintain or increase their ability to execute a learned strategy or skill. The initial findings of the teacher observations and interviews are followed by a more in-depth and systematic approach (see Table 3) to interpreting the meaning of the numbered and boldfaced phrases from the interviews. 
This systematic study of these teacher participant comments (see Table 3) enabled me to write the following composite description of the satisfaction of the teacher participants' perceptions to the sustainability of the specialized professional development provided by CES. When teachers were selected which components of the specialized professional development they implemented in their own classrooms, they were committed to its success. The findings show teacher participants selected to focus on positive communication in their classrooms and the school building in general. Teachers had chosen to continue to speak kindly, say what they meant and listen to others. Teacher participants concentrated on the success of communicating positively to establish strong relationships with their students. They also worked on more teacher networking and collaboration that led to greater teacher support in the classroom. Teacher participants acknowledged the relationship between their commitment to the professional development and the sustained use of the strategies and skills introduced to them by CES.

The interviews clearly depicted the voice of the teachers and their perceptions about the impact of the professional development provided by CES. I continued to focus on these five final research themes. I placed the five themes on the survey to support answers to my third research question: were the instructional strategies provided during the CES professional-development sessions sustained, as perceived by the teachers? The five final themes as they appeared on the final survey were as follows:

1. Content knowledge,

2. Skills in pedagogy; CES protocols, essential questions, higher-order questions, and inquiry-based questions,

3. Involvement in professional=learning communities,

4. Ability to communicate positively, and 
5. Ability to develop student relationships.

The rating scale the teachers used ranked their thoughts about each area: stagnant, struggling, improving, strong, or not applicable (N/A).

Of the 24 surveys, the teachers expressed several areas they felt most strongly as teachers. Building relationships and communicating positively were marked strong for 20 out of 24 teachers. The teachers' comments continuously stated how important it was to take time at the beginning of the year to establish a safe and trusting community in their classrooms. The teachers emphasized the principal's message at the beginning of the year was to spend at least the first 4 to 6 weeks to establish relationships with the students and families in their classrooms. Every teacher survey made a comment directly connected to the importance of building relationships.

Another category teachers ranked strongly was pedagogy. A total of 21 out of 24 ranked this category strong. There were three teachers who still felt they were improving in this area. Understanding different ways to teach allowed the teachers to become more effective in the classroom. CES provided professional-development sessions on the following topics to improve classroom instruction: protocols (CES activities to engage students in their learning), higherorder questions (practice developing higher-order questions to push student to think), essential questions (writing focus questions for each lesson taught) and inquiry-based lessons (with the teacher as facilitator and students driving the activity through discovery and discussion).

Teachers felt that they had grown as a result of CES professional-development topics. Every teacher survey commented positively on the impact of the CES protocols, essential questions, higher-order questions, or inquiry-based lessons and how they improved student engagement in their classrooms. Teacher participants spoke directly about the impact protocols 
had made and still make on them as teachers now. During my observations, each teacher had a focus question listed for the lesson they were teaching. There was evidence of several CES professional-development topics in East Elementary School classrooms now, even though it is not a directive by the administration at this school. The teachers have made a professional decision to continue to use these strategies and skills presented to them 3 or more years ago.

According to the survey, the two main areas the teachers ranked as improving for themselves were first in the area of professional-learning communities. Professional-learning communities require time. In a professional-learning community time is specifically denoted for reflection, for teachers to grow in their craft. Teachers had opportunities to share student work and network about successes and failures in the classroom. Professional-learning communities are driven by the teachers, not administrators. East Elementary School teachers marked this as improving with comments to support it, saying it was challenging to find the time to meet with others in their own grade levels, and especially to find time to meet with other grade levels. Additional comments noted that it was still a concentrated effort by teachers to make this happen.

The second area the teachers ranked as improving themselves was increased content knowledge. Teachers wanted more time to delve deeper into their content areas to strengthen both their content background knowledge as well as their students' content background knowledge. That teachers only received support from C\&I specialists once a month was insufficient to delve into all of the content they were expected to master and to teach. Teachers commented on the survey sheet that they missed the weekly support CES provided for them and wished they had another opportunity to received support from an outside venue again. 
On the final survey, teacher participants clarified the reasons behind the lower rankings for two categories: there was not enough time to process all the information offered at the professional-development sessions or to enough time to meet with one another to debrief. However, the information they gained was beneficial and impacted their students positively and successfully in their classrooms.

As I reflect on Research Question 3—was the information provided by CES during the professional-development sessions sustained, as perceived by the teachers? - The findings in this last section show the impact of positive discourse, building relationships, and implementing the many different strategies offered by CES. This last part of this research was conducted 3 years after CES concluded its time at East Elementary School. The findings show conclusive evidence that CES professional-development-session information is still being used by teachers at East Elementary School. 


\section{Chapter 5: Conclusions}

"Do not confine your children to your own learning for they were born in another time."

—Hebrew Proverb

\section{Introduction}

As an aid to the reader, this final chapter of the dissertation restates the research problem and reviews the methods used in the study. The major sections of this chapter summarize the results and discuss their implications.

The improvement of education relies on the development of a highly qualified teacher workforce with the knowledge, skills, and disposition to stimulate exceptional student learning in today’s classrooms (Darling-Hammond \& Sykes, 1999). Student learning is dependent on what teachers know and are able to do (Killion, 2002). Most agree the objective of professional development is to improve teaching and ultimately enhance student learning. Without professional development, teachers’ content knowledge and skills waiver (Shulman, 1987). This lack of education has the greatest impact on strengthening instruction, as well as strengthening relationship building in high poverty, high minority school districts. Research indicates a strong need for incorporating professional development into a well-orchestrated reform effort (Craig, 2006; Elmore, 2002; Fishman \& Marx, 2001).

CES was selected to develop East Elementary School's reform model. The sustainability of the professional development provided by CES was the focus of this study. There is limited research on the sustainability of adopted professional-development models such as the one presented by CES, after their time concludes with a school. This study analyzes the implementation of positive discourse, relationship building, and sustainability of the professional 
development implemented by this CSR model, CES. This study emphasizes the importance of sustainability of professional development from the perceptions of teachers.

\section{Review of Methodology}

The focus and outcomes of this research, including data collection, participant selection, and the understanding of the lived experience, were presented a case study. However my position as the researcher in this study along with the process of data analysis were both conducted through a process of self-reflection.

Throughout the study, as the researcher, I gave considerable thought to my own experience and to explicitly claim the ways in which my position or experience related to the issues being researched. The final document included my personal connections and the philosophical bases on which interpretation occurred (Allen, 1996; Cotterill \& Letherby, 1993).

In Phase 1, the preliminary observations followed two teachers from fall of 2008 through spring of 2010. These two teachers continued to implement information they had learned in professional-development sessions provided by CES. The interviews involved two teachers, trained by CES.

In Phase 2, observations were conducted with the same teachers however five additional teachers were added to the observation list. There were a total of seven teachers interviewed. Teachers varied in ages, ethnicity, race, years of teaching experience, and also varying degrees of experience with CES. In the fall of 2011, the teachers at East Elementary School were asked to complete a final survey. Of the 25 teachers asked, 24 of them returned the survey. The purpose of this survey was to investigate the sustainability of the professional-development sessions provided between 2006 and 2008, as perceived by the teachers. 
Ongoing reflection. In this study, data analysis is best characterized as an ongoing reflection because the analysis process required me to reflect continuously on the observations and the teachers' interview comments. This reflection involved reading and rereading my notes and teachers' comments in an attempt to "unearth something 'telling,' something 'meaningful' something 'thematic' in the various experiential accounts” (van Manen, 1990, p. 86). As van Manen (1990) stated, “we work at mining meaning” (p. 86) from these accounts.

My ongoing reflection began in the fall of 2008 when I conducted the first observation and the first round of interviews and continued through October 2011. This reflection consisted initially of reading to obtain a general sense of the teachers’ perceptions. I organized the information in two ways: (a) according to teachers' perceptions of the impact of the professional development provided by CES, and (b) the sustainability of the professional development presented by CES. This provided me an overall sense of the teachers' thinking. As I read my observation sheets and the interview sheets, I made informal notes, and codes regarding my initial impressions. Substantive themes emerged from the teachers’ comments that developed into my second research question in this study.

During the next 4 months, as I continued to read my observation notes and the teachers’ comments, I followed what van Manen (1990) identified as the selective highlighting approach to identification. In the selective approach, a researcher reads a text several times and asks, What statement(s) or phrase(s) seem particularly essential or revealing about the phenomenon or experience being described? (italics in the original, p. 93). Applied to my study, this question became, "What statement or phrases seem particularly essential or revealing about the phenomenon or experience, as perceived by the teachers?” Moustakas (1994) described this early 
process of analysis as identifying similar statements, creating meaning units, and clustering themes.

To determine what statements or phrases seemed essential to the teachers, I focused on recurring phrases or related statements. This method is consistent with the following description by van Manen (1990), “As we thus study the lived-experience descriptions and discern the themes that begin to emerge, then we many note that certain experiential themes recur as commonality or possible commonalities in the various descriptions we have gathered” (p. 93). Four themes emerged as I repeatedly read, reflected on, and wrote about the teachers' comments. When a phrase occurred only once or twice and was unrelated to other teachers' statements, I determined it to be an incidental and nonessential theme of the phenomenon.

Reflective writing as a tool for thinking. The importance of reflective writing in a case study cannot be overstated. I agree that writing is a tool for thinking and learning, as asserted by Forget (2004). In this study, my writing was not just a means of reporting my findings; my writing facilitated my reflective thinking and understanding. The process of writing enabled me to interpret the teachers’ perceptions and describe the significance of their experiences.

Researcher as an instrument. My interpretation of the data was significantly influenced by my own experiences and beliefs about teaching and professional development. I have experienced teaching at all levels in the elementary school venue extending from teacher trainer in the school system to teacher-education instructor at the university level. I am also a parent helping my child negotiate his way through his first year of college.

I believe learning has great value to develop one's intellect and is fundamental to what it means to be human. I believe teaching to be extremely important. I also believe teachers to be powerful people in a students' academic career. Teachers have the unique privilege of helping 
their students develop as human beings and should be as highly skilled as possible. I have great passion for researching the experiences of teachers who chose to continue to increase their knowledge and skills through professional development to the benefit of themselves and their students.

I believe reflective writing is a valuable tool for learning and as elaborated by van Manen (1990). Fundamental to van Manen’s approach is the idea that educational research has a pedagogical orientation. The conviction expressed by van Manen (1990) reflects my own view, "I am not just a researcher who observes life. I am also a parent and a teacher who stands pedagogically in life” (p. 90). The purpose of educational research is not merely theoretical, but is ultimately pedagogic in nature. As a parent, teacher, and researcher, I believe it is vital that educational research intersects with and informs the practice of teaching. This study evolved from my interest in the sustainability of specialized professional development and its impact on teachers.

Trustworthiness. Trustworthiness is established when the researcher is (a) systematic, (b) explicit, and (c) rational in the collection, analysis, and interpretation of data (van Manen, 1990). The trustworthiness of this particular research study was derived from reflecting on the data analysis involving researching sources, according to van Manen, (1990) and Fetterman (2010),

1. I systematically conducted the observations. Each observation lasted for 30 minutes, and always began at the beginning of the teachers' lesson or activity. The observation sheet was the standard for each classroom. Every interview was conducted in a private setting with a given set of IRB-approved questions. The final survey was distributed at a school faculty meeting, so all teacher participants received the 
document at the same time. They were provided time to complete the survey at the end of the meeting.

2. I followed an explicit pattern for identifying the themes. I laid out the "chains of evidence" that supported, contradicted, or qualified emergent themes and interpretations as well as extended prominent patterns,

3. I developed rational descriptions of narrative accounts of participants' perceptions and experiences of the sustainability of the professional development provided by CES.

The systematic, explicit, and rational nature of identification and interpretation of themes is validated independently as readers read the study (van Manen, 1990).

\section{Response to the Research Questions}

Research Question 1. How did CES professional development impact the discourse between and among teachers and students? The results of the observational and interview findings addressed the first research question. The findings addressed how the CES professional development impacted the discourse between and among teachers and students.

The two fourth-grade teachers explained how the initial professional-development sessions with CES were spent focusing on the importance of speaking to students in a positive manner and tone. Those same two teacher participants, Kara and Katie, described how CES staff members modeled how to reframe their words into positive phrases. Kara added how the CES staff emphasized the impact teachers' words would have on their students. According to both teacher participants, the teachers were told they were the only ones who were able to make sure their impact was positive on their students. 
My findings relevant to Question 1 coincided with Vygotsky’s (1978) research that word choice truly shapes learners, and words impact students from the beginning of the day until the end. It is true that words shape one's thoughts, feelings, and experiences. The findings for Question 1 in this study support the concept that not only what we say, but how we say it impacts students as learners and human beings. It impacts a student's sense of self, ability to solve problems, and how to function in a relationship with another student or adult. These findings also support the research by Denton (2008) that students who are addressed with a sense of dignity have a sense of self-worth and this can begin with the way a student is greeted or not greeted at the doors of the school. Kara and Katie both commented they believed the positive change was a direct result of the positive discourse exchanged in their own classrooms.

My observations found the teachers at East Elementary School were impressive people in the lives of many of their students. In classrooms where I observed, the teachers who spoke in a positive tone to their students in return had students who were more apt to speak positively, participate, and be risk takers. The teachers in these classrooms understood that the role of the teacher comes with great responsibility. Their responsibility began with communication: to speak kindly, mean what you say, and listen well. My findings show that teachers realized that the impact of positive discourse affected students on an emotional level as well as an academic level.

On an emotional level, the findings pertinent to Question 1 concur with findings of other researchers, such as Fisher and Frey’s (2008) assertions that creating classrooms where students feel safe, respected, and trusted is important. The CES staff strove to teach the importance of conveying a positive tone when communicating with students. The findings support the concept that the impact of positivity from the teachers made the students feel safe, comfortable, and 
confident. According to my findings, the teachers in this study worked hard to establish and then maintain a positive environment for their students to learn.

As discussed by several teacher participants, the teachers of East Elementary School wanted to change the negative tone they felt to be present in the school prior to the reorganization period. My findings in this study for Question 1 also concur with the assertions found in the study by Hart and Risley (1995) that the impact of hearing negative comments over positive comments can be make a student emotionally stagnant and even permanently scar them as a learner. My preliminary observational findings, demonstrate how stagnant the students were in the classroom initially. There was very little positive conversation between teacher and student and very few positive comments made in a 30-minute time period. After several months of modeling positive discourse by the teacher, the findings in the classrooms reflected a change. Communication was no longer stagnant, there were positive comments begin exchanged between teachers and student, and among students. Figures 1 and 2 in Chapter 4 show the rapid increase of positive comments exchanged between teacher and students over a 3-year time period. My research reports positive comments made in the classroom by either the teacher or student elicited more positive comments exchanged between the teachers and students.

My findings significant to Question 1, revealed an additional theme of perseverance. The repetition of certain words changed the culture of the school. For example when the teachers modeled how to greet another person when they entered the room, the students soon replied in the same fashion. Eventually students began to emulate this action in the classroom and around the building. This research presented the impact and the transference of positive words in a classroom. The teachers asserted that when simple words such as please, thank you, and sorry 
were spoken with meaning they made an impact on the students. The impact was a positive one resulting in students making positive comments to the teacher and other students as well.

The findings germane to Question 1 proved the positive words observed in these classrooms impacted students in a way that motivated them to speak in a more positive manner as well. This builds on Denton's (2008) research in that the teacher's words had power and made a difference in each of the students' days. The findings from this research support the idea that professional development on positive discourse changed the ways in which teachers’ communicated with their students. The findings also support that students then responded in a positive way, and reciprocated with positive comments in the classroom.

My data for Question 1 concludes that by working collaboratively as a school on positive discourse, the teachers and students increased the number of positive comments made during a 30-minute observation to almost one positive comment per minute (see Figures 1 and 2). The increase in positive discourse was evidenced by comments exchanged between teachers and students as well as among students. Many teachers commented that they began to see the results of using positive discourse play out in their classroom in the form of increased student interaction during a lesson. More students were willing to participate based on the positive exchange occurring during the lesson. One participant, Terri, said the positive comments were the glue to a successful lesson for her.

Based on the observational findings in this study relevant to Question 1, positive discourse in a classroom was described by some teacher participants as voices that lifted, inspired, encouraged, and promoted student learning and success. Other teacher participants said it could be a voice twisted with a bit of sarcasm when styled in a playful, nonthreatening way. The teacher participants continued to explain how a sarcastic tone when spoken in anger is 
hurtful to a student's ego and self-esteem. The teachers learned it was important to take a minute to collect their thoughts before speaking to students in anger.

Learning to control ones’ words was a challenge at first and some teachers continue to work on being mindful of what they say to students. These findings concur with Denton's (2008) assertion that words are powerful and can make a student feel empowered or powerless. Additionally, my findings applicable to Question 1 support the claim by Denton that students’ sense of self-efficacy can be altered based on a few words from a teacher. The findings from this research in relation to Research Question 1-How did CES professional development impact the discourse between and among teachers and students?- - support an increase in positive comments exchanged between teachers and students and among students during an activity, thereby resulting in a positive impact on teachers and students.

Research Question 2. How did the development of positive discourse impact the relationships between and among teachers and students? As my findings for Question 2 show, as a result of the increased exchange in positive discourse, the learning environment became an different classroom from the one it was before when there were few positive comments and much negative tone. The classrooms in East Elementary School became positive learning environments. This leads to the next research question: How did the development of positive discourse impact the relationships between and among the teachers and students?

The findings from this study relevant to Question 2 show how positive discourse also impacted the teacher-student relationship. In my observations, teachers’ efforts to develop relationships with students were recorded through the teachers' voices and their choice to speak positively. Speaking positively helped establish a tone of decency and trust between and among teachers and students. 
The positive discourse ratio was almost one positive student comment for every one positive teacher comment in 2010 observations. However, the positive comments recorded from the students had increased by eight times as many positive comments since 2008 in Kara’s classroom and almost 14 times as many positive student comments since 2008 in Katie’s classroom. My findings for Question 2 recorded students who were speaking positively in classrooms almost as often as their teachers were speaking positively.

As a result of teachers modeling positive comments and feedback, they provided a safe environment for students to take risks. My findings pertinent to Question 2 show that in the safe environment students began to trust their teachers and each other. Additional findings support the concept that relationships between teachers and students in this study were built based on the trust established as a result of positive communication between teachers and students. According to my observations, in the security of a trusting relationship, students were more confident to engage in the discussion and make positive comments.

The evidence of relationship building was prevalent in the classroom based on the observational findings pertinent to Question 2 of this study. Students transferred what the teacher modeled in the classroom. Students spoke positively and kindly to one another as well as to adults in the classroom. The development of CES Principle 7, a tone of decency and trust, was effective in the transference of positive teacher discourse to the students' conversations and in their relationships. The strongest impact from the findings was the amount of communication that now existed between teacher and student. Most of the comments exchanged, recorded in my data, was positive discourse. The findings significant to Question 2 in these observations coincided with the research by Irving and Fraser (1998): when students feel respected and trusted in their environment, they are more willing to share their personal thoughts and opinions. 
There were four additional themes that emerged from the interviews in response to Research Question 2. As I interpreted and reflected on teachers' thoughts, the following themes emerged in connection to building relationships between teachers and students: (a) remain calm and listen, (b) be precise with words, (c) believe in students' abilities and intentions, and (d) put words into action. My findings for Question 2 concur with Charney’s (2002) assertion that there are specific ways to convey expectations to students clearly: Keep demands short and simple; dignify words with actions; say what one means and mean what one says, and use words that invite students to solve problems and cooperate with one another. These assertions are similar to findings in my research; that each person is focused on being mindful of what they say and respectful in how they implement what is said.

The teachers at East Elementary School commented, through this experience, that they have learned to communicate and establish a relationship with their students. The teacher participants explained the importance of the following four relationship building themes. First, a teacher must remain calm and listen. The findings relevant to Question 2 show that sometimes a teacher being quiet can be as helpful as when the teacher talks to the student. Teacher participants agreed that students need time to process, speak, and solve problem situations for themselves, and it is the job of the teacher to know when to speak and when to listen.

The second theme for building a relationship with students focused on when a teacher does speak. The findings for Question 2 support that when teachers speak, they need to be precise in their words. Students look to the teacher for guidance. Teachers need to speak firmly to the student, however in any given situation their tone should remain rational. According to the teacher participants, this stance assures students the teacher cares, but is not okay with the behavior or choices the student has made. 
The findings for this theme for Question 2 suggest the teacher should never threaten, demean, or create power struggles between or among students. The participants stated they would immediately lose respect if they allowed any of these things to occur in your classroom. The findings relevant to Question 2 in the study correspond to Bondy and Ross's (2008) research that claims students perceived such rational demands as evidence of teachers' commitments to them and their relationships.

The next important theme in building a relationship, as shown in the findings pertinent to Question 2 of this study was to believe in students' abilities and intentions. The teacher participants agreed that students know when teachers are being disingenuous. Communicating with students openly, honestly, and positively allowed teacher participants to establish and build strong teacher-student relationships.

The last theme in building a relationship was having the teacher put words into actions. The findings for Question 2 show that when the teachers of East Elementary School said what they meant and meant what they said, students were able to understand their teachers’ expectations. Communicating teacher's expectations is at the center of developing and maintaining strong teacher-student relationships. Communication between teachers and students is what all of these findings pertinent to Question 2 in this study pull together as a commonality between the four relationship-building themes. As the research pointed out, communication between teachers and students should be positive or positively framed if it is negative feedback.

To answer Research Question 2-how did the development of positive discourse impact the relationships between and among the teachers and students?—-The teachers at East Elementary School continuously sought to understand the impact of their words and how to use them to strengthen their relationships with their students. The teacher participants agreed positive 
discourse helped to establish trust between themselves and their students. In return, positive communication and trust helped increase the chances of building a relationship with each student.

Research Question 3. Was the information provided by CES during the professionaldevelopment sessions sustained, as perceived by the teachers?

In Phase 2, I began looking for evidence of the sustainability of positive discourse and strong teacher-student relationships to answer Research Question 3: Was the information provided by CES during the professional-development sessions sustained, as perceived by teachers? My findings relevant to Question 3 were collected through observations and interviews and concur with Peter's (1996) assertion that long-term effects emerged after the professional development ended. My research findings for Question 3 show specifically that long-term effects of professional development are provided by teachers. It was clear that teachers were still practicing the strategies they had learned from the members of CES during their professionaldevelopment sessions. The teachers believed the information they had been taught was important and helped their students learn.

My findings relevant to Question 3 elicited that teachers play the central role when addressing the sustainability of professional development. The research in this study discussed the commitment of the teachers from the very beginning of the reorganization in 2005. The teachers had to decide if they wanted to commit to an additional 2.5 hours of time weekly to this school and its students. These findings for Question 3 coincide with a statement by Garet et al. (2001): “Teachers are necessarily at the center of reform, for they must carry out the demands of high standards in the classroom” (p. 916). 
Various types of professional-development projects are offered to support and qualify these teachers, but in this research CES was the reform model selected to provide teachers with professional development. The expected effects of the reform efforts by facilitators and participants are not only related to the professional development of individual teachers to improve teacher quality, but also to the enhancement of the quality of the entire school.

The findings in relation to Question 3 of this study show that the desired effects of all reform models are teachers who are provided support and strategies to enhance student learning. This research corresponds with a statement by Kerka (2003): “Funders, providers, and practitioners tend to agree that the ultimate goal of professional development is improved outcomes for learners” (p. 1).

My findings for Question 3 determine that teachers played a key role in sustaining the effects of the professional development. However, teachers cannot sustain those effects alone. It was important to establish a professional-learning community for support. Of the seven teachers interviewed during the study, six teachers commented that professional-development sessions were a good opportunity to grow, not only as an individual but also as a network of teachers, too. The sessions helped teachers understand the importance of developing relationships with their students and with their fellow teachers. With the establishment of relationships, instruction could be more deeply developed and instruction more personalized. Teacher participants commented on the successes of the professional-learning communities that evolved.

These finding for Question 3 concur with Hurd's (1997) assertion that teachers who created a network of resources and collaborated with one another felt successful in their classrooms. Teachers shared student artifacts and provided one another with feedback to improve their own teaching. According to the teachers in this study, professional-learning communities 
helped strengthened their confidence to implement the strategies they learned in professionaldevelopment sessions.

These findings relevant to Question 3 show how teachers strove to achieve change through professional development. In concurrence with a statement by Supovitz (2001), "High quality professional development will produce superior teaching in classrooms, which will, in turn, translate into higher levels of student achievement” (p. 81). As these research data show, teachers were committed to learning the material presented by CES and were equally committed to its continued practice in their classrooms. Additionally my findings support a claim by Hattie (2003): "It is what teachers know, do, and care about which is very powerful in this learning equation” (p. 2).

My findings applicable to Question 3 contribute that teachers are vital to the long-term positive effects of professional development in a school. Professional-development success is not only based on teacher commitment and the opportunity to select professional-development topics, it is also based on the relevance of the topic as its direct connection to the teacher and students' needs. Final conclusions for Question 3 concur with the following quote from Ingvarson, Meiers, and Beavis (2005): "Professional development for teachers is now recognized as a vital component of policies to enhance the quality of teaching and learning in our schools. Consequently, there is increased interest in research that identifies features of effective professional learning” (p. 2).

\section{Summary of Findings}

This case study presented results that described the personal experiences of the teachers who were committed to learning strategies to positively impact students. Teachers started by focusing on developing positive discourse in their classrooms. The words teachers speak can 
make a difference in the lives of their students, as well as in their learning environment at the school.

In the interviews, teacher participants cited a few basic strategies that emerged from this process to ensure a conversational tone that will support student learning and help create the positive discourse and respectful learning environment desired. Several themes emerged as teachers participants worked to establish positive discourse in their classrooms. Those themes were remain calm and listen, be precise with words, believe in students’ abilities and intentions; and conform word to actions. Teachers used these strategies to develop positive discourse in their classrooms. The common thread was that teacher needed to communicate expectations to students in a positive way. These findings concur with Denton's (2008) assertion that teachers need to use words carefully to help create a positive learning environment where students can succeed academically and socially.

How a teacher said things mattered, but what students believed about their teachers’ intentions mattered more (Bondy \& Ross, 2008; Irving \& Fraser, 1998). The words from the teacher were communicated in a calm voice, communicating the belief the students wanted to, and knew how to, listen, cooperate, and perform quality work. This increased the chance that students saw themselves as respectful listeners, cooperative people, and competent workers, ready to learn. The teachers needed to take time to seek the positive; then make positive comments to students. Teachers were the constant observers, with a positive eye.

Teachers in this study believed the impact that CES had made on East Elementary School has been sustained over the past few years. In the interviews there was a common thread connecting teachers on why they believed this idea of developing positive discourse and building relationships had sustainability. When I probed more deeply in the final interviews and asked, 
the teachers agreed, it was because each of them committed to the idea of professional development and specifically to the importance of building positive discourse and relationships in their classrooms.

\section{Conclusions}

This study presented results from Phase 1, preliminary observations and interviews, and Phase 2, observations and interviews, as well as results from a final survey. All findings were presented through a qualitative lens. The study described the personal experiences of teachers who were committed to professional development designed to make a difference in this struggling school. This research provides evidence that the short-term and long-term effects of the CES professional development can be considered to be sustainable.

After CES professional-development sessions ended, teachers continued to maintain the level of expertise with the knowledge learned from CES. This research determined that teachers are the key to the sustainability of the professional development. When they are able to see the benefits and effects of the professional development and how it directly impacted their students, they were committed to learning the ideas presented.

According to these findings, sustainability itself cannot be definitively defined as the lasting continuation of achieved benefits and effects of a reform model or professionaldevelopment sessions beyond its last session. These findings concur with Fullan’s (2006) assertion that short-term effects are "necessary to build trust with the public or shareholders for longer-term investments” (p. 120). Besides these short-term effects, long-term effects also need to be considered; otherwise the result could be to "win the battle, [but] lose the war" (Fullan, 2006, p. 120). 
Perhaps the fact that teachers were still implementing CES strategies a year after the program ended can be attributed to the sustainability of the CES program. However this study asked about the long-term effects of CES professional development and the findings state the sustainability of the CES concepts are based strictly on the efforts of the teachers at East Elementary School. They believed in the program and the results they saw with their students and therefore were willing to maintain their efforts to continue to implement the strategies learned with CES after the program ended.

Hargreaves and Fink (2003) stated, “Sustainable improvement requires investment in building long term capacity for improvement, such as the development of teachers' skills, which will stay with them forever, long after the project money has gone” (p. 3). Student learning was also dependent on the development of teachers' skills. Killion (2002) of the NSDC described the importance of professional development as “deeper content knowledge, more content-specific instructional strategies, and greater understanding about how students learn. This enables teachers to craft instruction to meet the varying needs of students and help them to achieve rigorous content standards” (Killion, 2002, p. 16).

Strong professional development, such as the sessions by CES, helped provide the instructional support teachers needed to strengthen their skills, and content knowledge base as much as it developed their instructional delivery. Both were extremely demanding, but necessary. The effectiveness of a skilled teacher was extremely important.

Several researchers (Governor's Commission on Quality Education in Maryland, 2005; McFarland, 2005; Rényi, 1996; Sparks, 1994, 1998 ) reported that the single largest factor affecting academic growth of student populations was the difference in the effectiveness of individual classroom teachers. Available research on learning and student achievement 
demonstrates the necessity for educators to keep informed about improved methodologies to meet students' diverse cultural and academic needs and to connect pedagogy with subject-matter content. Educators needed more opportunities to refine their conceptual knowledge of the content and to maintain their craft.

Most teachers would agree that the objective of professional development is to improve teaching and ultimately enhance student learning. Researchers (Fullan, 2004; Lieberman \& Grolnick, 2005; Lieberman \& Wood, 2002; Shulman,1987; Sparks, 1994) stressed the importance of teacher expertise in improving student learning. Good instruction requires that teachers have strong knowledge of the subjects they teach, a repertoire of instructional skills to teach the content, knowledge about their students, and attitudes that encourage high levels of learning for their students. High quality teachers are produced from high-quality professionaldevelopment sessions.

Ensuring that high-quality professional development is accessible and valuable to teachers of the most vulnerable and at-risk students should be a schoolwide priority (Corcoran, 1995). State education policy needs to support professional development for new and practicing educators. Retaining and supporting high-quality teachers requires a comprehensive system of professional development. The Maryland Teacher Professional Development Advisory Council (2004) reported that insufficient time, support, and incentives mean many teachers lack adequate access to professional-development opportunities. The Council (2004) defined, in nine standards, what it considers to be high-quality professional development:

1. deepens teachers’ content knowledge;

2. ensures that all teachers have research-based skills and knowledge;

3. ensures teachers are prepared to collaborate with others; 
4. ensures all teachers are able to meet the diverse learning needs of students;

5. ensures that teachers can create safe, secure, and supportive learning environments;

6. ensures teachers have the ability and disposition to involve families and community members in education;

7. relies on the analysis of data;

8. employs rigorous evaluation to assess its impact on teaching and student learning;

9. reflects best practices in how and why adults learn.

Researchers have documented the inadequacies of typical professional-development programs and as a result have suggested changes in policy and practices to construct highquality professional development and provide for improved teacher learning (Ball \& Cohen, 1999; Borasi \& Fonzi, 2002; Elliott; 2005; Hawley \& Valli, 1999). While these nine standards of professional development are important, the overarching idea here is teacher commitment to the program. The sustainability of the CES professional-development sessions was based on the teachers who believed in the information presented in the sessions. The CES 10 common principles, described by CES were considered best practices by the teachers. The CES principles are still highly effective and practiced at East Elementary School today.

Even though this research supports the success of one school to sustain the information presented through professional-development sessions, the implications of sustaining professional development continues to plague education researchers. In the last few years, numerous surveys, studies, and reports have been conducted and published providing some context to this complicated problem that seems to have the greatest impact on instruction in high-poverty, highminority school districts (Ed.gov, 2010). East Elementary School is a high-poverty, highminority school. Findings from this research supported the idea that East Elementary School 
should continue to be engaged in professional development. It provided instructional support for its teachers and in turn benefitted its students.

This study looked at professional development as part of a reform model. Research indicated a strong need for incorporating professional development into a well-orchestrated reform effort (Craig, 2006; Elmore, 2002; Fishman \& Marx, 2001; Fullan, 2001b; Lieberman \& Grolnick, 2005; Senge et al., 2000). These efforts should be supported by policymakers, and teaching must be treated as a learning profession requiring renewal of professional-development experiences for teacher recertification (Ball \& Cohen, 1999).

\section{Implications for Future Practice}

Research Question 1. How did CES professional development impact the discourse between and among teachers and students?

The professional development provided by CES taught teachers how to establish an exchange of positively discourse in their classrooms. The professional-development sessions provided examples for the teachers of how to reframe a negative comment positively. The findings for both the teachers and students increased significantly between 2008 and 2010 with this new found positivity in the classroom.

The implications are that the teachers' positive discourse led to the changes in the positive comments exchanged between the students. Yet another interpretation was that teachers began to see the benefits of the positive discourse and began to increase the use of positive comments to get more positive interactions from their students. The significant gains recorded in the number of positive comments by the students highlighted the importance of teachers modeling the expected behavior. Another consideration for the student increase was that students may have seen the positive feedback other students were receiving from teachers for making 
positive comments. Therefore students may have decided to speak positively based on whether they wanted praise from the teacher. The teachers could have unconsciously affected the students' growth by providing them with or without feedback or encouragement.

Research Question 2. How did the development of positive discourse impact the relationships between and among the teachers and students?

The development of positive discourse helped teachers establish relationships with students. Once students began to trust teachers and believe they were invested in their futures, relationships began to develop. Communicating expectations in a positive manner was at the core of building relationships with students.

The implications are that the changes in how teachers and students communicated with one another were associated with professional-development strategies learned from CES, that led to the building of relationships between teachers and students. Another interpretation based on teacher comments and interactions is that teachers had to learn that some words hurt. A teacher who has a sarcastic personality had to learn how to use words carefully. Relationships were lost or not even started because of teacher's sarcastic comments. Students are led to believe adults can be trusted, however it was implied that the students were confused when teachers were not specific with their words or mindful of what they said. Being precise with their words was important to the students.

Research Question 3. Was the information provided by CES during the professionaldevelopment sessions sustained, as perceived by the teachers?

The information provided by CES during the professional-development sessions was sustained, as perceived by the teachers. The teachers who were interviewed and observed in both phases of this research were practicing strategies developed and introduced by CES. 
All seven teacher participants in Phase 1 and Phase 2 of this study had participated in at least one year of professional development with CES. However, the survey results included more than the seven teacher participants. The survey included all teachers at East Elementary School in the fall of 2011. There were teachers providing feedback about CES who had never attended a CES professional-development session.

The findings related to Question 3 show there were teachers who had never worked with CES who felt proficient in using the strategies specific to CES. The implication is that teachers continued to share strategies such as protocols, essential questions, and relationship-building strategies previously taught in the CES professional-development sessions. The survey findings showed that the teachers felt they were improving or strong when it came to their understanding of best practices provided from professional-development sessions. Overall the interviews, observations, and survey provided strong support for the argument that teachers continue to practice strategies introduced to them by CES. Professional development had been sustained, as perceived by the teachers at East Elementary School.

\section{Future Research}

School systems are allotting large portions of money to local school systems to provide the professional development needed (Malen, Croninger, Muncey, \& Redman-Jones, 2002). The selection of the professional-development program needs to support the needs of the teachers as much as the needs of the students. The teachers need to believe the professional development has been designed for them (Borko, 2004), and is designed to help them meet the needs of the students in their classrooms. Teacher commitment to professional development is important to its success and sustainability. As this study demonstrated, teachers are important in sustaining the information shared in professional-development sessions; however, they are not the only factor 
in sustaining the information. Further research could prove the necessity for additional areas of study:

1. Do different professional-development models have different sustainable impacts?

2. Does a professional-development model result in a different sustainable impact on different participating teachers?

3. Does the amount of time the professional-development model remains in the school impact its sustainability?

4. In what ways can a model increase teacher commitment to its professional development?

\section{Concluding Remarks}

In the professional-development sessions, teachers commented when they felt empowered in their learning; they were committed to their learning. When the sessions were focused on providing them with strategies and best practices they could take back directly to their classrooms and implement, teachers were committed to learning. When teachers are provided with a tool they can use immediately, there is a greater chance they will use it (Guskey, 2003). If a teacher were asked to reflect on what happened after using that tool, there is a greater chance the teacher will grow from sharing that experience.

In this research, the formula for success and sustainability from professionaldevelopment sessions was a combination of teacher and time. Incorporating the teacher into the planning of the professional development increases the chance of teacher commitment to the sessions. Teacher input was crucial for topics of discussion. Teacher input was imperative when debriefing on successes and failures. Teacher input was necessary to define the needs of their students (Lieberman \& Miller, 2001). 
All teacher input needed to be coupled with time: time to process, discuss, and implement leads to success and sustainability of the practices shared by the members of CES through their professional-development sessions. Even when the support from CES ended, continued instructional support efforts provided teachers time to reflect on practice, examine student work, and make changes that improve learning for their students. This allowed teachers to sustain the information learned in professional-development sessions. Allowing teachers to be active participants and providing reflection time about topics discussed during professionaldevelopment sessions was imperative to the sustainability of the material learned (Servage, 2008).

“Too many resources are invested in professional development to ignore its impact over time” (Loucks-Horsley, Stiles, \& Hewson, 1996, p. 5). Despite its central importance, research on this issue is generally lacking (Rogers, 2003) and "few studies have actually examined the sustainability of reforms over long periods of time” (Datnow, 2006, p. 133). Hargreaves (2002) summarized the situation as follows:

As a result, many writers and reformers have begun to worry and write about not just how to effect snapshots of change at any particular point, but how to sustain them, keep them going, make them last. The sustainability of educational change has, in this sense, become one of the key priorities in the field. (p. 120) 


\section{References}

Allington, R. L. (2008). What really matters in response to intervention. Boston, MA: Allyn \& Bacon.

Arce, J., Luna, D., Borjian, A., \& Conrad, M. (2005). No Child Left Behind: Who wins? Who loses? Social Justice, 32(3), 56-71.

Avalos, B. (2010). Teacher professional development in Teaching and Teacher Education over ten years. Teaching and Teacher Education, 27, 10-20.

Ball, D. L., \& Cohen, D. K. (1999). Developing practice, developing practitioners: Toward a practice-based theory of professional development. In L. Darling-Hammond \& G. Skyes (Eds.), Teaching as the learning professional: Handbook of policy and practice (pp. 332). San Francisco, CA: Jossey-Bass.

Beasley, W. (2000). Systemic reform through teacher change: Congruence and contradiction. Teaching Education, 11, 39-45.

Blank, R. K., de las Alas, N., \& Smith, C. (2007). Analysis of the quality of professional development programs for mathematics and science teachers. Washington, DC: Council of Chief State School Offices.

Borasi, R., \& Fonzi, R. (2002). Professional development that supports school mathematics reform. Arlington, VA: National Science Foundation.

Borko, H. (2004). Professional development and teacher learning: Mapping the terrain. Educational Researcher, 33(8), 3-15.

Borko, H., \& Mayfield, V. (1995). The roles of cooperating teacher and university supervisor in learning to teach. Teaching \& Teacher Education, 11, 501-517. 
Borko, H., \& Putnam, R. T. (1995). Expanding a teachers’ knowledge base: A cognitive psychological perspective on professional development. In T. Guskey \& M. Huberman (Eds.) Professional development in education: New paradigms and practices (pp. 35-65). New York, NY: Teachers College Press.

Borman, G. D., Hewes, G. M., Overman, L. T., \& Brown, S. (2003). Comprehensive school reform and achievement: A meta-analysis. Review of Educational Research, 73, 125-230.

Brophy, J. (1991). Teachers' knowledge of subject matter as it relates to their teaching practice: Advances in research in teaching. Greenwich, CT: JAI Press.

Bussis, A., Chittenden, E., \& Amarel, M. (1976). Beyond surface curriculum. Boulder, CO: Westview Press.

Center on Education Policy. (2005). How have high school exit exams changed our schools? Some perspectives from Virginia and Maryland. Retrieved from http://www.google.com /url?q=http://www.cep-dc.org/cfcontent_file.cfm\%3FAttachment\%3DGayler_HSEEVAandMD_060905.pdf\&sa=U\&ei=UgdhT4ypHZOJtwes9ayuBQ\&ved=0CAQQFjAA\& client=internal-uds-cse\&usg=AFQjCNGEMAwuxbLFykHyeNj3x5mvZUFFmA

Chappuis, S., Chappuis, J., \& Stiggins, R. (2009). Supporting teacher learning teams: The learning-team model helps teachers make changes in practice that lead to improved student achievement. Educational Leadership, 66(3), 56-60.

Charney, R. (2002). Teaching children to care: Classroom management for ethical and academic growth K-8 (2nd ed.). Turners Fall, MA: Northeast Foundation for Children. Cheung, K. C. (1990). To grow and glow: Towards a model of teacher education and professional development. East Lansing, MI: National Center for Research on Teacher Learning. (ERIC Document Reproduction Services No. ED338575) 
Cochran, K. F., King, R. A., \& Deruiter, J. A. (1994). Pedagogical content knowledge: A tentative model for teacher preparation. East Lansing, MI: National Center for Research on Teacher Learning.

Cochran-Smith, M. (2003). Learning and unlearning: The education of teacher educators. Teaching and Teacher Education, 19, 5-23.

Corcoran, T. B. (1995). Helping teachers teach well: Transforming professional development. CPRE Policy Briefs, 16, 69-79.

Cotterill, P., \& Letherby, G. (1993). Weaving stories: Personal auto/biographies in feminist research. Sociology, 27, 67-79.

Covey, S. R. (1989). The seven habits of highly effective people: Powerful lessons in personal change. New York, NY: Simon \& Schuster.

Craig, C. L. (2006). Why is dissemination so difficult? The nature of teacher knowledge and the spread of curriculum reform. American Educational Research Journal, 43, 257-293.

Cuban, L., \& O’Neil, J. (2000). Fads and fireflies: The difficulties of sustaining change. Educational Leadership, 57(7), 6-9.

Darling-Hammond, L., \& Ball, D. (1999). Teaching for high standards: What policymakers need to know and be able to do. Philadelphia, PA: Consortium for Policy Research in Education, National Commission on Teaching for America's Future.

Darling-Hammond, L., \& Bransford, J. (2005). Preparing teachers for a changing world: What teachers should learn and be able to do. San Francisco, CA: Jossey-Bass.

Darling-Hammond, L., \& McLaughlin, M. W. (1995). Policies that support professional development in an era of reform. Phi Delta Kappan, 76, 206-212. 
Darling-Hammond, L., \& Richardson, N. (2009). Teacher learning: What matters? Educational Leadership, 66(5), 46-53.

Darling-Hammond, L., \& Sykes, G. (1999). Teaching as the learning profession: Handbook of policy and practice. San Francisco, CA: Jossey-Bass.

Datnow, A. (2005). The sustainability of comprehensive school reform models in changing district and state contexts. Educational Administration Quarterly, 41, 121-153.

Datnow, A. (2006). Comments on Michael Fullan's, “The future of educational change: System thinkers in action.” Journal of Educational Change, 7, 133-135.

Datnow, A., \& Stringfield, S. (2000). Working together for reliable school reform. Journal of Education for Students Placed At Risk, 5, 183-204.

Denton, P. (2007). The power of words: Teacher language that helps children learn. Turner Falls, MA: Northeast Foundation for Children.

Denton, P. (2008). The power of our words. Educational Leadership, 66(1), 28-31.

Denzin, N. (1989). Interpretive interactionism. Newbury Park, CA: Sage.

Desimone, L. M, Porter, A. C., Garet, M. S., Yoon, K. S., \& Birman, B. F. (2002). Effects of professional development on teachers' instruction: Results from a three-year longitudinal study. Educational Evaluation and Policy Analysis, 24, 81-112.

Dewey, J. (1902). The child and the curriculum. Chicago, IL: University of Press.

Dewey, J. (1927). The public and its problems. In A. Boydston (Ed.), The collected works of John Dewey. Cambridge, MA: Harvard University Press.

Dewey, J. (1938). Experience and education. New York, NY: Collier.

Dewey, J. (1956). The child and the curriculum and the school and society. New York, NY: Dover. (Original work published 1902) 
Ed.gov. (2010). Comprehensive School Reform Program. Title I Part F. Retrieved from http://www2.ed.gov/programs/find/title/index.html?src=ln

Eichelberger, R. (1989). Disciplined inquiry: Understanding and doing educational research. White Plains, NY: Longman.

Elliott, R. L. (2005, April). Professional development of professional developers: Using practice-based materials to foster an inquiring stance. Paper presented at a conference of the American Educational Research Association, Montreal, Canada.

Elmore, R. F. (2000). Building a new structure for school leadership. Washington, DC: Albert Shanker Institute.

Elmore, R .F. (2002). Bridging the gaps between standards and achievement. Washington, DC: Albert Shanker Institute.

Elmore, R. F., \& Burney, D. (1999). Investing in teacher learning: Staff development and Instructional improvement. In L. Darling-Hammond \& G. Kykes (Eds.), Teaching as the learning profession: Handbook of policy and practice (pp. 236-291). San Francisco, CA: Jossey-Bass.

Elmore, R., \& Fuhrman, S. (1993). Opportunity to earn and the state role in education. In The debate on opportunity-to-learn standards: Commissioned papers. Washington, DC: National Governors Association.

Fetterman, D. M. (2010). Ethnography: Step by step (3rd ed.). Thousand Oaks, CA: Sage.

Fisher, D., \& Frey, N. (2008). Releasing responsibility: We must transfer responsibility for learning to our students gradually_and offer support at every step. Educational Leadership, 66(3), 32-37. 
Fishman, B., \& Marx, R. (2001). Design research on professional development in a systemic reform context. Seattle, WA: American Educational Research Association.

Forget, M. (2004). MAX teaching with reading and writing: Classroom activities for helping students learn new subject matter while acquiring literacy skills. Victoria, Canada: Trafford.

Franke, M. L., Carpenter, T. P., Levi, L., \& Fennema, E. (2001). Capturing teachers’ generative change: A follow-up study of professional development in mathematics. American Educational Research Journal, 38, 653-689.

Freire, P. (1970). Pedagogy of the oppressed. New York, NY: Continuum.

Fullan, M. (2001a). Leading in a culture of change. San Francisco, CA: Jossey-Bass.

Fullan, M. (2001b). The new meaning of educational change (3rd ed.). New York, NY: Teachers College Press.

Fullan, M. (2004). School reform from the inside out: Policy, practice, and performance. Cambridge, MA: Harvard Education Press.

Fullan, M. (2006).The future of educational change: System thinkers in action. Journal of Educational Change, 7, 113-122.

Gadamer, H. G. (1975). Truth and method. New York, NY: The Seabury Press.

Garet, M., Porter, A., Desimone, L., Birman, B., \& Yoon, K. (2001). What makes professional development effective? Results from a national sample of teachers. American Educational Research Journal, 38, 915-945.

Gerring, J. (2007). Case study research: Principles and practices. Cambridge: Cambridge University Press. 
Goertz , M. E. (2001). The federal role in defining “adequate yearly progress”: The flexibility/accountability trade-off. Retrieved from http://www.cpre.org/federal-role -defining-adequate-yearly-progress-flexibilityaccountability-trade

Governor's Commission on Quality Education in Maryland. (2005). September 2005 report. Retrieved from http://www.msa.md.gov/megafile/msa/speccol/sc5300/sc5339/000113 /000000/000600/unrestricted/20050867e.pdf

Greene, M. (2001). Educational purposes and teacher development. In A. Lieberman \& L. Miller (Eds.), Teachers caught in the action: Professional development that matters (pp. 3-11). New York, NY: Teachers College Press.

Greenwald, R., Hedges, L., \& Laine, R. (1996). Interpreting research on school resources and student achievement: A rejoinder to Hanushek. Review of Educational Research, 66, 411-416.

Guskey, T. R. (1995). Professional development in education: In search of the optimal mix. In T. R. Guskey \& A. M. Huberman (Eds.), Professional development in education: New paradigms and practices (114-131). New York, NY: Teachers College Press.

Guskey, T. R. (1998). The age of accountability. Journal of Staff Development, 19(3), 37-43. Guskey, T. R. (2003). What makes professional development effective? Phi Delta Kappan, 85, 748-750.

Hammerness, K. (2001). Teachers’ visions: The role of personal ideals in school reform. Journal of Educational Change, 2, 143-163.

Hargreaves, A. (1995). Teachers’ work and the politics of time and space. Qualitative Studies in Education, 3, 303-320. 
Hargreaves, A. (2002). Sustainability of educational change: The role of social geographies. Journal of Educational Change, 3, 189-214.

Hargreaves, A. (Ed.). (2005). Extending educational change: International handbook of educational change. Dordrecht, The Netherlands: Springer.

Hargreaves, A., \& Fink, D. (2003). Sustaining leadership. Phi Delta Kappan, 84, 693-700.

Harper, D. (1988). Visual sociology: Expanding sociological vision. The American Sociologist, 54.

Harris, A. ( 2003). Behind the classroom door: The challenge of organizational and pedagogical change. Journal of Educational Change, 4, 369-382.

Hart, B., \& Risley, T. R. (1995). The early catastrophe: The 30 million word gap by Age 3. American Educator. Retrieved from http://www.aft.org/pubs-reports/american_educator /spring2003/catastrophe.html

Hartoonian, M., \& Laughlin, M. A. (1995). Social studies standards: A pathway to professional development. Social Studies and the Young Learner, 7, 30-32.

Haslam, M. B., Afolabi, K., \& Hewes, G. M. (2005). Maryland survey of teacher participation in high quality professional development, 2003-2004. Washington, DC: Policy Studies Associates.

Hattie, J. (2003, October). Teachers make a difference. What is the research evidence? Paper presented at the conference of the Australian Council of Educational Research: Building Teacher Quality. Melbourne, Australia. Retrieved from http://www.education.auckland .ac.nz/webdav/site/education/shared/hattie/docs/teachers-make-a-difference-ACER(2003).pdf 
Hawley, W. D., \& Valli, L. (1999). The essentials of effective professional development: A new consensus. In L. Darling-Hammond \& G. Sykes (Eds.) Teaching as the learning profession: Handbook of policy and practice (pp. 127-150). San Francisco, CA: JosseyBass.

Haynes, N. (1998). Overview of the Comer School development program. Journal of Education for Students Placed at Risk, 3, 3-11.

Heller, R., \& Greenleaf, C. (2007). Literacy instruction in the content area: Getting to the core of middle and high school improvement. Washington, DC: Alliance for Excellent Education.

Hong, L. K. (1996). Surviving school reform: A year in the life of one school. New York, NY: Teachers College Press.

Hopfenberg, W. S., \& Levin, H. M. (1993). The accelerated schools resource guide. San Francisco, CA: Jossey-Bass.

Hord, S. (1997). Professional learning communities: Communities of continuous inquiry and improvement. Austin, TX: Southwest Educational Development Laboratory.

Hoskins, M. (1995). Constructivist approaches for career counselors. Retrieved from ERIC database. (ED401505)

Huberman, M. (1999). The mind is its own place: The influence of sustained interactivity with practitioners on educational researchers. Harvard Educational Review, 69, 289-319.

Hurd, P. D. (1997). Scientific literacy: New minds for a changing world. Retrieved from http:// nuwrite.northwestern.edu/communities/science-writing-community/docs/science-writingassignments-grading/general-science-writing-skills/pedagogical-articles-research -studies/on-science-literacy/Hurd_scientific\%20literacy.pdf 
Husserl, E. (1962). Ideas. New York, NY: Collier. (Original work published 1913)

Ingvarson, L., Meiers, M., \& Beavis, A. (2005). Factors affecting the impact of professional development programs on teachers’ knowledge, practice, student outcomes and efficacy. Education Policy Analysis Archives, 13(10), 1-28.

Irving, J. J., \& Fraser, J. W. (1998). Warm demanders. Education Week, 17(35), 56-58.

Kalin, J., \& Zuljan, M. V. (2007). Teacher perceptions of the goals of effective school reform and their role in it. Educational Studies, 33, 163-175.

Kennedy, E. (2010). Improving literacy achievement in a high-poverty school: Empowering classroom teachers through professional development. Reading Research Quarterly, 45, 384-387.

Kerka, S. (2003). Does adult educator professional development make a difference? Myths and Realities, 28, 1-2.

Killion, J. (2002). What works in high schools: Results-based staff development. Oxford, OH: National Staff Development Council.

Knapp, M. S. (2003). Professional development as policy pathway. Review of Research in Education, 27, 109-157.

Ladson-Billings, G. (2006). From the achievement gap to the education debt: Understanding achievement in U.S. schools. Education Researcher, 35(7), 3-12.

Lewis, A. (2002). School reform and professional development. Phi Delta Kappan, 83, 488-489.

Lieberman, A., \& Grolnick, M. (2005). Educational reform networks: Changes in the forms of reform. In M. Fullan (Ed.), Fundamental change: International handbook of educational change (pp. 40-59). Dordrecht, The Netherlands: Springer. 
Lieberman, A., \& Miller, L. (2001). Teachers caught in the action: Professional development that matters. New York, NY: Teachers College Press.

Lieberman, A., \& Wood, D. R. (2002). Inside the national writing project: Connect network learning and classroom teaching. New York, NY: Teachers College Press.

Little, J. W. (2001). Professional development in pursuit of school reform. In A. Lieberman \& L. Miller (Eds.), Teachers caught in the action: Professional development that matters (2344). New York, NY: Teachers College Press.

Loucks-Horsley, S., Stiles, K., \& Hewson, P. (1996). Principles of effective professional development for mathematics and science education: A synthesis of standards. Madison: University of Wisconsin at Madison, National Institute for Science Education.

Louis, K. S., \& Kruse, S. D. (1995). Professionalism and community: Perspectives on reforming urban schools. Thousand Oaks, CA: Corwin Press.

Louis, K. S., Marks, H. M., \& Kruse, S. (1996). Professional community in restructuring schools. American Educational Research Journal, 33, 757-798.

Magnusson, S., Krajcik, J., \& Borko, H. (1999). Nature, sources, and development of pedagogical content knowledge for science teaching. In J. Gess-Newsome \& N. G. Lederman (Eds.), Examining pedagogical content knowledge (pp. 95-132). Dordrecht, The Netherlands: Kluwer Academic.

Malen, B., Croninger, R., Muncey, D., \& Redmond-Jones, D. (2002). Reconstituting schools: “Testing” the "theory in action,” Education Evaluation and Policy Analysis, 24, 113-132.

Marks, H. M., \& Louis, K. S. (1997). Does teacher empowerment affect the classroom? Educational Evaluation and Policy Analysis, 19, 245-275. 
Maryland Report Card. (2010). Statistical abstract for all Maryland schools. Retrieved from http://www.mdreportcard.org/AypIntro.aspx?AypPV=14:0:21:1701:3:000000

Maryland Teacher Professional Development Advisory Council. (2004a). Helping teachers help all students: The imperative for high-quality professional development. Baltimore, MD: Maryland State Department of Education.

McFarland, M. A. (2005, April). Review of social studies research and literature, 1995-2005. Report submitted to the Maryland Social Studies Task Force, Baltimore, MD.

McLaughlin, M., \& Mitra, D. (2001). Theory-based change and change-based theory: Going deeper, going broader. Journal of Educational Change, 2, 301-323.

Meier, D., \& Wood, G. (Eds.) (2004). Many children left behind: How the No Child Left Behind Act is damaging our children and our schools. Boston, MA: Beacon Press.

Merriam, S. B. (1998). Qualitative research and case study applications in education. (Rev. ed.). San Francisco: Jossey-Bass.

Merriam, S. (2002). Qualitative research in practice: Examples for discussion and analysis. San Francisco, CA: Jossey-Bass.

Miles, M. B. \& Huberman, A. M.(1994). Qualitative data analysis: An expanded sourcebook. Thousand Oaks, CA: SAGE Publications.

Moffet, C. (2000). Sustaining change: The answers are blowing in the wind. Educational Leadership, 57(7), 35-38.

Montessori, M., \& George, A. E. (1912). The Montessori method. New York, NY: Frederick A. Stokes. 
Mosenthal, J., Lipson, M., Mekkelsen, J., Russ, B., \& Sortino, S. (2001). Elementary Schools where students succeed in reading. East Lansing, MI: National Center for Research on Teacher Learning. (ERIC Document Reproduction Service No. ED459443).

Moustakas, C. (1994). Phenomenological research methods. Thousand Oaks, CA: Sage.

Muncey, D. E., \& McQuillan, P. J. (1996). Reform and resistance in schools and classrooms: An ethnographic view of the Coalition of Essential Schools. New Haven, CT: Yale University Press.

National Council for the Accreditation of Teacher Education. (2004). NCATE 2000 standards. Washington, DC: Author.

National Science Teachers Association. (1999). NSTA position statement. Arlington, VA: Author.

National Staff Development Council. (2008). Standards for professional learning. Retrieved from http://www.learningforward.org/standards/standards.cfm

Newmann, F. M., Smith, B., Allensworth, E., \& Bryk, A. S. (2001). Instructional program coherence: What it is and why it should guide school improvement policy. Educational Evaluation and Policy Analysis, 23, 297-321.

Noddings, N. (1984). Caring: A feminine approach to ethics and moral education. Berkeley: University of California Press.

Noddings, N. (1999). Renewing democracy in schools. Phi Delta Kappan, 80, 579-583. No Child Left Behind Act, PL 107-110. Retrieved from http://www.ed.gov/policy/elsec/leg /esea02/index.html

Organization for Economic Cooperation and Development. (2001). Schooling for tomorrow: What schools for the future? Paris: Author. 
Palmer, P. (1998). The courage to teach: Exploring the inner landscape of a teacher's life. San Francisco, CA: Jossey-Bass.

Patton, M. Q. (2002). Qualitative research \& evaluation methods (3rd ed.). Thousand Oaks, CA: Sage.

Payne, R. K. (1996). A framework for understanding poverty (4th rev. ed.). Highlands, TX: aha!Process.

Perez, M., Anand, P., Speroni, C., Parrish, T., Esra, P., Socias, M., \& Gubbins, P. (2007). Successful California schools in the context of educational adequacy. Washington, DC: American Institute for Research.

Pinar, W. F., Reynolds, W. M., Slattery, P., \& Taubman, P. M. (2004). Understanding curriculum: An introduction to the study of historical and contemporary curriculum discourses. New York, NY: P. Lang.

Rényi, J. (1996). Teachers take charge of their learning: Transforming professional development for student success. Washington, DC: The National Education Association Foundation. Retrieved from http://www.neafoundation.org/publications/takecharge.htm

Riley, R., Smith, M., Ginsburg, A., \& Plisko, V. (1999). Hope for urban education: A study of nine high-performing, high-poverty, urban elementary schools. Austin: The University of Texas, The Charles A. Dana Center.

Rogers, E. (2003). Diffusion of innovations. New York, NY: The Free Press.

Rose, M. (2010). Reform: To what end? Educational Leadership, 67(7), 6-11.

Ross, S. M., Stringfield, S., Sanders, W. L., \& Wright, S. P. (2003). Inside systemic elementary school reform: Teacher effects and teacher mobility. School Effectiveness and School Improvement, 14, 73-110. 
Sakofs, M. (1995). Developing a teacher development model: A work in progress. Journal of Experimental Education, 18, 128-132.

Saphier, J., \& Gower, R. (1997). The skillful teacher: Building your teaching skills. Carlisle, MA: Research for Better Teaching.

Saunders, W. (1994). Elements of improvement in secondary science teacher preparation. Journal of Science Teacher Education, 5, 146-151.

Saxe, G., Gearhart, M., \& Nasir, N. S. (2001). Enhancing students’ understanding of mathematics: A study of three contrasting approaches to professional support. Journal of Mathematics Teacher Education, 4, 55-79.

Schubert, W. (1995) Toward lives worth living and sharing: Historical perspective on curriculum coherence. In J. Beane (Ed.), Toward a coherent curriculum (pp. 146-157). Alexandria, VA: Association for Supervision and Curriculum Development.

Schwab, J., \& Harper, W. R. (1969). The practical: A language for curriculum. Washington, DC: National Educational Association Center for Study of Instruction.

Senge, P., Cambron-McCabe, N., Lucas, T., Dutton, J., \& Kleiner, B. (2000). Schools that learn. New York, NY: Doubleday.

Servage, L. (2008). Critical and transformative practices in professional learning communities. Teacher Education Quarterly, 35(1), 63-77.

Shulman, L. S. (1987). Knowledge and teaching: Foundation of the new reform. Harvard Educational Review, 57, 1-22.

Sizer, T. (1984). Council on 21st century learning. Retrieved from: http://www.essentialschools.org/pub/ces_docs/about/phil/10cps/10cps.html Sizer, T. R. (1996). Horace’s hope. New York, NY: Houghton Mifflin. 
Slavin, R., \& Madden, N. (2001). One million children: Success for all. Thousand Oaks, CA: Corwin.

Sparks, D. (1994). A paradigm shift in staff development. Journal of Staff Development, 15(4), 26-29.

Sparks, D. (1998). Teacher expertise linked to student learning. Results. Retrieved from http:// www.nsdc.org/library/results/4-98sparks.html

Spillane, J. (2002). Local theories of teacher change: The pedagogy of district policy and programs. Teachers College Record, 104, 377-420.

Stake, R.E. (1994). Case studies. In N.K. Denzin \& Y.S. Lincoln (Eds.) Handbook of Qualitative Research Handbook of Qualitative Research, (pp. 236-247). London: Sage Publications, Inc.

Stein, M. K., Smith, M. S., \& Silver, E. A. (1999). The development of professional developers: Learning to assist teachers in new settings in new ways. Harvard Educational Review, 69, 237-269.

Stigler, J., \& Hiebert, J. (1999). The teaching gap. New York, NY: The Free Press.

Summers, J. J. (2006). Effects of collaborative learning in math on sixth graders' individual goal orientations from a socioconstructivist perspective. Elementary School Journal, 106, 273-290.

Supovitz, J. A., Mayer, D. P., \& Kahle, J. B. (2000). Promoting inquiry-based instructional practice: The longitudinal impact of professional development in the context of system reform. Educational Policy, 14, 331-356.

To transform. (2004). In A. Soukhanov (Ed.), Encarta Webster's Dictionary of the English Language (2nd ed., p. 2208). New York, NY: Bloomsbury. 
Totten, S., Sills, T., Digby, A., \& Russ, P. (1991). Cooperative learning: A guide to research. New York, NY: Garland.

Van Manen, M. (1990). Researching lived experiences: Human science for an action sensitive pedagogy. New York, NY: State University of New York.

Van Manen, M. (1997). From meaning to method. Qualitative Health Research, 7, 345-396.

Vaznis, J. (2011). An untimely turn in a school turnaround. Globe Newspaper Company. Retrieved from http://www.boston.com/news/local/massachusetts/articles

Vygotsky, L. (1978). Mind in society. Cambridge, MA: Harvard University Press.

Warren Little, J., \& McLaughlin, M. (Eds.). (1993). Teachers’ work: Individuals, colleagues, and context. New York, NY: Teachers College Press.

Weissglass, J. (1994). Changing mathematics teaching means changing ourselves: Implications for professional development. In D. B. Aichele \& A. F. Coxford (Eds.), Professional development for teachers of mathematics (pp. 67-78). Reston, VA.: National Council of Teachers of Mathematics.

Wenglinksky, H. (2000). How teaching matters: Bringing the classroom back into discussions of teacher quality. Princeton, NY: Milken Family Foundation and Educational Testing Service.

Winerman, L. (2005). The mind’s mirror. Monitor on Psychology, 36(9), 48-49.

Wolk, S. (2008). Joy in school. Educational Leadership, 66(1), 8-14.

Yin, R. K. (1993). Applications of case study research. Newbury Park, CA: Sage Publications, Inc. 


\section{Appendix A: Commonly Used Terms}

Annual Yearly Progress (AYP).

In a manner that 1 ) results in continuous and substantial yearly improvement of each school and local education agency sufficient to achieve the goal of all children ... meeting the state’s proficient and advanced levels of achievement; [and] 2) is sufficiently rigorous to achieve the goal within an appropriate timeframe (as cited in Elmore \& Rothman, 1999, p. 85) by Goertz (2001).

Coalition of Essential Schools (CES). An organization created to further a type of wholeschool reform originally envisioned by founder Sizer in the book, Horace's Compromise. CES began in 1984 with 12 schools; it currently has 600 formal members.

Highly qualified. as defined under NCLB (Title IX) section 9101(23): The term highly qualified

A. when used with respect to any public elementary school or secondary school teacher teaching in a State, means that

(i) the teacher has obtained full State certification as a teacher (including certification obtained through alternative routes to certification) or passed the state teacherlicensing examination, and holds a license to teach in such State, except that when used with respect to any teacher teaching in a public charter school, the term means that the teacher meets the requirements set forth in the state's public charter school law; and

(ii) the teacher has not had certification or licensure requirements waived on an emergency, temporary, or provisional basis;

B. when used with respect to 
(i) an elementary school teacher who is new to the profession, means that the teacher (a) holds at least a bachelor's degree; and

(b) has demonstrated, by passing a rigorous state test, subject knowledge and teaching skills in reading, writing, mathematics, and other areas of the basic elementary school curriculum (which may consist of passing a state-required certification or licensing test or tests in reading, writing, mathematics, and other areas of the basic elementary school curriculum)

Reconstitute and restructure. Two terms used by the State of Maryland to describe the reform process. Reconstitution and restructuring policies vary, but, at their core, these strategies involve removing a school's incumbent administrators and teachers (or large percentages of them) and replacing them with educators who, presumably, are more capable and committed. Reorganize. A term this paper uses to describe the efforts of East Elementary School to quickly execute fundamental, instructional changes to a school's operation and culture and to improve student achievement, involving restaffing and additional professional development. It is a layer of school reform.

Underperforming. A term defined for this paper to mean, a school that is not achieving AYP. 


\section{Appendix B: The CES Common Principles}

The CES Common Principles, based on decades of research and practice, are a guiding philosophy rather than a replicable model for schools. This research and practice reflects the wisdom of thousands of educators who are successfully engaged in creating personalized, equitable, and academically challenging schools for all young people. The CES Common Principles describe the core beliefs and characteristics of the Essential Schools. They describe resulting practices that successfully bolster student achievement.

CES Common Principles:

1. Learning to use one's mind well: The school should focus on helping young people learn to use their minds well. Schools should not be "comprehensive” if such a claim is made at the expense of the school's central intellectual purpose

2. Less is more, depth over coverage: The school's goals should be simple: that each student master a limited number of essential skills and areas of knowledge. While these skills and areas will, to varying degrees, reflect the traditional academic disciplines, the program's design should be shaped by the intellectual and imaginative powers and competencies that the students need, rather than by “subjects” as conventionally defined. The aphorism "less is more” should dominate: curricular decisions should be guided by the aim of thorough student mastery and achievement rather than by an effort to merely cover content.

3. Goals apply to all students: The school's goals should apply to all students, while the means to these goals will vary as those students themselves vary. School practice should be tailor-made to meet the needs of every group or class of students. 
4. Personalization: Teaching and learning should be personalized to the maximum feasible extent. Efforts should be directed toward a goal that no teacher have direct responsibility for more than 80 students in the high school and middle school and no more than 20 in the elementary school. To capitalize on this personalization, decisions about the details of the course of study, the use of students' and teachers' time and the choice of teaching materials and specific pedagogies must be unreservedly placed in the hands of the principal and staff.

5. Student-as-worker, teacher-as-coach: The governing practical metaphor of the school should be student-as-worker, rather than the more familiar metaphor of teacher-asdeliverer-of-instructional-services. Accordingly, a prominent pedagogy will be coaching, to provoke students to learn how to learn and thus to teach themselves.

6. Demonstration of mastery: Teaching and learning should be documented and assessed with tools based on student performance of real tasks. Students not yet at appropriate levels of competence should be provided intensive support and resources to assist them quickly to meet those standards. Multiple forms of evidence, ranging from ongoing observation of the learner to completion of specific projects, should be used to better understand the learner's strengths and needs, and to plan for further assistance. Students should have opportunities to exhibit their expertise before family and community. The diploma should be awarded upon a successful final demonstration of mastery for graduation - an "Exhibition.” As the diploma is awarded when earned, the school's program proceeds with no strict age grading and with no system of credits earned” by "time spent” in class. The emphasis is on the students' demonstration that they can do important things. 
7. A tone of decency and trust: The tone of the school should explicitly and selfconsciously stress values of unanxious expectation ('I won’t threaten you but I expect much of you”), of trust (until abused) and of decency (the values of fairness, generosity and tolerance). Incentives appropriate to the school's particular students and teachers should be emphasized. Parents should be key collaborators and vital members of the school community.

8. Commitment to the entire school: The principal and teachers should perceive themselves as generalists first (teachers and scholars in general education) and specialists second (experts in but one particular discipline). Staff should expect multiple obligations (teacher-counselor-manager) and a sense of commitment to the entire school.

9. Resources dedicated to teaching and learning: Ultimate administrative and budget targets should include student loads that promote personalization, substantial time for collective planning by teachers, competitive salaries for staff, and an ultimate per pupil cost not to exceed that at traditional schools by more than 10 percent. To accomplish this, administrative plans may have to show the phased reduction or elimination of some services now provided students in many traditional schools.

10. Democracy and equity: The school should demonstrate non-discriminatory and inclusive policies, practices, and pedagogies. It should model democratic practices that involve all who are directly affected by the school. The school should honor diversity and build on the strength of its communities, deliberately and explicitly challenging all forms of inequity.

Retrieved from: http://www.essentialschools.org/items/4 July 13, 2010 


\section{Appendix C: Phase 2 Interview Questions 2010-2011 \\ New Interview Questions for 2010-2011}

1. What is your present view of East Elementary School now the Coalition of Essential School's professional development sessions have ended?

2. What happened to the learning environment since the funding for the professional development session provided by the Coalition of Essential Schools has ended?

3. How were you affected during the influx of professional development during the Coalition of Essential School's tenure from the Fall of 2006- the Fall of 2008?

4. How were the students affected during the influx of professional development during the Coalition of School's tenure from the Fall of 2006- the Fall of 2008?

5. Now that CES professional development has ended, what is occurring at East Elementary School? 


\section{Appendix D: East Elementary Participant Update Professional Development/Learning Communities/Developing student relationships/Classroom instructional strategies}

I am collecting data on the PD provided by CES focusing on strategies implemented at Bester since 2005 and the impact on the teachers, students, and the learning environment. Your feedback would be greatly appreciated. Thank you so much for helping with this data collection! Name (optional)

1. Which of the following best describes your current teaching assignment?

Classroom teacher

Encore teacher

Student Achievement Specialist

Special education teacher

Paraprofessional

$\square \quad$ Building intervention teacher

$\square \quad$ Other (please specify)

2. Did you work at East Elementary School before the reorganization in 2005?

$\square \quad$ Yes

$\square \quad$ No, I came to Bester in

If you answered no for \#2, did you worked in a Title I school before you were hired to work at East Elementary?

Yes 
$\square \quad$ No

3. Are you familiar with the Coalition of Essential Schools?

$\square \quad$ Yes

$\square \quad$ No

If yes, can you list anything that comes to mind when you think of CES?

4. Have you learned any relationship strategies during your time working at East Elementary that have helped you meet the needs of your students as a result of PD provided by CES?

$\square \quad$ Yes

$\square \quad$ No

If yes, can you list one you are still currently using?

5. Have you learned instructional strategies from CES PD during your time working at East Elementary that have helped you meet the needs of your students?

$\square \quad$ Yes

$\square \quad$ No 
If yes, can you list one you are still currently using?

6. Have you observed improvement in student/teacher relationships since you began working at East Elementary as a result of PD provided by CES?

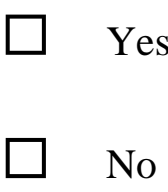

Please provide a brief explanation

7. Have you observed improvement in the classroom instruction since you began working at East Elementary as a result of PD provided by CES?

$\square \quad$ Yes

$\square \quad$ No

Please provide a brief explanation or example:

8. How many years or months have you worked at East Elementary? Please complete the following chart: 


\begin{tabular}{|l|l|l|l|l|}
\hline $\begin{array}{l}\text { Please select one } \\
\text { rating of yourself as } \\
\text { a teacher for each } \\
\text { category: }\end{array}$ & \multicolumn{1}{|c|}{ Strong } & Improving & Struggling & Stagnant \\
\hline $\begin{array}{l}\text { Content Knowledge, } \\
\text { content vocabulary }\end{array}$ & & & & \\
\hline $\begin{array}{l}\text { Skills in Pedagogy; } \\
\text { CES protocols, } \\
\text { essential questions, } \\
\text { higher-order } \\
\text { questions, and } \\
\text { inquiry-based } \\
\text { lessons, }\end{array}$ & & & & \\
\hline $\begin{array}{l}\text { Involvement in } \\
\text { professional learning } \\
\text { communities }\end{array}$ & & & & \\
\hline $\begin{array}{l}\text { Ability to } \\
\text { communicate } \\
\text { positively }\end{array}$ & & & & \\
\hline $\begin{array}{l}\text { Ability to develop } \\
\text { student relationships }\end{array}$ & & & & \\
\hline
\end{tabular}

Briefly describe your growth as a result of the opportunities provided by CES at East Elementary in any one of the following areas: professional development, learning communities and developing student relationships and classroom instructional strategies. 


\section{Appendix E: Participant Request Letter}

\section{West VirginiaUniversity}

\section{College of Human Resources and Education}

teachers at East Elementary School. I am looking for participants who would be willing to be interviewed, observed or possibly both about this topic. Per the IRB process, all names will be changed to provide anonymity to the participants. If you are willing to participate, please return the bottom portion of this form in the pre-paid envelope included. If you are unable to participate at this time, no response is required. However, I would like to take this time to thank you for your interest in this study.

Sincerely,

Kris McGee

__ Yes, I will be able to participate in the follow-up study on the sustainability of the Coalitions of Essential School's professional development as perceived by teachers at East Elementary School.

My contact information is as follows:

Participant’s full name

Phone number/Email address

Please select the best day(s) to be contacted:

Monday Tuesday Wednesday Thursday Friday

Best time(s) of the day to be contacted:

8:00-11:00 am Noon to 3:00 pm 4:00-6:00 pm 


\section{Appendix F: Observation Tool for Classroom Observations}

Observation Tool for Classroom Observations

Teacher-Student Interaction

Examples of tone of decency and trust:

Examples of student-as-worker (teacher):

Examples of teacher-as-coach (facilitator):

Description of relationship between:

Teacher-student Student-teacher Student-student

Instructional strategies implemented: 


\section{Appendix G: Preliminary Interview Questions:}

Basic Information:

Teacher or Substitute

How long have you been in education/teaching?

How many years have you taught at East Elementary School? Before reorganization/after?

Explain how your teaching journey led you to East Elementary School.

Describe what the learning environment was like in your opinion before the reorganization efforts began with CES professional development in Fall 2006.

Can you compare East Elementary School to another teaching/learning experience? Pros/Cons 
How has the learning environment changed over the past three years (2006-2008)?

What do you believe was the catalyst which brought about the change?

How has the evolution at this school impacted you as a teacher or substitute?

What do you see as changes in the students/community 